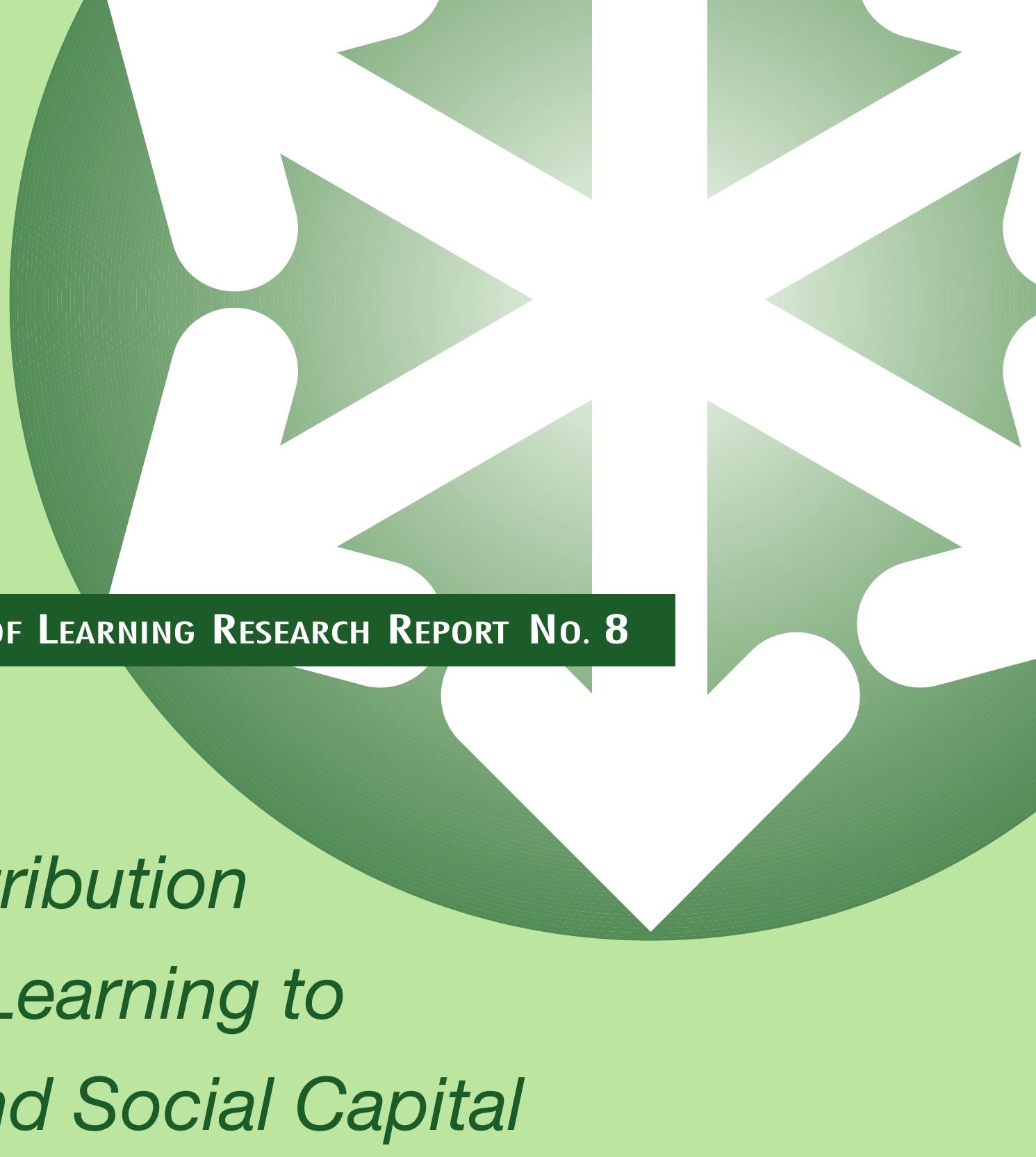

Leon Feinstein

Cathie Hammond

Laura Woods

John Preston

John Bynner 
Other WBL Publications in the series include:

The Wider Benefits of Further Education: Practitioner Views by John Preston and Cathie Hammond

Parental Perspectives of Family Learning by Angela Brassett-Grundy

Learning, Continuity and Change in Adult Life by Tom Schuller, Angela Brassett-Grundy, Andy Green, Cathie Hammond and John Preston

Learning, Family Formation and Dissolution by Louisa Blackwell and John Bynner

Quantitative Estimates of the Social Benefits of Learning, 1: Crime by Leon Feinstein

Quantitative Estimates of the Social Benefits of Learning, 2: Health (Depression and Obesity)

by Leon Feinstein

Education, Equity and Social Cohesion: A Distributional Model by Andy Green, John Preston and Ricardo Sabates 


\section{THE CONTRIBUTION OF ADULT LEARNING TO HEALTH AND SOCIAL CAPITAL}

Leon Feinstein, Cathie Hammond, Laura Woods, John Preston and John Bynner

May 2003 
Published by

The Centre for Research on the Wider Benefits of Learning Institute of Education

20 Bedford Way

London WC1H 0AL

(C) Leon Feinstein, Cathie Hammond, Laura Woods, John Preston \& John Bynner

ISBN $189845339 \mathrm{X}$

Individual copy price: $£ 7.50$

The Centre for Research on the Wider Benefits of Learning (WBL) was established in 1999 by the then Department for Education and Employment, now the Department for Education and Skills (DfES). The Centre's task is to investigate the social benefits that learning brings to individual learners and to society as a whole. The Centre is a joint initiative between the Institute of Education and Birkbeck College, University of London.

The views expressed in this work are those of the authors and do not necessarily reflect the views of the Department for Education and Skills. All errors and omissions are those of the authors. 


\section{Executive Summary}

\section{Objectives and methods}

- The aim of this research is to investigate the effects of adult learning upon a range of measures of health and social capital and cohesion.

- The study has a broad scope. We estimate effects of adult learning on a wide range of outcomes. We break down participation in learning in a number of ways, and we assess the different impacts of participation on different groups. The primary objective is to assess the nature and extent of wider effects of adult learning. More detailed findings relating to specific outcomes, types of courses taken and groups of learners are extremely interesting and indicate directions for further research.

- The National Child Development Study is the database used for analyses. We use data relating to almost 10,000 adults born in Britain in 1958, focusing upon changes in their lives between the ages of 33 (in 1991) and 42 (in 2000).

- The effects of participation in learning between the ages of 33 and 42 are estimated. Participation in learning is broken down according to the type of course taken courses resulting in academic and vocational qualifications, work-related training and leisure courses.

- Previous, closely related research on the effects of adult learning focused on wage effects only and neglected non-accredited learning of the kind considered here. The current project is, therefore, a timely reminder that many learners take courses in adult learning that are not accredited and for reasons other than wage returns. A proper assessment of the value of adult learning must take these wider benefits into account.

- The outcomes considered are changes between age 33 and 42 in social and political attitudes, civic participation, health behaviours (smoking, alcohol consumption and exercise), self-reported life satisfaction and onset and recovery from depression.

- Effects of participation upon these outcomes are estimated for the whole sample. In addition, the different effects of participation are separately estimated for men and women, and for those without Level 2 qualifications at age 33 .

- We restrict selection bias by exploiting the fact that our data are longitudinal. We attempt to consider effects on individuals as they change over time, making before and after comparisons. We also control for a wide range of life-course background, achievement and developmental factors.

\section{Headline findings}

- Adult learning plays an important role in contributing to the small shifts in attitudes and behaviours that take place during mid-adulthood.

- Participation in adult learning has positive effects on a wide spectrum of health and social outcomes. 
- The evidence for effects is robust to changes in specification. The same picture of wide-ranging effects of adult learning on changes in health and social outcomes is found when alternative specifications are used to measure participation in learning (linear, categorical, dummies, and quadratic functions).

- Effect sizes are small in absolute terms. However, there is little change in attitudes and behaviours during mid-adulthood and, relative to this baseline, participation in adult learning is an important driver for change.

- We are confident that our estimates reflect genuine effects of participation in adult learning. We have made strenuous attempts to minimise selection bias in modelling them. Our findings apply to changes rather than to absolute levels of outcomes, and they hold up as controls are added for demographic, educational and other background factors, as well as for changes in life circumstances during midadulthood.

- The finding that some of the benefits we measured predict as well as follow on from adult learning suggests that participation in adult learning is a very important element in positive cycles of development and progression.

- Taken together, the case study evidence and statistical evidence converge at the same conclusions; educational participation has a range of non-economic benefits that extend beyond the classroom into personal life and into the community. These results supply endorsement to government strategies to promote lifelong learning and suggest that adult learning might do better than it tends to do in the battle for education resources.

\section{Health outcomes}

- We consider effects of adult learning on six health outcomes. We estimate effects on four yes/no (binary) outcomes: whether smokers gave up smoking; whether those depressed at 33 recovered from depression; whether those not depressed at 33 were less likely to become depressed; and on whether or not people increased their level of exercise. We also considered the change in units of alcohol drunk and in life satisfaction.

- Participation in adult learning contributes to positive and substantial changes in health behaviours and small improvements in wellbeing.

- Overall, we have not found evidence that participation in adult learning protects against onset or progression of depression. Indeed, in some cases it may trigger or reinforce it. This contrasts with findings from the Centre's fieldwork programme, which suggested that participation in adult learning can sustain and improve psychological health (Schuller et al., 2002). The relationships are complex and important, and require deeper examination.

- Positive effects of participation in adult learning are found in relation to two of the three measures of health practices: giving up smoking and taking more exercise.

- Participation in each of the four types of learning (academic accredited, vocational 
accredited, work-related and leisure) has effects on the adoption of health practices.

- Taking vocational accredited and leisure courses reduces alcohol consumption, and taking work-related courses increases it. These effects are masked when effects of adult learning aggregated over course type are estimated.

- Effects of taking leisure courses on the adoption of health practices are particularly pervasive.

- For example, the estimated effect of taking one to two courses (aggregating types) over this period is a $3.3 \%$ point increase in the probability of giving up smoking between 33 and 42. In other words 33 in 1000 more adult learners taking one or two courses will quit smoking than non-learners, a substantial public health benefit.

- To contextualise this and all other effect sizes, we consider them relative to the predicted level of change for non-learners with the same observed characteristics as learners. We take again the example of smoking. Allowing for these background characteristics, $24 \%$ of smokers who took no courses quit by age 42 . The $3.3 \%$ point effect of one or two courses brings this percentage up to $27.3 \%$ of those who took one or two courses who give up smoking, which represents an increase in the chances of giving up by a factor of well over one eighth.

- Participation in adult learning is related to taking more exercise. We predict that $38 \%$ of adults with the characteristics of learners would increase their level of exercise between 33 and 42 without taking any courses. The estimated effect of taking three to ten courses is $7 \%$ points, increasing this percentage from $38 \%$ to $45 \%$. This represents an increase in the chances of taking more exercise by a factor of almost a fifth.

- In relation to giving up smoking and reduced alcohol consumption, positive effects tend to be found for those taking few courses. For those taking high numbers of courses, the effects are pernicious. A possible explanation for this is that the increased socialising that participation in learning can lead to is itself associated with smoking and drinking, so that the effects of increased social activity offset the other effects of participation in adult learning upon the adoption of healthier practices.

Selection bias is an alternative explanation.

- Life satisfaction, our proxy measure for wellbeing, is stable during mid-adulthood. There is a slight reduction between the ages of 33 and 42, which is offset consistently, but to a small degree - by participation in adult learning. For example, taking three to ten courses offsets the predicted decline in life satisfaction for those who took no courses, by $35 \%$.

- Effects on life satisfaction are found for participation in each type of course.

- When we unpack findings relating to wellbeing and depression by course type and by the gender and educational background of participants, negative as well as positive associations emerge. This suggests that participation in adult learning involves an element of risk to wellbeing and psychological health. 


\section{Social capital outcomes}

- The first three outcomes considered under this heading are the changes between age 33 and 42 in race tolerance, political cynicism and authoritarianism. We also take as an outcome a yes/no measure indicating increased political interest. The final two social capital proxy outcomes are also yes/no measures: the first indicating that the individual increased their level of civic participation, the second indicating that the individual voted in 1997 having abstained in 1987.

- There is strong evidence that adult learning contributes to changes in attitudes and behaviours that promote social capital and, possibly, social cohesion.

- Effects of participation in adult learning are found for three of the four measures of change in social and political attitudes, and for both of the proxy measures for civic and political participation.

- Social and political attitudes are fairly stable during mid-adulthood for this cohort, but we nevertheless find substantial effects of participation in adult learning. Taking one or two courses changes three of the four measures of social and political attitudes in ways that contribute to social capital by between 2 and 5\% points, which represents increases of between $12 \%$ and $34 \%$ from the baseline level predicted for those who took no courses.

- The marginal effect of taking one or two courses is to raise the proportion of adults in the sample who increased their number of memberships of organisations by $3 \%$ points. The predicted level of increase of those with similar characteristics who took no courses is $8.6 \%$. Therefore, the relative effect of taking one or two courses is $34 \%$.

- Participation in each of the four types of adult learning considered here (academic accredited, vocational accredited, work-related and leisure) contributes separately to positive changes in social and political attitudes. Participation in three of the four course types (the exception being vocational accredited courses) contributes to increases in civic and political participation.

- Taking academic accredited courses plays a particularly important role in the development of attitudes that promote social capital and social cohesion. For example, taking one academic accredited course increases race tolerance by $94 \%$ more than the predicted increase for similar adults who took no courses at all.

- Participation in leisure courses has important effects. For example, taking three to ten leisure courses raises race tolerance by $73 \%$ more than the predicted change in this attitude for similar adults had they taken no courses. The estimates in relation to most attitude changes are large in magnitude, especially considering the relatively low levels of commitment and time demanded by participation in leisure courses as compared to those for academic accredited courses.

- Taking leisure courses is also integral to the growth of civic participation. For example, $14 \%$ of adults who took one or two leisure courses increased their memberships between the ages of 33 and 42 , as compared to the predicted $9 \%$ of 
adults with similar characteristics who took no courses of any type.

- The effects of taking leisure courses on civic participation are particularly marked for those with qualifications below Level 2 at age 33 . 


\section{Preface}

The WBL Centre's principal task is to explore the impact learning has on a variety of domains. Whilst almost everyone believes that taking part in learning has a beneficial impact on individuals and their wider communities, establishing clear causal links is methodologically extremely difficult, and it is remarkable how few large-scale studies there are which address this systematically. This paper marks a major advance in our understanding, both in the results which it presents and in the methodology it deploys. Taking advantage of unique cohort data from the NCDS, it tracks changes in people's lives between the ages of 33 and 42, and relates these to different levels and forms of participation in learning.

The analysis is extremely rigorous in the way in which controls have been applied to reduce to a minimum the influence of other factors. Although, therefore, the reported impact of learning may in itself appear quite small in most of the outcome areas, it is highly significant (in the non-statistical sense) that effects are found at all, given the number of other things that intervene during nine years of people's lives.

The work presented here has also opened the way for the next phase of the Centre's work, in which we shall be fully integrating quantitative and qualitative work, with in-depth interviews of small samples drawn from the NCDS. This will enable us to explore further at least some of the many intriguing lines of thought opened up in this report, in what should be an ongoing iteration between different research modes.

Tom Schuller 


\section{Contents}

Acknowledgements

1. Introduction

2. Theoretical background

2.1 A typology of potential mediators linking adult learning with health and social capital and cohesion outcomes $\quad 8$

2.2 Evidence on effects of AL 12

3. Data 14

3.1 Measures of adult learning 14

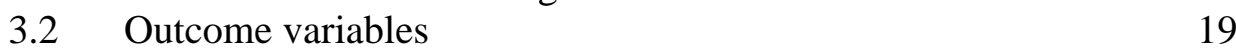

4. Method 31

4.1 Identifying effects of adult learning: the problem of selection bias 31

4.2 Dealing with selection bias $\quad 32$

4.3 Overview of methods used 34

5. Results 35

5.1 The effects of the number of courses taken 35

$\begin{array}{lll}5.2 & \text { Interpretation of effect sizes } & 37\end{array}$

5.3 Assessing causality 47

5.4 Summary of key and specific findings $\quad 52$

6. Results by type of adult learning, gender and prior qualifications 53

6.1 Results by type of course 53

6.2 Differences in results for men and women 61

6.3 Differences in results for individuals with low levels of
qualification

$\begin{array}{ll}\text { 6.4 Summary of key and specific findings. } & 70\end{array}$

7. Conclusions, interpretations, and policy implications 71

$\begin{array}{lll}7.1 & \text { Main findings } & 72\end{array}$

$\begin{array}{ll}7.2 \text { Detailed findings } & 75\end{array}$

$\begin{array}{lr}\text { References } & 80\end{array}$

$\begin{array}{ll}\text { Appendices } & 85\end{array}$ 


\section{List of Tables}

Table 1 Health behaviour variables 20

Table 2 Wellbeing variables $\quad 22$

Table 3 Social attitude variables $\quad 24$

Table $4 \quad$ Civic and political involvement variables 28

Table 5 Estimated effects of number of courses taken on the 12

Table $6 \quad$ Estimated effects of three levels of participation in learning. 38

Table 7 Interpretation of effect sizes for three levels of participation in learning 41

Table 8 Estimated effects of each outcome on probability of participation in learning at age 42

Table 9 Rates of participation in each type of learning 55

Table 10 Interpretation of effect sizes for each course type 59

Table 11 Estimated effects of participation in adult learning by gender 63

Table 12 Differences between the two education groups in the marginal effects of participation in each type of course 68

Table 13 Interpretation of effect sizes for each course type 76

\section{List of Figures}

$\begin{array}{lll}\text { Figure } 1 \text { The take-up of adult learning } & 15\end{array}$

Figure 2 Participation rates in adult learning, by course type 15

Figure 3 The take-up of adult learning, by course type 16

$\begin{array}{lll}\text { Figure } 4 & \text { The adult learning variables. } & 17\end{array}$

Figure 5 Histogram of changes in units of alcohol drunk 21

Figure 6 Histogram of changes in life satisfaction 23

Figure 7 Histogram of the change in race tolerance 25

$\begin{array}{lll}\text { Figure } 8 & \text { Histogram of changes in political cynicism } & 26\end{array}$

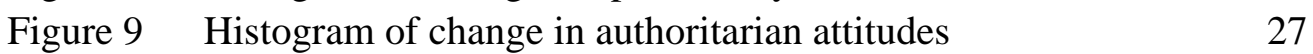

Figure 10 Odds ratios for age 33 outcomes, by academic educational level 30

Figure 11 Associations and causality 32

Figure 12 Two possible explanations $\quad 34$

Figure 13 Sizes of estimated effects of taking one to two courses in the context of predicted levels of change for those who took no courses - binary variables 44

Figure 14 Sizes of estimated effects of taking one to two courses in the context of predicted levels of change for those who took no courses - continuous variables 45

Figure 15 Proportions taking at least one course of each type by gender 62 


\section{Acknowledgements}

We would like to thank Tom Schuller, Andy Green and Sue Stone, for helpful comments and suggestions as well as participants at the DfES Research Conference, Nov 2002, and members of NIACE who participated in a seminar on the results presented there in May 2003. We are also grateful to senior members of DfES Analytical Services, who provided much helpful information and discussion during the research process. Lars Malmberg provided very helpful data analysis in earlier versions of the work. We would also like to thank Ceri Hollywell for fabulous administrative assistance in the preparation of this report. 


\section{Introduction}

The emphases of the white paper 'The Learning Age' (DfEE, 1998) reflects shifts away from the narrowly focused educational goals of enhanced productivity, which dominated the education policy agenda for most of the 1980s and 1990s, to a wider set of important, but less tangible, benefits. Though much is known about the economic returns to education, both at the individual level in terms of enhanced earnings and to society in terms of productivity gains, there is far less hard evidence on those returns to learning that are not primarily economic, especially during adulthood ${ }^{1}$.

Some outcomes of learning, such as more fulfilling use of leisure time, represent private benefits in the sense that the primary return is to the individual in terms of improved quality of life. Others, such as those concerned with health, serve the individual and society in the sense that improved health both enhances the quality of life and reduces the cost to the taxpayer by placing less of a burden on the health service. Others are primarily of benefit to the community in the sense that enhanced interest in politics and civic activity serves the democratic goals of active citizenship. All are typically mediated by what the Further Education Development Agency (now the Learning and Skills Development Agency) described as the immediate "personal and social outcomes" of learning: basic and generic skills, confidence, self-esteem and social relationships (Foster et al., 1997).

Knowledge of the wider benefits of learning clearly offers an evidence base for policy, not only in relation to education but to a range of policy areas, including those within the remits of the Departments of Health, and Work and Pensions and the Home Office. Demonstrable benefits can point to the value of more investment in the particular forms of learning where benefits have been identified. The research evidence can also reveal additional factors such as the demographic attributes of learners and their circumstances, which add to or interact with the effects of learning, pointing to sub populations where the investment is likely to be most effective. The reverse side of the coin is the relatively rare identification of negative effects or disbenefits of learning. When these occur, policy needs to address the prior circumstances of learners and the conditions in which learning is provided so that means can be found of transforming a negative experience into a positive one.

The critical question we address in this report is: to what extent does the simple act of participation in learning during adult life produce measurable benefits to the individuals engaged in it and to the community more widely? We have already addressed the question though fieldwork in which the learning biographies of a sample of 140 individual adults were investigated in depth (Schuller et al., 2002). In this study we take a quantitative approach drawing on a nationally representative

\footnotetext{
1 The little work that has been done mostly focuses on the returns to school level qualifications and years of schooling, e.g. Behrman, J. \& Stacey, N. (1997).
} 
dataset: the National Child Development Study based on a cohort of all individuals born in a single week in 1958 and followed up throughout their lives.

Through the adult phases of the survey at ages 23,33 and most recently 42 , data were collected about the education and training undertaken. We focus here on participation in learning and new qualifications acquired between the ages of 33 and 42. A detailed record was collected over this period of all forms of engagement in various types of lifelong learning.

We choose this period of the life course because adulthood has certainly been reached, but retirement and old age are still distant. Although attitudes and behaviours may have settled, there are nevertheless many life changes that adults at this stage in their lives share. Other research investigating economic returns to participation in adult learning have focused on exactly this phase, using the same data (Jenkins, 2002). In addition, other research based on analyses of data from the Labour Force Survey suggests that a substantial component - over $10 \%$ of adult accredited learning (measured in hours) - is taken between the ages of 33 and 42 (Conlon, 2002/3).

In this report we estimate the effect of participation in four key types of learning:

- accredited academic courses;

- accredited vocational courses;

- $\quad$ work-related courses;

- leisure courses.

Information was also available on access courses, basic skills courses and other unaccredited government courses and modern apprenticeships, but as we describe in the main body of the report, numbers participating in these important courses were not sufficient for the statistical analyses we wanted to conduct.

Our fieldwork research illustrates how the impacts of adult learning vary according to the characteristics of participants. We therefore examine the separate effects of adult learning upon men and women, and upon adults with relatively high and relatively low levels of prior qualifications.

Our analysis focuses on the effects of these forms of adult learning upon a number of outcomes in the domains of health and social capital and cohesion. We define these terms broadly so that in terms of health, we consider health-related behaviours, psychological wellbeing and life satisfaction. In the domain of social capital and cohesion, we look at democratic values, including race tolerance, political cynicism, authoritarian attitudes and increased political interest. We also look at numbers of memberships and voting behaviour.

In each case, a measurement of the attribute was taken at age 33 and 9 years later at age 42. The difference between the two indicators was taken as the measured benefit. 
It is important to recognise that we are not dealing here with data from an experimental setting, where subjects are randomly assigned to either a treatment or no treatment, but with naturally occurring variation. The longitudinal nature of the data does not remove the problem that those who participate in adult learning might be systematically different from those that don't. This means that differences in outcomes may be due to these "selection" differences rather than to genuine effects of participation. We attempt to deal with this problem in the estimation process and return to it again in the interpretation of our results.

To partially address the problem, the impacts of the different forms of participation were examined controlling for prior circumstance and experience variables, including prior measures of school achievement and highest qualification achieved. Other changes across the period when lifelong learning was measured were also taken into account in the statistical model that was applied. Further analyses investigate the extent of selection bias.

This report is intended as an initial, broad review of the implications of the data across 4 different types of learning on 12 different outcomes. These types of learning are very different in terms of the nature of participants and of objectives, duration, pedagogy and curriculum. The outcomes considered are very different, too, in terms of measurement issues, propensity to change, social significance and the kinds of factors and processes by which they are influenced. We have named just a handful of aspects for each.

We recognise that each type of learning and each outcome is worthy of deeper consideration in its own right than is possible in the uniform approach taken here. Yet this approach is necessary if the presentation is to be manageable. Important differences are ignored but a wider field investigated. The results must be taken together in terms of preliminary indications which will be explored in subsequent work in more detail and with more allowance for the often subtle, but crucial, differences that are glossed over in this first foray.

In the next section, we describe theoretical foundations for the influence of adult learning on health and social capital and cohesion. In Section 3, we describe the adult learning and outcome variables used in the study. The estimation method is described in Section 4. Results are reported in Sections 5 and 6, and Section 7 concludes. Throughout, reporting of technical issues is kept to a minimum and mainly reserved for the appendices. 


\section{Theoretical background}

In this section, we contextualise our research by summarising what is already known about the wider benefits of learning. Although this is a relatively new field, there is a great deal of relevant evidence, albeit fragmentary and scattered across a range of disciplines. During the first phase of the Centre's work, we attempted to gather this evidence and piece it together. The aim was to develop a coherent picture of the relationships between learning and its wider benefits. See Schuller et al., 2000; Hammond, 2002.

We therefore present a typology of mediating factors that we suggest might link adult learning with health and social capital and cohesion. The typology is based upon evidence from other studies concerning the effects of learning, learning generally being measured by years spent in education or highest qualification gained. We then discuss the relatively small literature that already exists concerning the effects of adult learning.

In drawing linkages between health and social capital and cohesion we need to be aware of an important contrast in the nature of these two types of outcomes. Health is primarily a property of individuals, despite the importance of healthy communities and healthy societies. Social cohesion on the other hand is a societal property and therefore the use of individual proxies, which are the measures available in our dataset, is problematic. In this report we are examining those properties of individuals which may contribute to "social capital" or "community cohesion", As a shorthand, we call this social capital.

Although they are treated as separate outcomes, social capital and health interrelate. Many of the national initiatives in health promotion in Britain seek to promote health through developing healthier communities; for example, Health Action Zones and the National Healthy Schools Standard. A recent Social Action Research Project developed social capital within the local community in order to tackle health inequalities, and the evaluation suggests that some health outcomes improved as a result (Monks \& Bie Nio Ong, 2002). Living in a community that is supportive emotionally and practically is likely to bolster psychological health, reduce levels of experienced stress, furnish practical aid in times of stress and ill health and will be more effective in mobilising health resources if they are wanted (Putnam, 2000). In addition, healthy individuals are better able to contribute to their communities, and so may be in a better position to develop social capital. There is also evidence that less

\footnotetext{
2 The formation of social capital will be contextualised in area-level and societal research, which will be undertaken separately by the WBL. See the current research programme on www.learningbenefits.net.
} 
polarised and therefore possibly more socially cohesive societies experience better health outcomes (e.g. Wilkinson, 1996; Ellison, 1999³).

\subsection{A typology of potential mediators linking adult learning with health and social capital and cohesion outcomes}

We hypothesise six primary channels for effects of adult learning. These are:

- effects due to the development of specific skills;

- generic cognitive development;

- personal development;

- $\quad$ peer group effects;

- positional benefits; and

- $\quad$ economic effects.

These channels are likely to be interrelated in complex and important ways. Each are presented separately as a simplifying classification device in order to clarify why we think there may be such wide-ranging effects of adult learning.

\subsubsection{Effects due to the development of specific skills}

We would expect some specific work-related courses such as those involving health and safety or first aid to have a direct impact upon health. Courses on equal opportunities issues may raise consciousness and change attitudes towards race and gender issues. Some work-related training is provided by trade unions and this may serve to build more solidaristic and anti-discriminatory attitudes.

In addition, adult learning can develop skills in areas such as information technology, which might be useful in other civic contexts. Leisure courses involving physical activity, sport or dance may have obvious benefits in terms of both health and life satisfaction.

\subsubsection{Generic cognitive development through specific learning}

The cognitive skills which students acquire on many types of courses, such as reasoning, are transferable to many social situations.

Cognitive development is an important influence on a wide range of attitudes and practices, such as challenging racist attitudes (Emler and Frazer, 1999) and voting (Emler and Frazer op. cit.). Changes in general cognitive abilities may lead to deeper interrogation of one's own values and attitudes leading to behaviour change. Better

\footnotetext{
3 Wilkinson and Ellison suggest different explanations for the statistical association between income inequality and average health status. Wilkinson emphasizes the socio-political and psychological impact of inequality on individual health, which links social cohesion directly to health outcomes. Ellison emphasises the impacts of underinvestment in a variety of public health goods amongst countries with high income inequality. The latter explanation links social cohesion to health outcomes indirectly.
} 
problem solving skills and the capacity for critical evaluation of information may contribute to better coping mechanisms, improved access to heath services and the adoption of health practices; all crucial for sustaining psychological, mental and physical health.

We would expect academic courses to develop cognitive skills. We might not expect vocational courses to be as effective in building general cognitive capacities and consequently to be inferior in delivering the wider benefits associated with such cognitive skills. However, there is much diversity within this qualification group, which means that cognitive development may also take place in this context. In this research we cannot unpick this, but we do look at differences between vocational and academic courses in terms of a range of benefits.

\subsubsection{Personal development through learning}

A related channel for effects on the wide range of outcomes considered here is through the development of psychological resilience, self-efficacy and wellbeing. Resilience is thought of as a protective feature of the individual that, in enabling individuals to deal with stressful conditions, enhances the capacity to maintain positive health behaviours and a socially benign outlook. If adult learning feeds into components of resilience such as self esteem, hope and motivation, it may have important effects on the outcomes considered.

Self-efficacy is a related notion, referring to the extent to which individuals feel they can exert an influence on their lives. This is an important element in the adoption of both healthy practices and socially cohesive attitudes and activity (e.g. Kickbusch, 1990). Wellbeing, too, can be enhanced by learning, with positive effects upon the desire to engage in healthy behaviours and the development of socially benign and participatory attitudes.

Learning can influence emotional resilience, self-efficacy and wellbeing by a number of routes, for example by deepening understanding of the social environment and so enabling individuals to better contextualise their lives. Other routes involve enhancing status through positional effects, and the satisfaction and boost to confidence that might result from completing a course of learning, understanding something or being able to achieve some task for the first time. These examples suggest that academic courses may have particularly strong effects through this channel.

As a counterpoint, vocational qualifications and work-related training based around some occupations may present the opportunity for the development of wider skills other than cognitive ones, such as mastery over a craft and practical performance. Therefore, we might expect some civic and even health benefits to arise.

Leisure courses are of a different order to the other categories of courses studied. By definition, they are intended for personal enjoyment, though there may be other 
positive benefits for the student and their community. Therefore, one of the most important mechanisms through which leisure courses may have an effect is through intrinsic enjoyment that may result in enhanced personal satisfaction and self-esteem. As they are unaccredited, this may present a chance for students to deviate from a formal curriculum, engaging in more discussion and general association than in accredited academic or vocational courses. Courses in arts and crafts may have particular benefits in terms of increasing life satisfaction, developing resilience and protecting mental health. Indeed, a recent qualitative study of adults' perceptions of informal learning in arts and cultural venues found that participants report wider benefits from learning in these settings, where, presumably, many of the courses are arts-related (Lines et al., 2003). Benefits ranged from specific theoretical knowledge of a subject to practical and technical skills, interpersonal and social skills, and personal confidence. These personal gains were more important to most participants than obtaining qualifications or accreditation.

\subsubsection{Peer group effects}

Participating in a group is a component of many of the forms of learning that contribute to the development of the skills, abilities and emotional development described above. Simply mixing with others in a supportive context, where objectives are shared and discussion and co-operation encouraged, contributes to the wellbeing of individuals who are otherwise relatively isolated. Widened networks are potential sources for emotional and practical support, protecting psychological, mental and physical health. The attitudes and behaviours of peers also influence the adoption of health practices (e.g. Campbell \& Mzaidume, 2001).

For more confident individuals, mixing with the diverse and new may be particularly effective in terms of generating wider benefits. Individuals often attend courses in a milieu separate from their immediate workplace or their local community. This introduces the possibility that participants will associate with people who hold alternative points of view, possibly challenging unquestioned views and attitudes. This may impact upon social capital.

Perhaps only slightly ambitiously, recent commentators have referred to the possibilities of building social capital and cohesion within workplaces (Wolfe, 1998), with training serving as one possible arena for bringing individuals together.

The mechanism for changes in social and health-related attitudes and behaviours may be associated with the social mix of students, but the fact that this mixing takes place in the context of learning may also be important. Learning begins with the recognition of relative ignorance in certain areas, and extends boundaries in relation to skills, knowledge and understanding. In a positive learning environment, this process occurs in a context of support and co-operation. Where learning encompasses examination of attitudes, participants will be encouraged to express their own attitudes openly and listen to those of others with respect. Such free discussion will almost inevitably lead to the re-examination of values and beliefs, and also to personal 
relationships that are particularly open, honest and co-operative, and where the parties involved respect one another. Consequently, the impacts of peer groups upon social capital and cohesion, wellbeing and health practices, will be amplified by the context of learning.

\subsubsection{Positional effects}

Adult education may be a conduit for increases in status. We can distinguish between structural and cultural changes in status. A structural change in status would be one where the material components of one's networks or employment position changes. For example, Nie et al. (1996) argue that the relationships between education and political engagement are largely due to individuals increasing their proximity to the centre of influential social networks. Changes in social class are perhaps a more obvious form of an increase (or decrease) in status, and one which we can control for in our dataset. Cultural changes in status are more subtle, based upon changes in attitudes or behaviours, which are used as markers of distinction between individuals. For example, adult education may not only advance social class in terms of SES, but lead to identification with (ostensibly) "middle class" attitudes and behaviours. Such individuals would use practices such as civic participation as a marker of distinction consolidating their changing class position and outlook.

Accredited qualifications are often associated with an increase in social status and the validation of cultural capital and as with the channel associated with generic cognitive development: this may be particularly so for academic courses. Indeed, the historically rigid social positioning of the academic above the practical has particular relevance in the current UK policy context. Therefore the role of learning, and especially gaining academic qualifications in creating social distinction between learners and non-learners, may be a possible causal mechanism.

\subsubsection{Economic effects}

Related to the three previous channels are the returns in the labour market to those psychological, skill-based and cognitive attributes which have been conceptualised as human capital and identity capital (Becker, 1964; Cote, 2002). Through influences on either form of capital, learning might ameliorate participants' earnings, work conditions and employment opportunities with subsequent benefits. For example, protection from occupational and material insecurity is likely to reduce levels of chronic stress (Wilkinson, 1996). Occupational self-direction is related to selfefficacy and psychological wellbeing (Kohn \& Schooler, 1983, Kohn et al., 1990). Income may be an important determinant of a healthy diet (Variyam, Blaycock \& Smallwood, 2002). Therefore, the economic benefits of learning may feed into other benefits.

Work-related training is also expected to have important economic effects, with increases in wages or promotion strongly relating to the provision of, and take-up of, these courses. The workplace has been somewhat neglected as an arena for lifelong 
learning, and in this study we begin to address this omission. The content of workrelated courses varies immensely, especially the extent to which they relate either generally or specifically to occupation. At the margins there will be some overlap with both academic and vocational fields of study. Critically, the setting and content of these courses are likely to influence wider benefits.

\section{$2.2 \quad$ Evidence on effects of $\mathrm{AL}$}

As well as the general evidence on the effects of learning that is referred to above, there is also a small literature on the specific effects of adult learning. A substantial part of the relevant evidence has been generated by the Centre and we return to this in Section 2.3.

Most of the quantitative evidence concerning the impact of learning on social benefits has involved the use of crude indicators of the learning experience such as years of schooling or highest educational qualification attained. Although there is much research evidence on the social benefits of Higher Education (Bynner and Egerton, 2001; Bynner et al., 2003), there have been very few investigations into the effects of adult learning. Evidence that lifelong learning has an impact on health and civic participation is located in an extensive review of the literature by MacMahon (2002). However, a close examination of the studies cited reveals that they are typically using years spent in education and highest educational level attained as indicators of lifelong learning. Another study, conducted by the WBL Centre in collaboration with the Learning and Skills Development Agency, surveyed over 10,000 practitioners in Further Education about their perceptions of the wider benefits of participation by students aged 16 and over. The results suggest that Further Education leads to psychological and social benefits (Preston \& Hammond, 2002; Preston \& Hammond, 2003).

Existing quantitative research has little to say, then, concerning the relationship between adult education and the types of wider benefits considered here. However, there is quantitative evidence from longitudinal studies that lifelong learning may lead to an increased probability of re-entering the labour market (Jenkins, Vignoles, Wolf and Galindo-Rueda, 2002).

In contrast, there is a plethora of qualitative studies linking adult education with beneficial psychological and social outcomes. A growing body of qualitative and practitioner evidence across many types of provision leads one to expect that there are general benefits of adult education for which, so far, we only have evidence in particular settings from case study, ethnographic and action research approaches. For example Hammond (2002a and b, and 2003), cites several qualitative studies linking adult education with self-efficacy and health. This research is backed up by practitioner and student evidence from bodies such as NIACE (Alexander and Clyne, 1995; Coare and Thomson, 1996; Thompson, 2002) as well as our own wide-scoping qualitative research in the centre (Schuller et al., 2002). 


\subsubsection{Qualitative evidence from the WBL}

The WBL fieldwork programme just cited comprised over 140 one-to-one interviews with adults who had participated in adult learning. Respondents were invited to explore the meanings of learning experienced throughout their lives. In addition, eight group interviews were conducted with learning practitioners in which group participants discussed, on the basis of their experience as learning providers, the ways in which adult learning had effects upon learners. We describe some findings here selected because they have influenced our choice of research questions. In addition, they relate to issues that are not easily addressed using quantitative data and techniques. We draw on these and other findings from the qualitative fieldwork programme when we discuss the findings of the quantitative research in Sections 5 and 6.

\section{The complexity of learning-life relationships}

The fieldwork findings emphasise the enormous complexity of relationships between learning, life events and the outcomes of interest. As a simple example: joining a mother and toddler group might have positive impacts upon wellbeing and social confidence, and widen social contacts. This may prompt participation in learning, and this learning in turn may improve the learner's wellbeing, self-belief and communication skills, and widen her social network further, giving her the confidence to engage in a more challenging programme of learning. Here, therefore, both reverse causality and effects of learning can be observed. They operate together in a process through which the individual builds her confidence, wellbeing, and widens her social horizons. Learning is central to this process, but cannot be separately identified as the one-and-only cause of change.

\section{The interplay between outcomes of adult learning.}

Learning may lead to increased wellbeing, the adoption of health behaviours, changes in social attitudes and increased civic participation, but these outcomes also feed into one another. For example, as an individual feels better about herself, she may feel more confident to participate socially, and the enjoyment and social confidence derived from mixing with other people will increase her sense of wellbeing. The examples set by other students combined with increased self-value may also contribute to changes in attitudes and lifestyle that are better for the individual's health and contribute to social capital (and cohesion). This finding supports our focus on sets of outcomes rather than considering only one outcome. Although we do not model here the interactions between the outcomes themselves, it is only by considering impacts across a wide range of outcomes, as here, that the overall picture can begin to be assembled.

The importance of context and type of provision.

Context encompasses the social, political, economic and cultural environments in which learning takes place, the previous experiences of the learner, their family background, their current circumstances and the stage in their life at which they experience learning. The type of provision covers the setting in which learning takes 
place, the pedagogical approaches employed, the subject matter, level and forms of assessment. The match between the interests, strengths and needs of the learner and the type of learning provided affects the extent to which the learning experience is beneficial to the individual and their community. This evidence has informed choices about which control variables to include in the models and, possibly more significantly, which research questions the models are used to investigate - for example, the effects of different types of learning provision and how the effects of participation differ according to the characteristics of the learner (see Section 6).

\subsubsection{Summary}

The cumulative evidence that higher and lifelong learning lead to social (and employment) benefits is substantial. However, because learning does not lead to benefits in a direct or simple way, much of this evidence relates to only part of the processes involved. The Centre has already completed qualitative research mapping out the wider benefits of lifelong learning. The next stage of our work, presented here, is to map out these wider benefits using a nationally representative dataset. We are not aware that a comprehensive quantitative study of this kind has been conducted before.

\section{Data}

We turn now to the data. The 1958 cohort began as a perinatal mortality survey of every baby born in a week in March in 1958 - over 17,400 babies. Follow-up occurred at ages $7,11,16,23,33$ and 42 , when 11,500 of the original cohort were still participating. During the cohort members' childhoods, the data were collected by health visitors from parents and from children through educational and medical assessments. Teachers also supplied information. Through adulthood, data have been collected direct from cohort members by structured interview.

The possibility of initial sampling bias (in 1958) and of attrition in later sweeps raises the issue of how representative the sample is of adults born in 1958 and growing up in Britain. This is discussed in Appendix 1. We conclude that it is not a serious problem; if anything, response bias will result in underestimates of effects.

\subsection{Measures of adult learning}

The measure of adult learning available in our data is a self-report of participation in adult learning between the ages of 33 and 42 for individuals aged 42 in 2000. The questions used to identify participation in adult learning are given in Appendix 2. They exclude participation in learning at the time of the survey. This measure is preferred because we are interested in estimating effects that follow from (and therefore postdate) learning. Figure 1 shows the take-up of adult learning for the sample. 
It can be seen that $42 \%$ did not experience any learning in this period. Only $4 \%$ of the sample took more than 9 courses. Nonetheless there is considerable variation in the variable, particularly in the range between 0 and 10 .

Figure 1: The take-up of adult learning

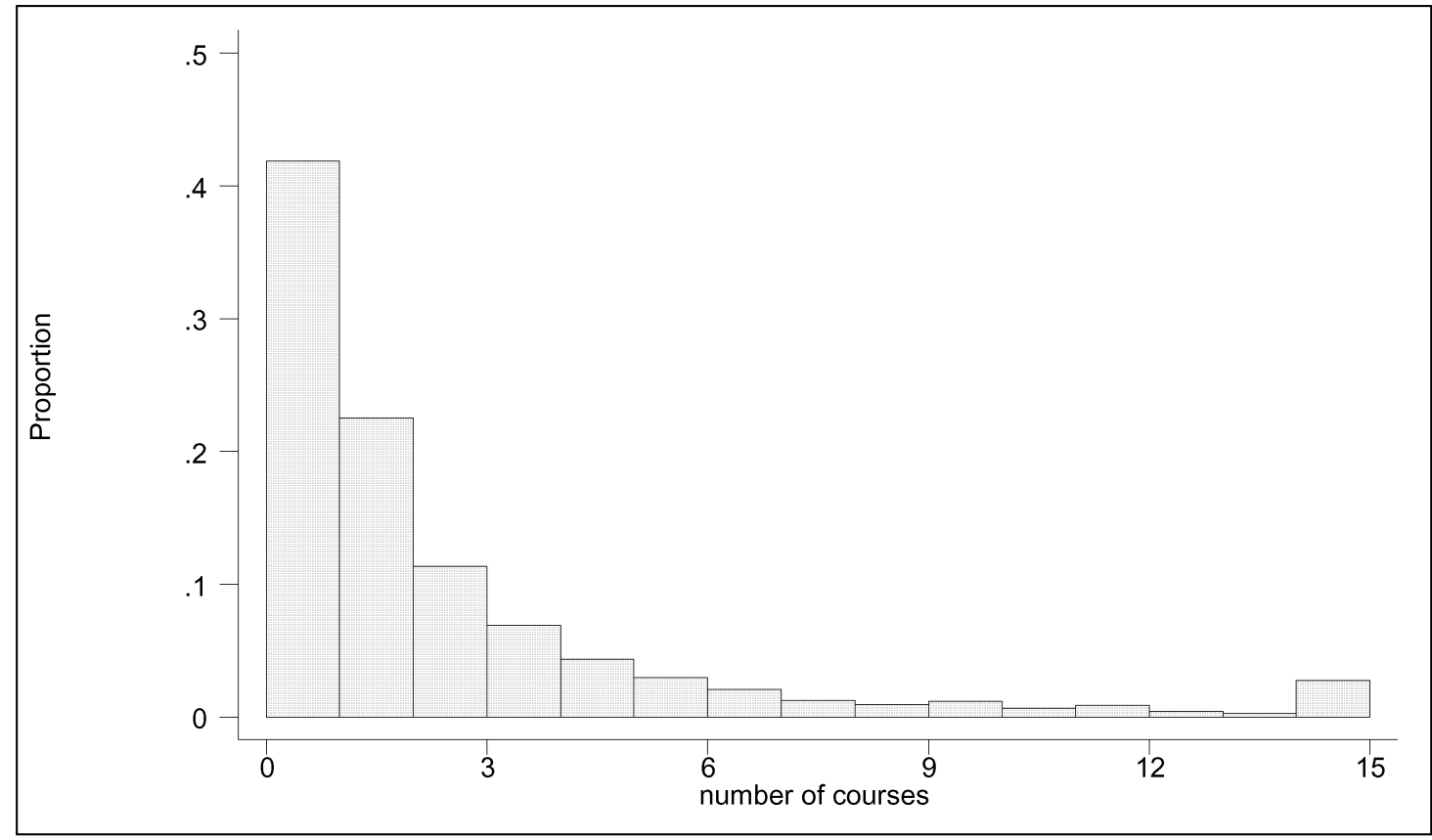

NOTE: maximum of 15 courses imposed for this figure. 204 individuals recorded more than 15 courses, $2.1 \%$ of the sample representing 4,836 courses, $22.4 \%$ of the total number of courses.

Participation is recorded in terms of the seven categories illustrated in Figure 2, which reports participation rates by course type.

Figure 2: Participation rates in adult learning, by course type

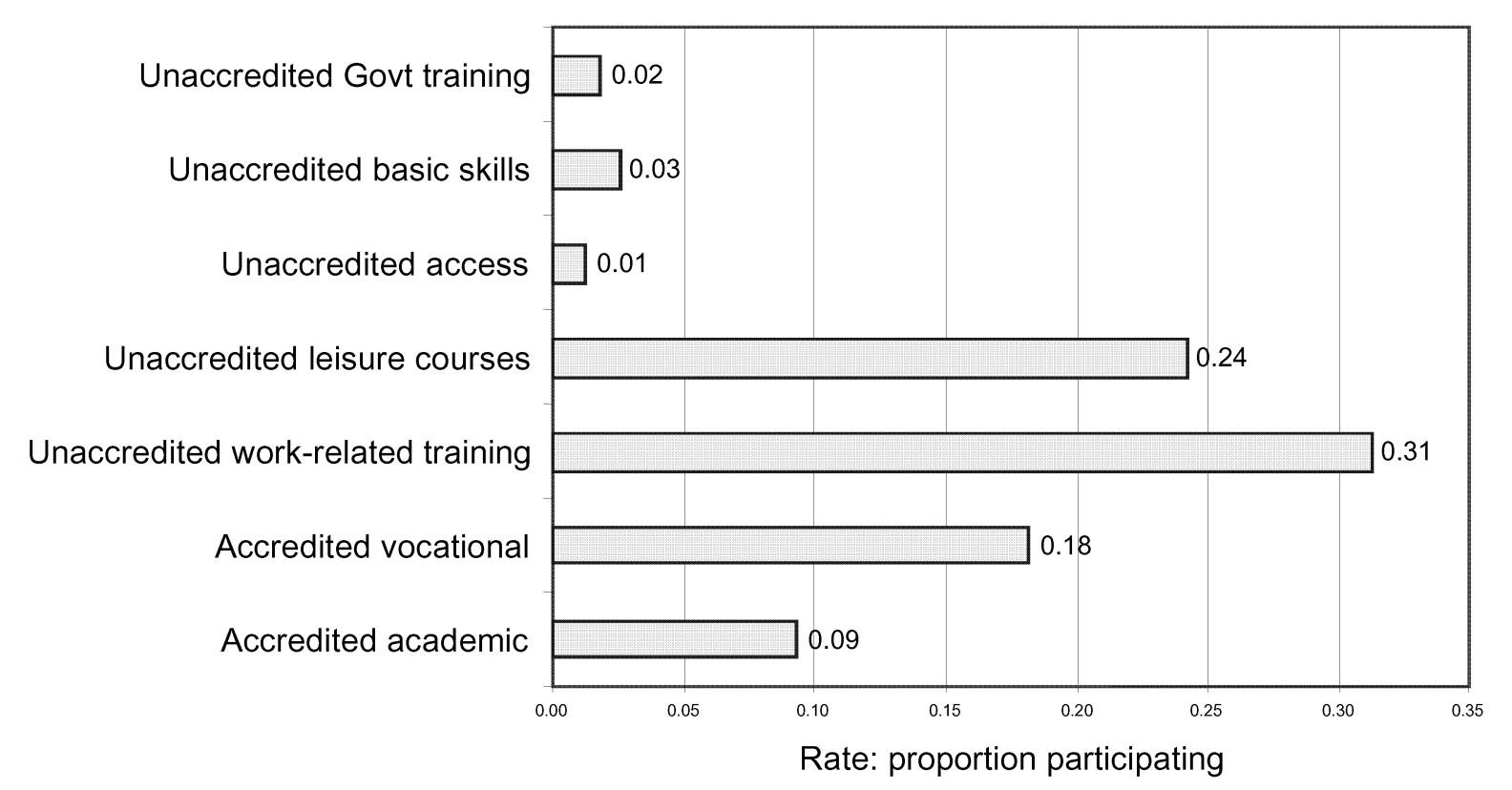


Participation rates in work-related training are relatively high with $31 \%$ of the sample participating in at least one work-related training course. Further description is provided in Figure 3, which shows the proportions of courses taken by type.

Figure 3: The take-up of adult learning, by course type

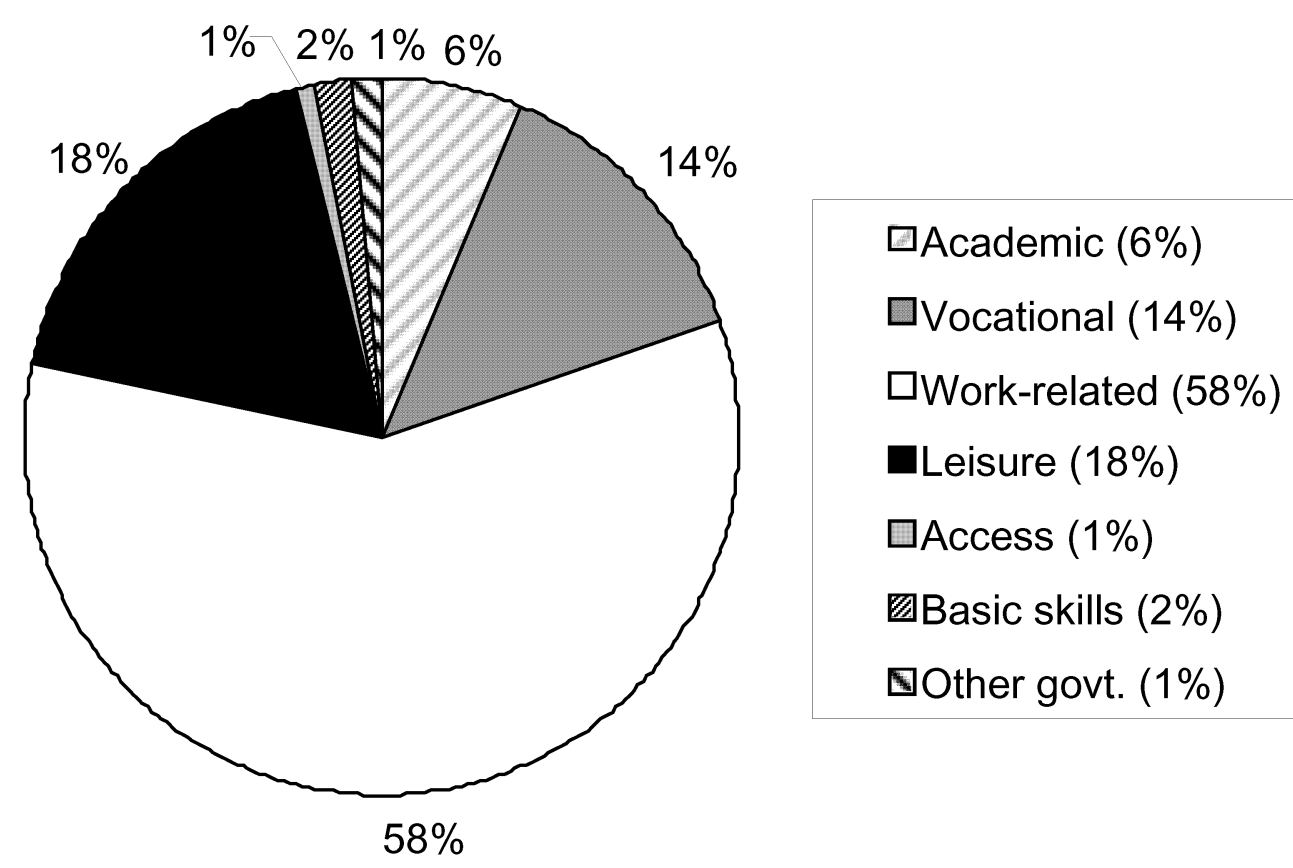

Nearly $60 \%$ of all courses were work-related. This is unsurprising in the sense that these are the courses of shortest duration. Against this, they are only available to those in work. Only $4 \%$ of courses were basic skills or access courses or other government training. These numbers are insufficient for the estimation of reliable effects, comparable to those that can be estimated for the other course types. We therefore exclude them from the analyses reported here. The four types of courses remaining are accredited academic, accredited vocational, work-related and leisure courses.

In 2000, cohort members were asked whether they had gained "any of the following" qualifications since 1991. The academic and vocational qualifications listed are comprehensive. These questions exclude participation in courses designed to lead to qualifications where the learner failed to achieve any qualification. The effects of such an experience warrant investigation but are not tackled here.

Note also that the processes involved in acquiring vocational qualifications are particularly varied, and consequently the effects associated with the acquisition of this group of qualifications are also likely to be varied. See Appendix 1 for further details and discussion.

The questions prompting for participation in work-related training and leisure courses follow after the questions prompting for participation in courses resulting in 
qualifications. Therefore, our interpretation is that work-related and leisure courses do not lead to qualifications, although in a minority of cases they may do.

Descriptive statistics for the variables used to measure participation in learning are summarised in Figure 4.

Figure 4: The adult learning variables

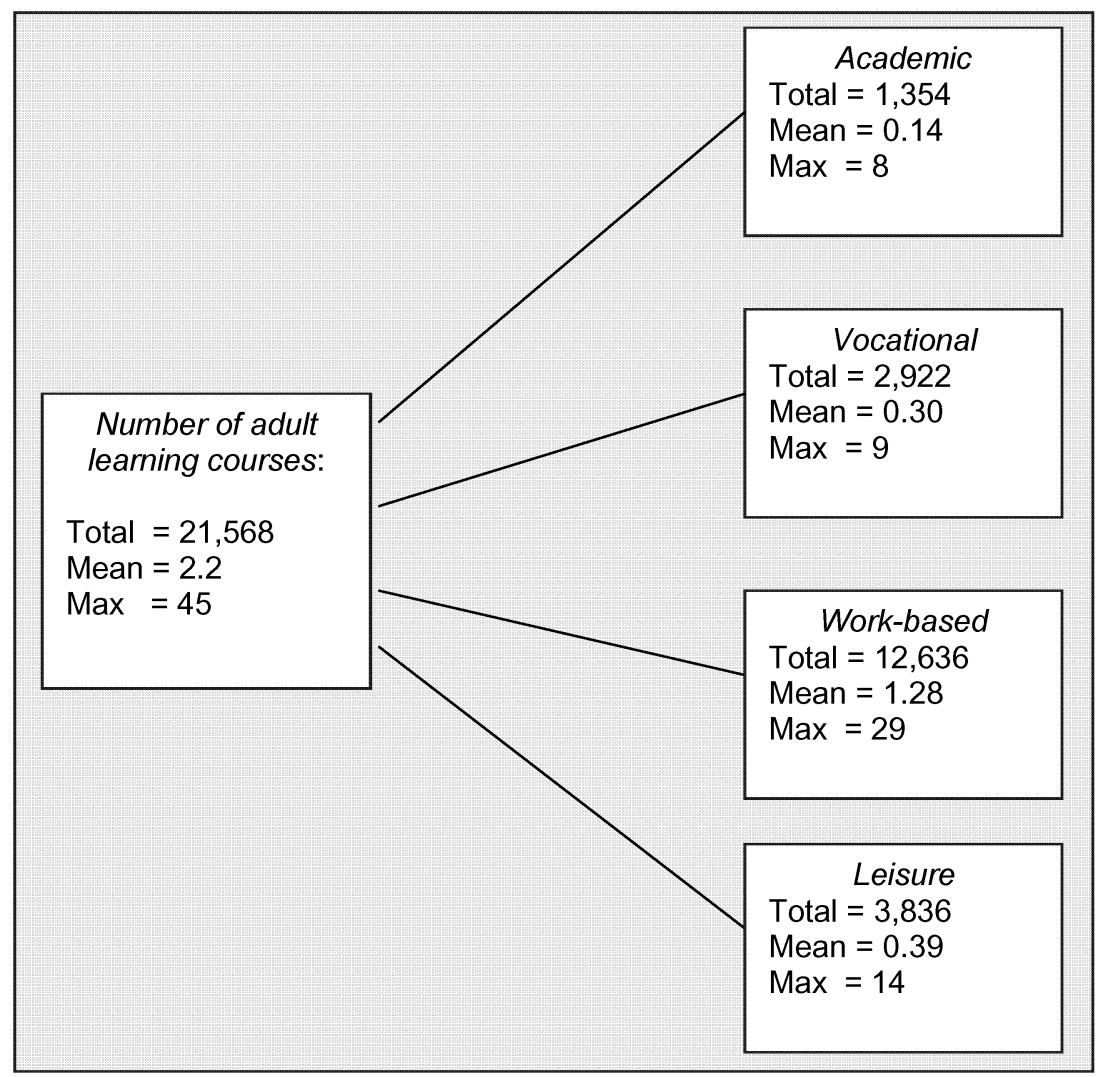

\subsubsection{Reliability of measures of adult learning}

In order to test the reliability of our measures of adult learning, we compare participation rates in the NCDS with those reported by other studies. Analysis of the NCDS using the measure of participation described above suggests that $61 \%$ of those born in 1958 participated in learning between 1991 and $2000^{4}$. Further investigations based upon our measures of participation provide evidence that a much higher proportion of those with higher (as opposed to lower) levels of qualifications in 1991 participated, and that rates of participation did not differ between men and women.

\footnotetext{
4 The proportion of adults learning given in Figure 1 is $58 \%$, but this value does not include participation in learning at the time of the survey. Current participation is included in the estimates of participation referred to in this section for closer comparisons with the measures used in other surveys.
} 
In order to compare these findings with those from other British surveys, we draw on results from analyses of three surveys: the National Adult Learning Survey (NALS), the Labour Force Survey (LFS), and one conducted by the National Institute of Adult and Continuing Education (NIACE). The surveys use different definitions of learning and ask different samples of the population about participation over different periods of time. Consequently, comparisons are not straightforward. The NALS measures match ours most closely.

The NALS definition of learning includes both taught and untaught learning, and specifies between the two forms. The definition of taught learning is slightly broader than ours, encompassing not only the taught courses covered in the NCDS, but also all types of driving instruction, learning to play a musical instrument, sporting activities and distance learning. In addition, it includes participation in all courses meant to lead to a qualification, whereas we include participation in courses meant to lead to a qualification only if a qualification was obtained. On this basis, we would predict participation in taught learning on the basis of data from the NALS to be higher than participation rates estimated using data from the 2000 sweep of the NCDS.

On the other hand, our definition of participation includes learning during the previous ten years, whereas the NALS definition refers to learning during the previous three years only. This difference will raise our estimates of participation rates relative to those based on the NALS dataset. However, it is likely that many of those learning during the three years between 1998 and 2001 were the same people who were learning between 1991 and 1998. We cannot test whether this is so using the data available in the NCDS because they do not include precise timings for unaccredited courses. However, analysis of the data that are available in the NCDS shows that $84 \%$ of those taking courses at the time of the survey in 2000 had also taken courses during the previous nine years.

Despite the differences between the measures of taught learning used in NALS and the NCDS, the estimated rates of participation are remarkably similar. Our own analyses of the NALS dataset find a participation rate of $62 \%$ for those aged 42 or 43 in $2001^{5}$, as compared to the $61 \%$ participation rate found using the NCDS. Our findings of gender and education differences in participation are also matched by the analyses of NALS, which report roughly equal rates of participation in taught learning amongst men than women, and a steep gradient in relation to qualification level.

We now consider comparisons of participation rates with those estimated using data from the other two surveys.

The LFS uses a definition of adult learning which encompasses part-time study at educational institutions, part-time correspondence courses, and vocational training in the four weeks prior to interview (Hillage et al., 2000). The parameters of this definition of learning are fairly similar to our own in that they include taught but not

\footnotetext{
${ }^{5} 272$ respondents in NALS fall into this age band.
} 
untaught learning. However, the sampling frame is different because it includes all adults aged between 25 and 64 . Nevertheless, the rates of participation in taught learning at the times of the surveys (1998 and 2000 for the LFS and NCDS, respectively) are similar. Hillage et al. report a participation rate of $13 \%$ based on analysis of the LFS data, and our estimated participation rate at the time of the survey is $15 \%$.

The NIACE survey uses a very broad definition of learning, encompassing learning in any setting, untaught as well as taught. For example, the definition of learning explicitly includes reading and practicing. The ages of those sampled are also different to the cohort sampled in NCDS, with all adults aged 17 and over surveyed. $29 \%$ were currently participating in adult learning in 2001 (Aldridge \& Tuckett, 2001), which is much higher than rates of current participation in the specified courses included in the 2000 sweep of the NCDS, which we find to be just $15 \%$. This difference probably reflects the difference in definition of participation in learning.

Overall, we conclude that participation rates based on the NALS and LFS datasets are consistent with those that we estimate using the NCDS data. This is evidence for the reliability of our measures of participation in learning. Although participation rates based on the NIACE survey differ from our estimates, this can be explained by differences in the measures of participation in learning used and in the sampling frame.

\subsubsection{Data omissions}

Although a considerable body of information is available for this study, it should be noted that it does not include the precise timing of the course undertaken. Ideally, the researcher would know the level of the outcome at the initiation of the course and subsequently, enabling comparisons to be made between outcome values before and after participation in earning. The omission of this information means that it is more difficult to draw conclusions about effects of learning from our analyses. This important issue is discussed more fully in Section 4.

Another important omission is information about the duration of courses. This means that the results of analysis necessarily average across different course durations as well as different times since course completion. More precise and detailed information would result in better estimates.

\subsection{Outcome variables}

We investigate relationships between adult learning and outcomes in terms of two categories - health and social capital and cohesion. These categories are very broadly defined so that health includes health behaviours, wellbeing, and depression, and social capital includes social and political attitudes, as well as voting and memberships. In the following paragraphs, we describe the outcome variables available in the data. 
Our objective in this paper is to estimate the effects of adult learning. Yet, the analysis techniques available allow us only to test the existence of correlations between adult learning variables and outcome variables. In an attempt to overcome this difficulty, we undertake our analyses in terms of the change in outcome variables, rather than their level. The reasons for this are discussed fully in the methodology section (Section 4). The consequence in terms of measures of outcome variables is that it necessary to restrict attention to those outcomes that are observed both before and after the potential experiences of adult learning. Full details of the questions used to measure the outcome variables are given in Appendix 1.

\subsubsection{Outcomes 1, 2 and 3: Health behaviours}

We test the hypothesis that participation in adult learning leads to a change in health behaviours. To our knowledge, this hypothesis has not been tested before using largescale British datasets, apart from a recent study that found an effect of higher education in reducing levels of smoking (Bynner et al., 2003). We do not have much direct evidence to support this hypothesis from the WBL fieldwork programme because the respondents rarely mentioned the impact of adult learning upon their health behaviours.

In this analysis, we consider three types of health behaviour - smoking, alcohol consumption, and exercise. Descriptions of the available measures of change in these outcomes are given in Table 1. The information is described in more detail in the following paragraphs.

\section{Table 1: Health behaviour variables}

\begin{tabular}{|c|c|c|c|c|c|c|c|}
\hline & Outcome & Variable type & Obs. & Mean & S.d. & Min. & Max. \\
\hline 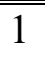 & Gave up smoking & Binary & 2961 & 0.28 & 0.45 & 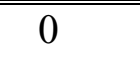 & $\overline{11}$ \\
\hline 2 & Change in units drunk & Continuous & 7944 & -0.71 & 15.17 & -145 & 96 \\
\hline 3 & Increased level of exercise & Binary & 7997 & 0.41 & 0.48 & 0 & 1 \\
\hline
\end{tabular}

\section{Outcome 1: Giving up smoking}

The first outcome variable is an indicator of giving up smoking, for those who were smoking at 33 . This is a binary variable, i.e. one that can take a value of 1 , indicating that the event happened or 0 , indicating that it didn't. The event in this case is that the individual gave up smoking. Therefore, we can test the hypothesis that adult learning has an effect on the probability of giving up smoking.

Table 1 reports that the mean of this variable is 0.28 . For binary variables the mean is the proportion for whom the event occurred. This means, therefore, that $28 \%$ of those who were smoking at age 33 had given up by age 42 .

\section{Outcome 2: Change in alcohol consumption}

As mentioned above, higher levels of education appear to be associated with moderate alcohol consumption, as opposed to excessive drinking or abstinence. Medical 
guidelines advise that moderate drinking is not detrimental to one's health, but that excessive drinking is. Excessive drinking is defined as 14 plus units per week for women and 21 plus units per week for men. We use as our outcome variable the change in the number of units of alcohol consumed per week at age 33 and age 42. The measure is based on the responses of sample members to questions about their weekly consumption of beer, wine and spirits. For many individuals this will involve crossing the (somewhat arbitrary) line between moderate and excessive drinking ${ }^{6}$.

Some authors have criticised the use of self-report measures of alcohol consumption. During a later phase of the research it will be possible to cross-validate this measure with others based on an instrument designed to identify dependency on alcohol.

The measure used is on a continuous scale. Therefore, since we are dealing with changes in outcomes, the mean shown in Table 1 is the average change in the outcome. This average change in units of alcohol drunk was a fall of 0.71 units. This is a small amount compared to the average level of consumption at age 33,11.1 units per week. Figure 5 shows there were not many extreme changes in the data.

Figure 5: Histogram of changes in units of alcohol drunk

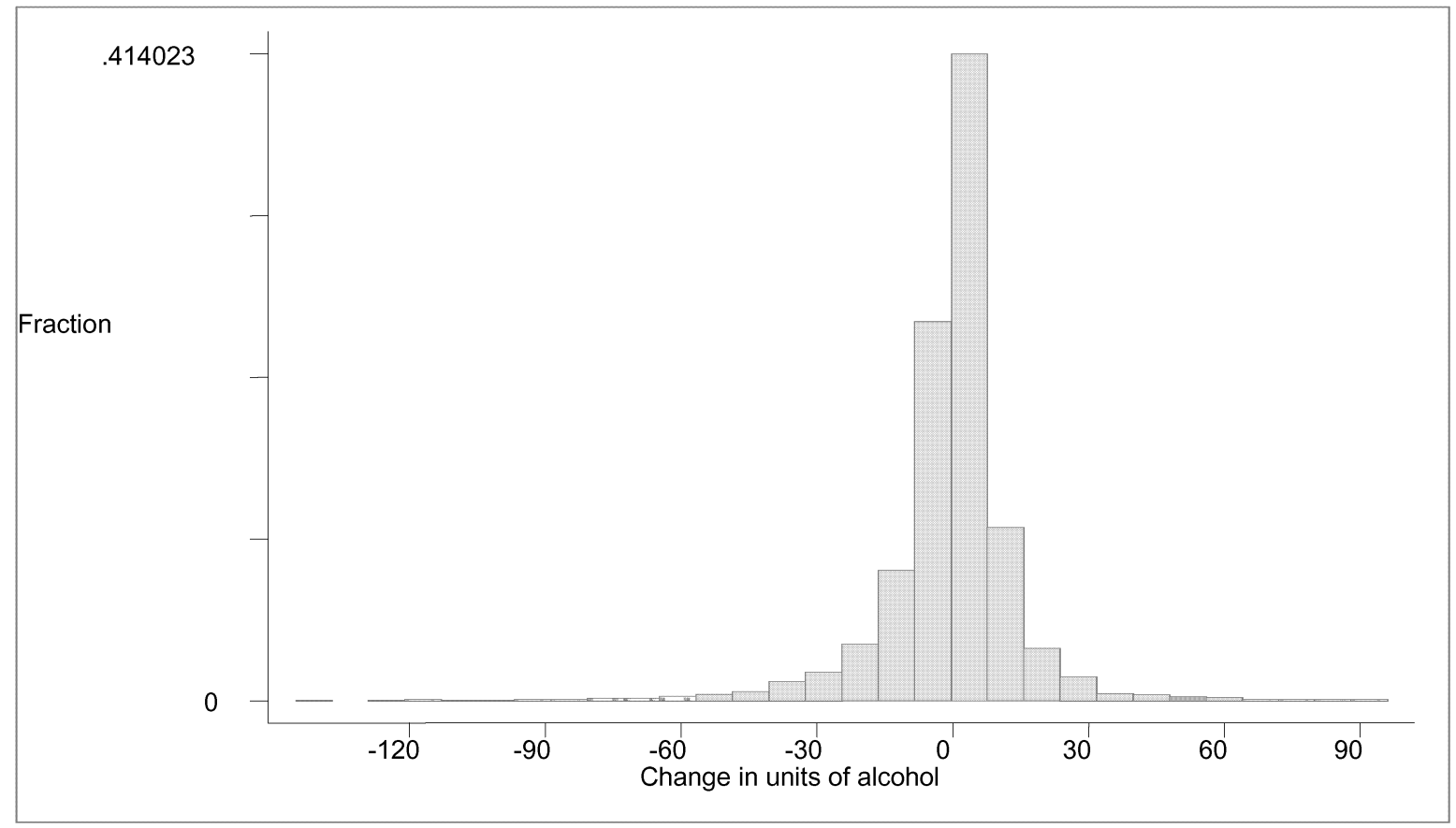

\section{Outcome 3: Increased level of exercise}

The final health behaviour considered was exercise. In both surveys, sample members reported the number of times they undertook serious exercise in an average week. It would be useful to have information on the nature of the exercise but this was not available at both periods. Therefore, we created a binary indicator variable, taking a value of 1 if the individual increased the frequency of exercise over the period, 0

\footnotetext{
${ }^{6}$ Experiments with the use of a binary variable indicating crossing this line suggested that the results
} apply equally to that outcome. Use of a continuous variable was preferred on technical grounds. 
otherwise. Individuals who were already recording the highest possible level of exercise at age 33 (i.e., every day or most days) were omitted from the analysis. From the mean reported in Table 1, it can be seen that $41 \%$ of those remaining in the sample increased the level of exercise over the period.

\subsubsection{Outcomes 4, 5 and 6: Wellbeing}

The variable used here to measure wellbeing is life satisfaction. This is a subjective appraisal of whether one is happy about one's life. It has been measured in relation to certain life domains, such as job and marital satisfaction, but here we use measures of overall life satisfaction. Self-report measures such as these are usually biased in the direction of socially desirable moods and traits. However, Deiner (2000) reports that family members provide convergent validation for self-reported happiness, and that reported happiness is associated with other positive affective characteristics such as extrovert tendencies and positive mood.

It is known that the determinants of happiness differ from the determinants of depression, indicating that these qualities are not two extremes of a single continuum. This reflects the difference in nature between wellbeing and depression. Wellbeing is understood as primarily a psycho-social state, whereas depression is diagnosed and treated primarily as a physiological one, albeit with psycho-social causes and ramifications. We test here the hypothesis that participation in adult learning has an effect upon the chances that individuals enter into clinical depression or exit from it between the ages of 33 and 42 .

There is strong evidence from a number of studies that associations exist between years of schooling or levels of qualification and depression (e.g. Montgomery and Schoon, 1997). It is likely that to some degree, this association is explained by protective effects of education upon the onset and progression of depression (e.g., Feinstein, 2002). However, the extent to which education affects the onset and progression of depression is unclear.

Descriptions of the available measures are given in Table 2.

Table 2: Wellbeing variables

\begin{tabular}{lllrrrrr}
\multicolumn{1}{c}{ Outcome } & Variable type & Obs. & Mean & S.d. & Min. & Max. \\
\hline \hline 4 & Change in life satisfaction & Continuous & 9266 & -0.22 & 1.20 & -7.22 & 6.86 \\
5 & Became depressed & Binary & 9102 & 0.09 & 0.29 & 0 & 1 \\
6 & Exited depression & Binary & 616 & 0.41 & 0.49 & 0 & 1
\end{tabular}

\section{Outcome 4: Change in life satisfaction}

The measure used for life satisfaction is based upon two items that were asked to respondents at the ages of 33 and 42. They were asked to give a score between 0 and 10 for :

- how satisfied they are about "the way their life has turned out so far;"

- how satisfied they "expect to be in ten years' time." 
In each case the score ranged from 0 for completely dissatisfied to 10 for completely satisfied. Life satisfaction at each age is calculated as the mean of the two scores. Change in life satisfaction is taken to be the difference between these scores at ages 33 and 42 . This is then standardised on the norm of the age 33 scores, providing a change variable whose metric is standard deviations of age 33 life satisfaction.

The mean change was slightly below zero, the mode was zero. The full distribution is shown in Figure 6.

Figure 6: Histogram of changes in life satisfaction

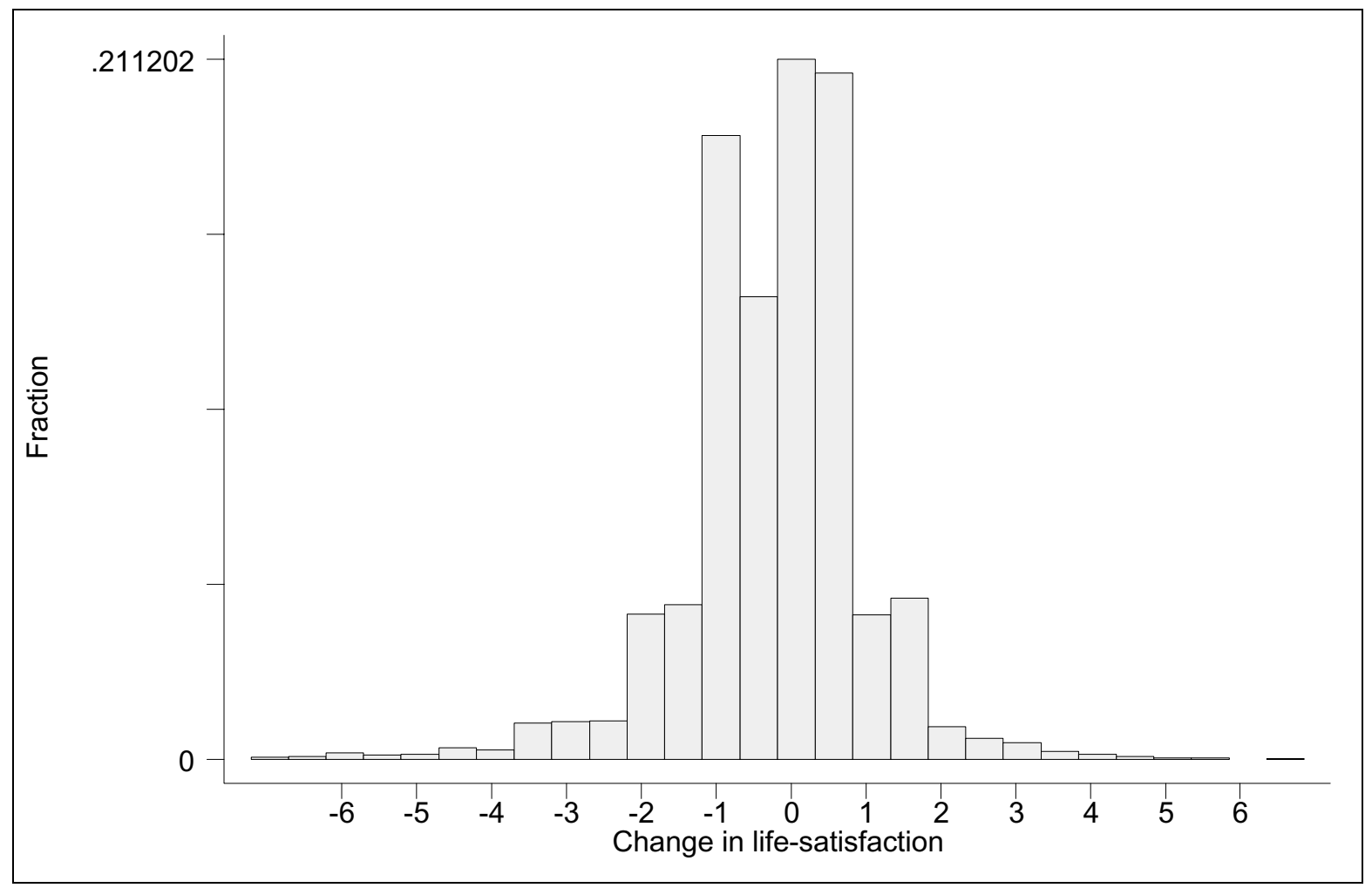

\section{Outcomes 5 and 6: Onset and recovery from depression}

The instrument used to measure depression is the "malaise inventory", which consists of 24 questions designed to identify individuals experiencing clinical depression (Rutter et al., 1970). A positive answer to any one of these 24 questions scores one point, and clinical depression is indicated by a score of eight points or higher. The questions used in the malaise inventory are presented in Appendix 3. Outcome 5 is an indicator variable for moving into clinical depression. It considers those who were not recorded as clinically depressed at age 33 and gives a score of one to those who became depressed at age 40 and zero to those who did not. It can be seen from Table 2 that $9 \%$ of those who were not depressed at 33 were depressed at 42 .

Outcome 6 is the reverse of this. It considers those who were depressed at age 33 and takes a value of one if they were no longer depressed at 42 . This was the case for $41 \%$ 
of those who were depressed at 33. Sample numbers are particularly low for this outcome because only those who were depressed at age 33 are considered.

\subsubsection{Outcomes 7, 8, 9 and 10: Social and political attitudes}

We consider the effects of adult learning on a set of four attitudinal outcome variables, summarised in Table 3 . As with life satisfaction, the continuous attitude scores are expressed in terms of standard deviations of the age 33 level.

Table 3: Social attitude variables

\begin{tabular}{lllccccc}
\multicolumn{1}{c}{ Outcome } & $\begin{array}{l}\text { Variable } \\
\text { type }\end{array}$ & Obs. & Mean & S.d. & Min. & Max. \\
\hline \hline 7 & Change in race tolerance & Continuous & 9374 & 0.19 & 0.86 & -4.08 & 5.25 \\
8 & Change in pol. cynicism & Continuous & 9348 & 0.44 & 1.02 & -3.88 & 4.74 \\
9 & Change authoritarianism & Continuous & 9372 & 0.26 & 0.83 & -4.02 & 5.62 \\
10 & Increased political interest & Binary & 8372 & 0.19 & 0.39 & 0 & 1
\end{tabular}

\section{Outcome 7: Change in race tolerance}

Our variable for support for race equality is based upon measures at ages 33 and 42 of self-reported agreement on a five-point scale with the following statements:

- "It is alright for different races to get married";

- "I would not mind if a family from another race moved in next door to me";

- "I would not mind if my child went to a school where half the children were of another race";

- "I would not mind working with other races";

- "I would not want a person from another race to be my boss".

The average change in this variable is small relative to the scale of the level but there were more positive changes than negative ones over this period, as shown in Figure 7 and Table 3. 


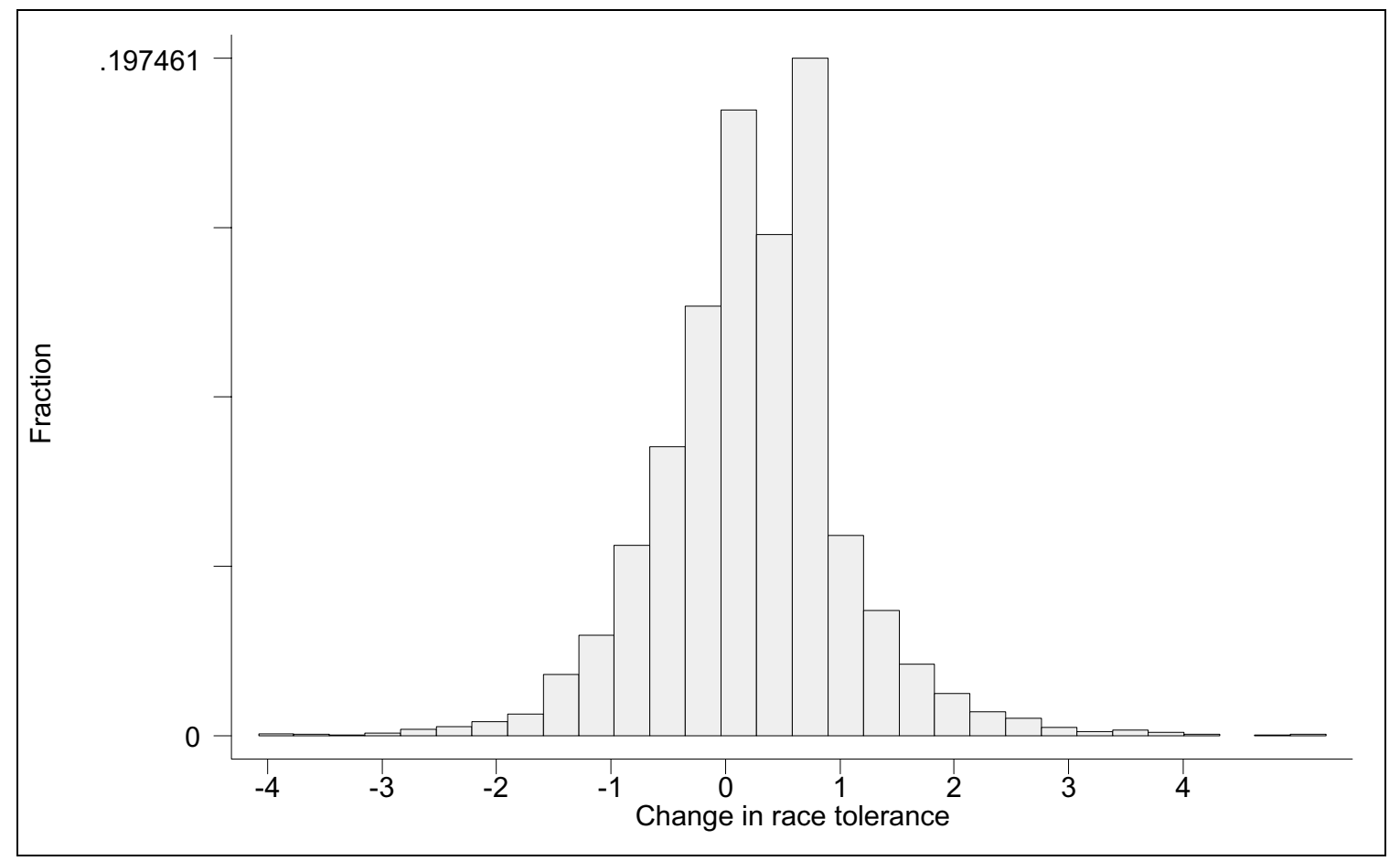

\section{Outcome 8: Change in political cynicism}

Political cynicism as measured in the NCDS is primarily a measure of "external political efficacy" (Clarke and Acock, 1989). It measures the extent to which individuals believe in the ability of the political system to respond to the needs of the electorate rather than their ability to influence political events. Therefore, although education may foster a general support for democracy (Emler and Fraser, 1999) there is a difference between this liberal attitude and belief that a specific electoral system will deliver voter preferences. Quantitative analyses have found correlations between voting behaviour, political interest, and political cynicism (Nie, 1996; Bynner et al., 2003), and it appears that in the UK there was an increase in political cynicism during the 1990s. We investigate the effect of adult education on the level of political cynicism reported by individuals. This is measured in the NCDS by the level of reported agreement (again on a five-point scale) with the statements:

- "None of the political parties would do anything to benefit me";

- "It does not really make much difference which political party is in power in Britain";

- "Politicians are mainly in politics for their own benefit and not for the benefit of the community".

$70 \%$ of the sample increased their level of political cynicism between the ages of 33 and 42. Evidence suggests that this is less an effect of the maturation of the individuals in the sample and more a general cultural shift over the period (Bynner et al., 2003). The increase in political cynicism can be seen from Figure 8 and Table 3. 


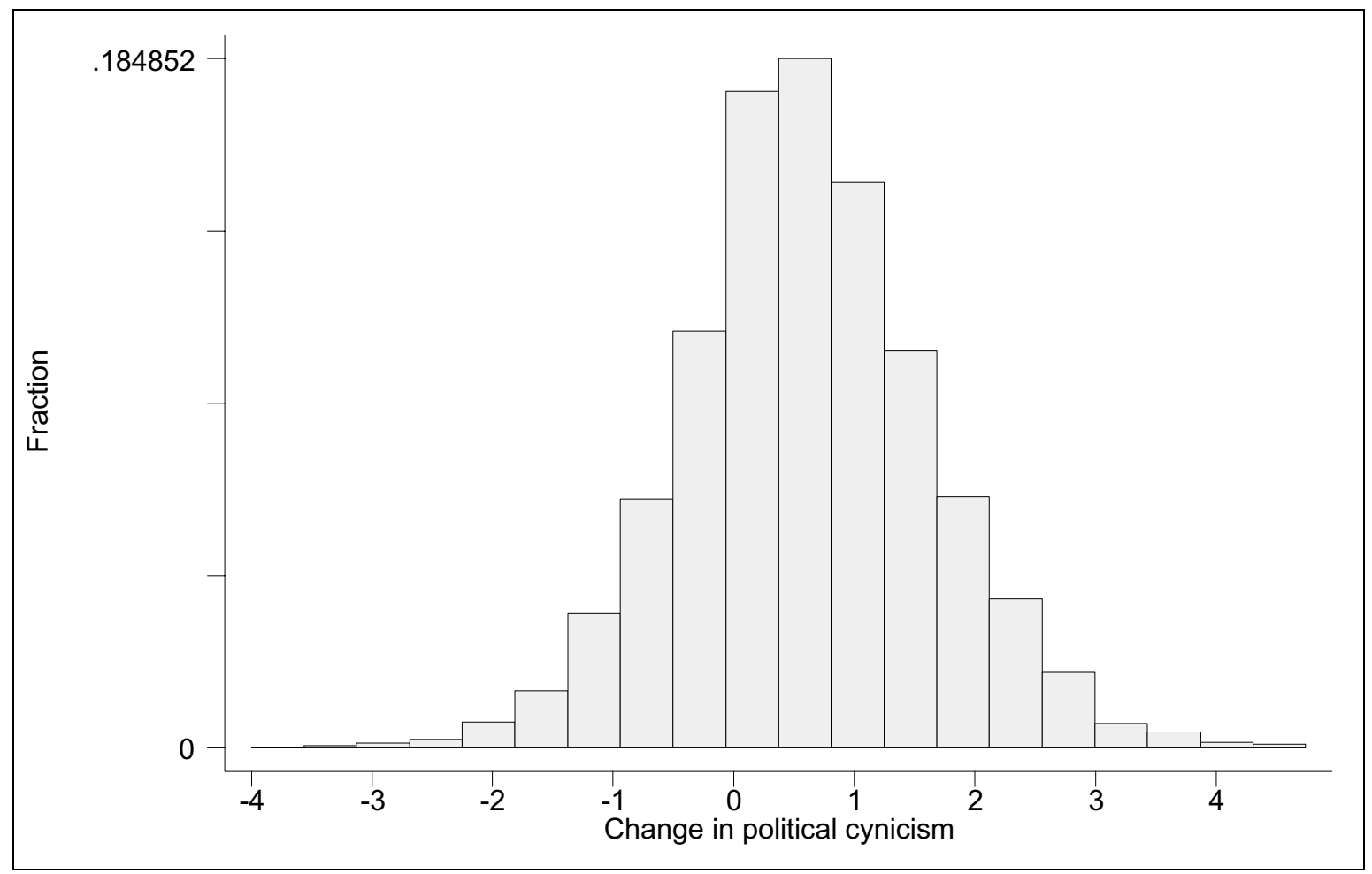

\section{Outcome 9: Change in authoritarianism}

The impact of education on authoritarian attitudes has a long lineage dating back to seminal work by Adorno et al (1950). There are certainly positive connections between entrenched authoritarian attitudes and racism. Learning effects on racism and authoritarianism appear to be similarly mediated by the development of general cognitive abilities. Analysis of the fieldwork data suggests that participation in adult learning can develop an individual's capacity to question and appraise information critically. Consequently, we include a measure of the change in individuals' authoritarian attitudes between the ages of 33 and 42 . The outcome is measured using level of agreement (along the same five point scale as the previous measures) to six statements, the same at both ages:

- "The law should be obeyed even if a particular law is wrong";

- "For some crimes death penalty is the most appropriate sentence";

- "Censorship of films and magazines is necessary to uphold moral standards";

- "People who break the law should be given stiffer sentences";

- "Young people today don't have enough respect for traditional British values";

- "Schools should teach children to obey authority".

There was little change in the sample's authoritarian attitudes over the period. The mean is only marginally higher than that for race tolerance (see Table 3). This strong central tendency can be seen in Figure 9. 


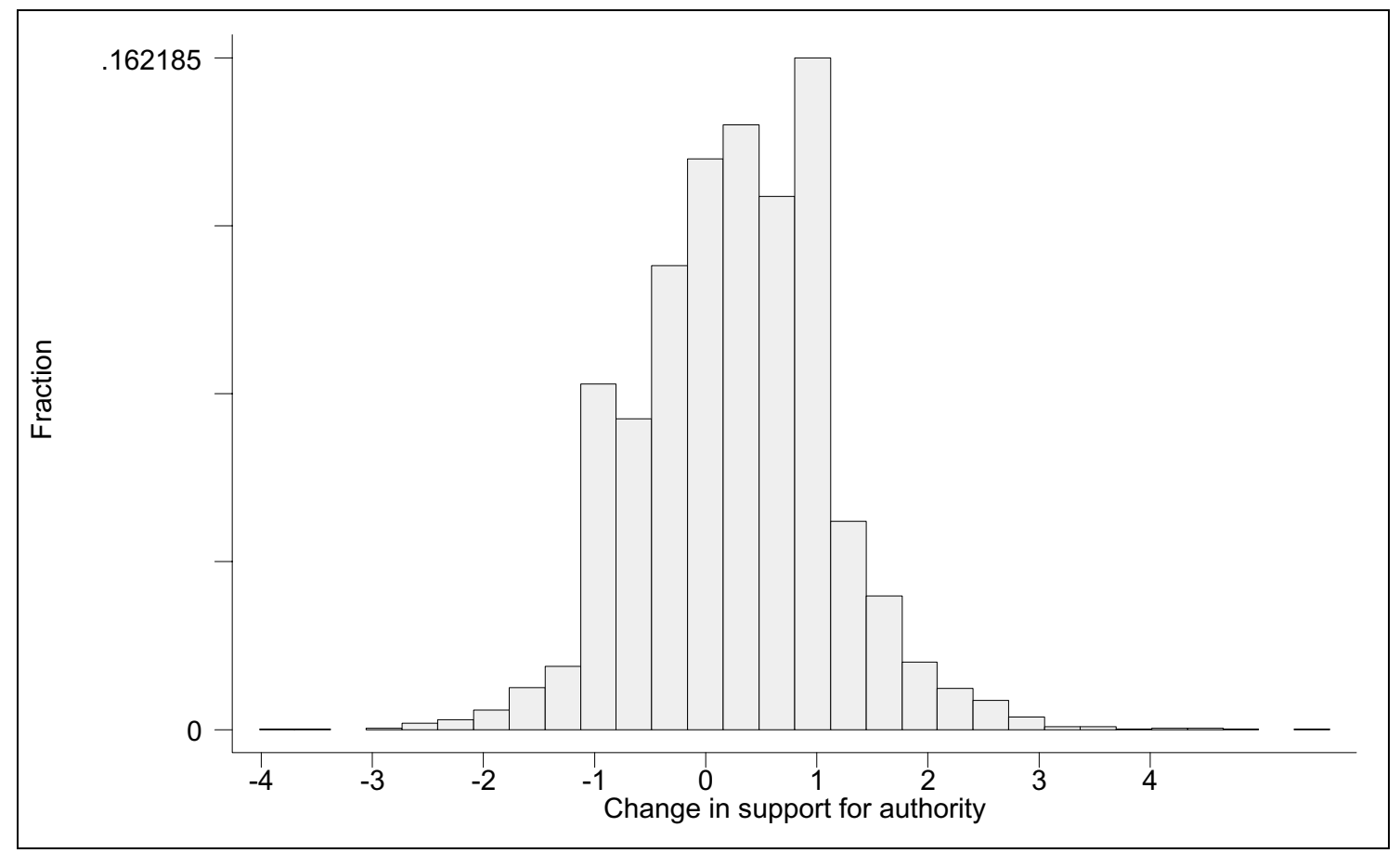

\section{Outcome 10: Increased political interest}

Linked with concerns about declining civic participation is a decline in interest in politics. Unlike political cynicism, interest in politics shows a clear and strong association with education in much of the related literature (Emler and Fraser, 1999). Interest in politics is measured using a four point scale of self-rated interest, the survey instrument being the same at both ages.

Because there is considerably less variation in this variable than the previous ones, we do not treat it as continuous but instead construct a binary variable, coded as 1 for those whose interest in politics increased over the period and 0 otherwise. Those who already had interest at the highest level at age 33 are omitted. Nearly $20 \%$ of those remaining recorded an increase in political interest (Table 3).

\subsubsection{Outcomes 11 and 12: Civic participation (memberships and voting)}

\section{Outcome 11: Increased civic membership}

Declining levels of civic participation have been cited in the United States, and to some extent elsewhere, as a component of declining levels of social capital (Putnam, 2000). Although there is less evidence to support this thesis in the United Kingdom (Hall, 1999) there are similar policy concerns regarding civil society. Educational level correlates with civic participation (Putnam, 2000), but there is little quantitative evidence that educational interventions, such as adult learning, increase civic participation. Civic participation in terms of associational memberships is of policy importance in terms of building what has come to be called "social capital," community cohesion and economic regeneration. 
To test whether adult learning has an effect on civic participation, we use a variable which indicates whether the number of civic participations has increased between 33 and 42. Civic participation is taken to include membership of a political party, a charity or voluntary group, women's groups, townswomen's guilds and women's institutes, parents and school organisations and tenants and residents associations. The variable takes a value of 1 if civic participations increased between 33 and 42, 0 otherwise. Summary statistics are reported in Table 4. Twelve per cent increased their number of civic memberships.

Table 4: Civic and political involvement variables

\begin{tabular}{lllllllc}
\multicolumn{1}{c}{ Outcome } & $\begin{array}{l}\text { Variable } \\
\text { type }\end{array}$ & Obs. & Mean & S.d. & Min. & Max. \\
\hline \hline 11 & $\begin{array}{l}\text { Increased number of civic } \\
\text { memberships }\end{array}$ & Binary & 9756 & 0.12 & 0.33 & 0 & 1 \\
12 & $\begin{array}{l}\text { Voted in 1997 having } \\
\text { abstained in 1987 }\end{array}$ & Binary & 2116 & 0.50 & 0.50 & 0 & 1
\end{tabular}

\section{Outcome 12: Voted in 1997 having abstained in 1987}

Perhaps due to its infrequency (for general elections, only once every four years), the low level of activity required, and the paradoxes associated with voting (why vote when an individual vote makes little difference?) voting has proven to be different from other forms of political and civic behaviour in terms of its antecedents (Bynner and Ashford, 1994). The propensity of individuals to vote depends on their individual characteristics and also on historical factors such as the state of the economy. The evidence that education has a direct impact on voting is mixed (Emler and Fraser, 1999).

Given the policy importance of increasing electoral turnout, we examine the impact of adult learning for a sub-cohort of our sample, namely those who abstained in the election of 1987. Half of those who didn't vote in 1987 did so in 1997 (Table 4).

The values of this outcome is limited by the timing of voting in relation to the timing of data collection. Respondents were asked about participation in learning and about the range of outcomes in 2000, three years after they had either voted or abstained. Roughly a third of the learning that they report will therefore have taken place after or concurrently with, rather than before, the decision to vote.

\subsubsection{The importance of education}

In order to contextualise subsequent results about the effect of adult learning on the outcomes described, we first explore the apparent importance of qualifications gained prior to age 33 , for the outcomes at age 33 .

In Figure 10, we report the differences in the age 33 outcomes according to academic education level. The full results are shown in Appendix 4. 
The figure illustrates levels of each outcome for those with academic qualifications at age 33 relative to baseline levels of the same outcome for those with no qualifications, which are set to one. The differences in outcomes are heavily stratified by academic educational level. For example, the odds of being a smoker for those with qualifications above level $2^{7}$, relative to those with no qualifications are 0.2 . The equivalent odds ratio for those qualifications at or below level 2 is 0.4 . These differences are all statistically significant and indeed those with qualifications above level 2 are likely to have better outcomes for all outcomes, at $99 \%$ significance. Those concerned with equity in adult outcomes might hope that the differences are addressed by subsequent participation in adult learning.

Raw differences between those with qualifications at or below level 2 and those with no qualifications are apparent, but not for all outcomes. There are no differences for the following outcomes:

- alcohol consumption;

- life satisfaction;

- race tolerance;

- authoritarian attitudes.

Differences are significant for the other outcomes.

\footnotetext{
${ }^{7}$ We categorise highest qualification levels using the framework devised by the Qualifications and Curriculum Authority. This means that those with one or more GCSE A*-C passes are taken to have academic qualifications at Level 2.
} 
Figure 10: Odds ratios for age 33 outcomes, by academic educational level

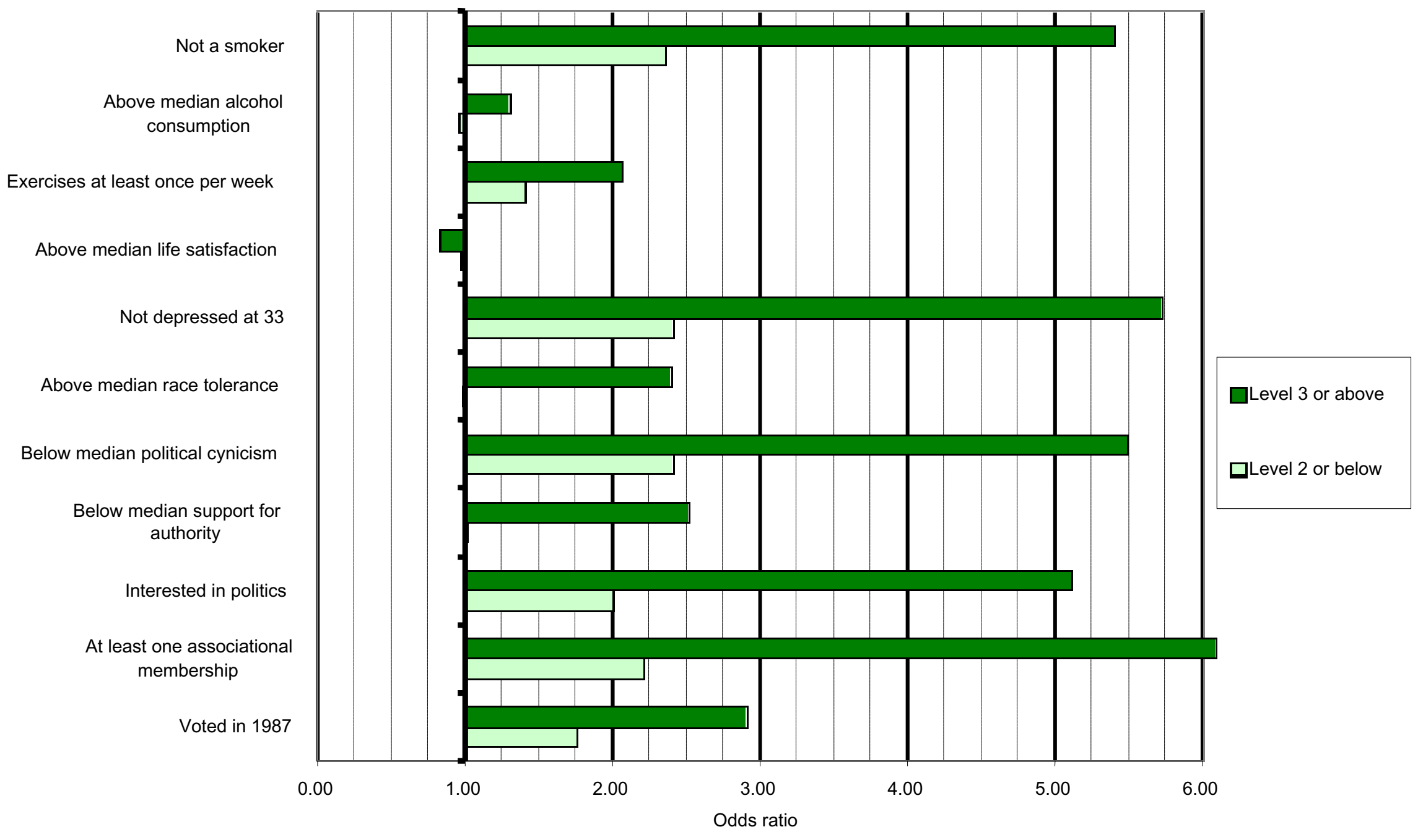




\section{Method}

\subsection{Identifying effects of adult learning: the problem of selection bias}

Having described the outcomes we now return to the issue of selection bias ${ }^{8}$. In the current context, selection bias would refer to the situation where those who participated in adult learning were systematically different to those who did not. One could not generalise from simple estimates of the effects of participation because any benefits that accrued to those who participated would not necessarily hold for the wider population. "Selection bias" would result.

Consider a case where:

- $\quad$ people with a higher level of ambition undertake more adult learning;

- people with a higher level of ambition have better outcomes (e.g., better health and greater social capital);

- ambition is unobserved in the data.

In this case, selection bias will result as there is a systematic relationship between participation in learning and the outcomes. However, causality does not run from participation to outcomes. Rather, there is some unobserved feature (ambition) that alone explains the correlation between learning and outcomes ${ }^{9}$.

This problem would be particularly acute if the analysis is conducted in terms of the level of the outcome. However, if the effect of the level of ambition is constant over time, then any change in outcomes cannot be due to ambition. The bias is removed by considering the change in the outcome rather than the level at a single point in time. Therefore, we conduct analysis in terms of changes rather than levels. The estimation therefore attempts to quantify the first relationship indicated in Figure 11.

However, although substantially reduced, it is still possible that selection effects remain. There are two main types, resulting from:

- an improvement or deterioration in outcomes that leads to more or less adult learning, i.e. reverse causality;

- an unobserved experience which is associated with both a change in outcomes and participation in adult learning, i.e. confounding bias.

The first kind is where the change in outcomes precedes and perhaps causes the adult learning. This is illustrated by the second of the relationships in Figure 11.

For example, it is possible that individuals who increased their number of memberships participate in adult learning as part of a general expansion in their life activity. A positive association between participation and increased memberships

\footnotetext{
${ }^{8}$ This problem and our approach are described in more detail in Appendix 5.

9 Statistically experienced readers might also think of this bias as an example of confounding bias. In this case either term might be applied to the bias problem.
} 
would result not because adult learning increases civic participation, but because increases in civic participation lead to taking more courses.

Figure 11: Associations and causality

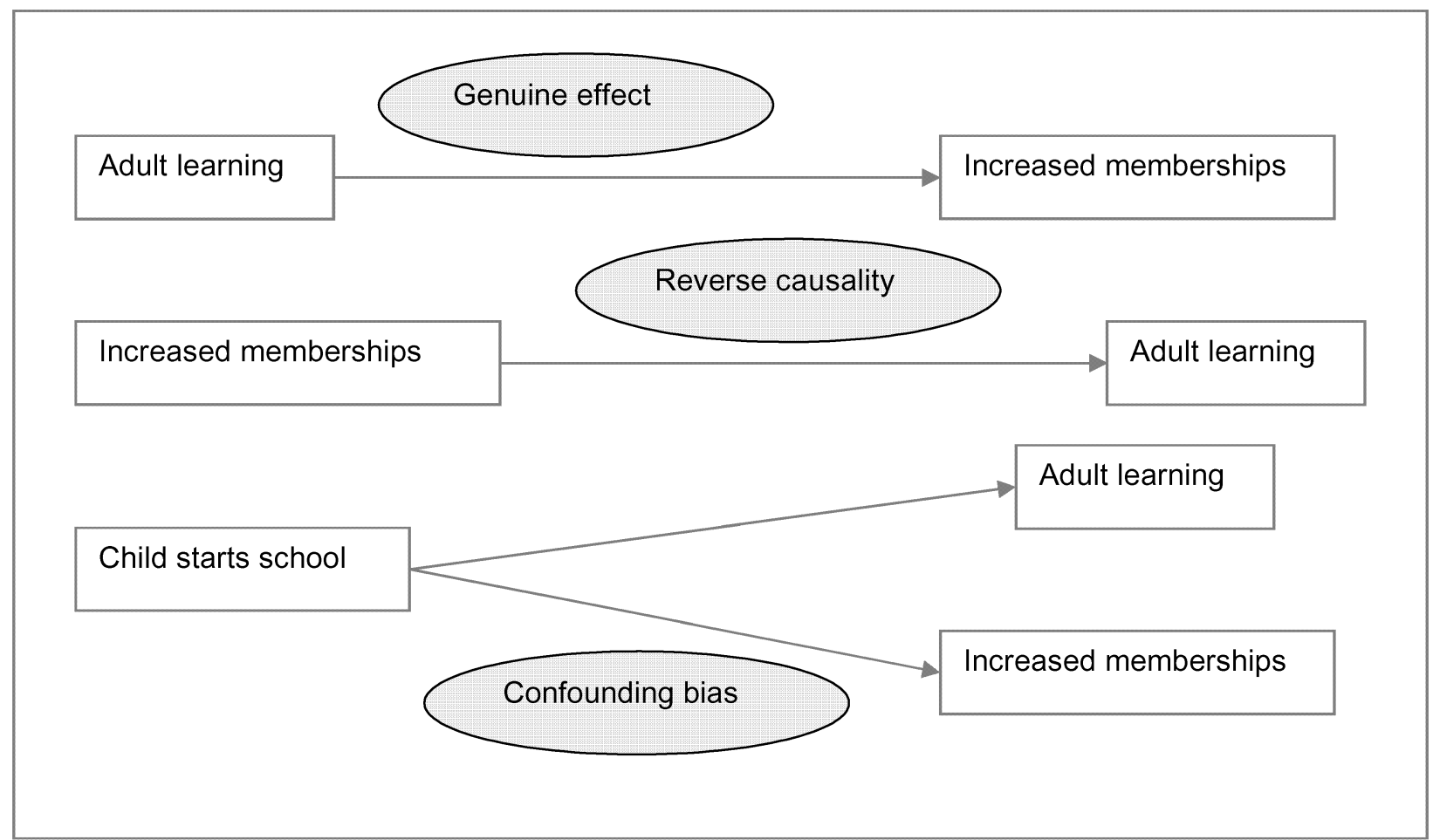

Although it is plausible that increased civic participation leads to participation in adult learning, it is rather less plausible that giving up smoking does. This reverse causality seems more plausible, therefore, for some outcomes than for others. We address the issue empirically in section 5.3.

The second type of selection bias is where an unobserved event or change leads both to participation in adult learning and to a change in outcomes. The example of unobserved motivation would provide one such case. To give another example, it may be that some change in perspective leads an individual to quit smoking and to take a course. This would lead to a spurious association between adult learning and quitting smoking. Or a child starting school might enable a mother to take a course and also coincide with her joining the Parent School Association. This example is shown in the third part of Figure 11.

\subsection{Dealing with selection bias}

We deal with selection bias in three ways. The first is to include in our models controls for possible sources of confounding bias up to and including the age of 33 . The second is to extend this set of controls to include changes in life circumstances between the ages of 33 and 42, which are concurrent with our measures of participation in learning and changes in health and social capital. The third approach is to assess the extent to which reverse causality accounts for observed associations 
between participation in learning and changes in health and social capital by employing a reciprocal model, which estimates the effects of changes in health and social capital between 33 and 42 upon participation in learning at age 42 .

\subsubsection{Controlling for life circumstances up to age 33}

In order to reduce selection bias, we include in our models measures of covariates that we think might be driving both participation in adult learning and changes in the outcomes variables. These can be used to control for and hence remove a proportion of the potential biases.

The control variables used comprise gender, highest academic and vocational qualifications, social class and the value of the outcome variable, all at age 33 . We have experimented with using larger sets of control variables measured up to age 33, but including them makes very little difference to our results. Given this, we judge it better not to include the additional controls, because including in the model variables that are associated with one another can reduce the precision and statistical significance of estimated effects. Full details of controls included in the model and of the experiments with other sets of controls are given in Appendix 6 and Appendix 7 respectively.

If correlations between adult education and outcome variables persist, even after including our selected control variables, then the evidence for a causal relationship between adult learning participation and the outcome variables is more convincing. Nevertheless, there remain causes for confounding bias not included in the model because they are not measured in the data. One example is level of ambition, referred to at the beginning of this section, which we should probably not assume to be constant over time, and which is likely to affect both participation in learning and changes in several of the outcomes used. Here, there is no feasible option but to recognise that the problem cannot be dealt with quantitatively. To the extent that this occurs any estimated effect of adult learning would be biased.

\subsubsection{Controlling for life changes between 33 and 42}

As a further test for selection bias, we include in the models an additional set of variables proxying for changes in life circumstances between the ages of 33 and 42 . Details of these variables are given in Appendix 8.

Because these variables are measures of changes after the age of 33, they are coincident with our measures for participation in learning, and with the changes in health and social capital which we refer to as outcomes. Therefore, if inclusion of changes in life circumstances in the specification attenuates the sizes of associations between participation in learning and changes in outcomes, then two explanations are possible. The first is selection bias - changes in life circumstances lead to both participation in learning and changes in outcomes. Including changes in life circumstances in the model would therefore reduce the magnitudes of estimated 
effects of adult learning on changes in outcomes. The second, which is not an example of selection bias, is that participation in learning may lead to changes in life circumstances which in turn lead to changes in outcomes. In other words, adult learning has effects but these are to some extent mediated by changes in life circumstances. The two hypotheses are illustrated in Figure 12 below.

Figure 12: Two possible explanations

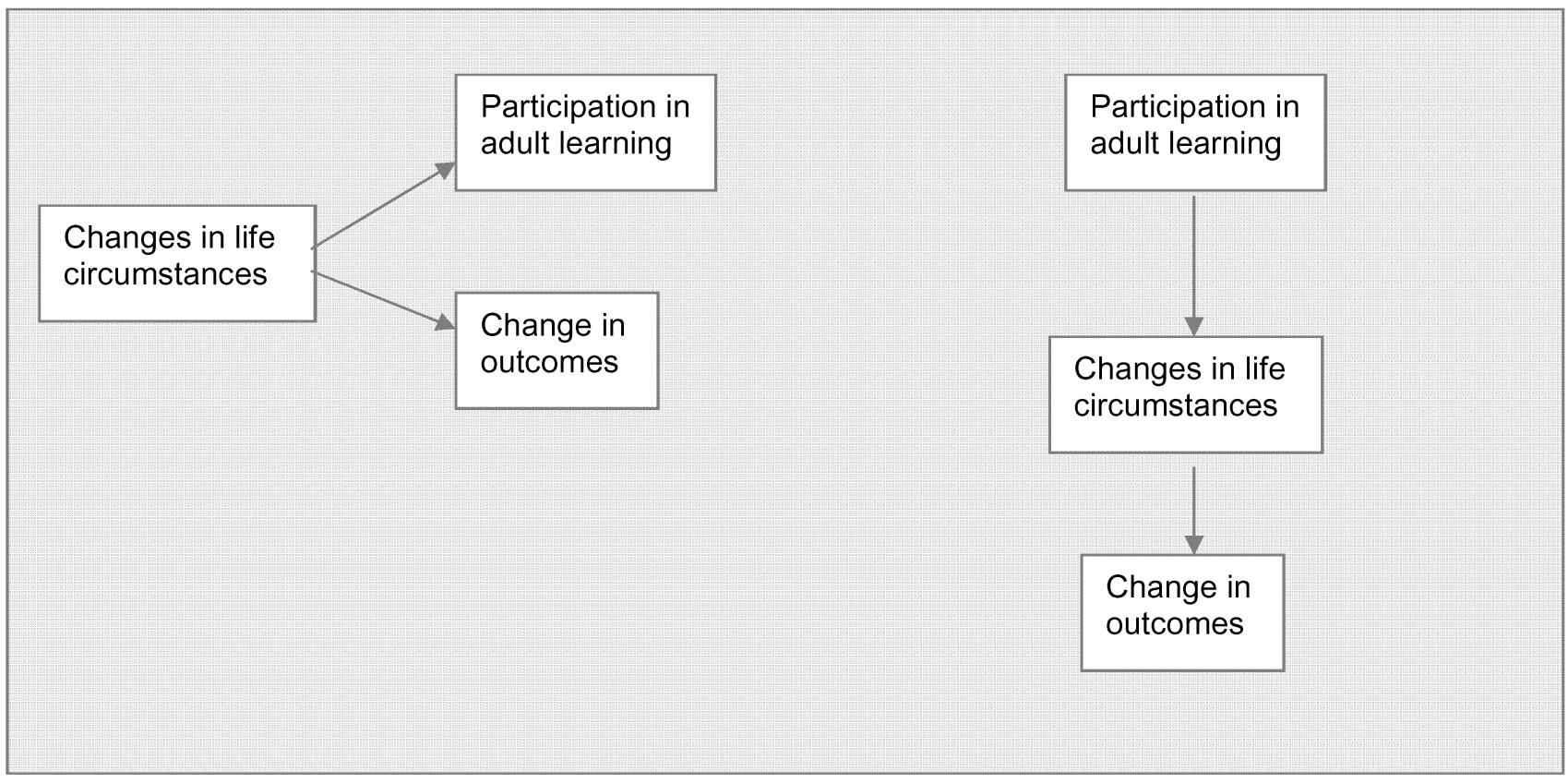

\subsubsection{Attempting to assess the impact of reverse causality}

An important limitation in our data is that the precise timing of participation in adult learning and changes in outcomes between 33 and 42 are not recorded. Therefore, we have insufficient data to identify the sequence of changes and so rule out the effects of reverse causality. Thus some positive bias may remain in our estimates.

Although we cannot remove the potential for reverse causality in our models, we are able to examine the extent to which changes in health and social integration outcomes between the ages of 33 and 42 determine participation in adult learning at the age of 42. This is possible because cohort members were asked about their current participation in learning when they were interviewed at the age of 42 . To some extent, therefore, we can test whether selection bias is likely to be a problem. Results are presented in Section 5.3.2 and Appendix 9.

\subsection{Overview of methods used}

As described above, our analyses were conducted in three phases. The first phase attempts to isolate effects of adult learning by including in our models the control variables mentioned above. We then examine relationships between participation in learning between the ages of 33 and 42, changes in outcomes, and other life changes 
over this period. In the final stage of the analysis, we attempt to assess the effects of reverse causality.

A number of other issues also need to be addressed. One is how the adult learning variable should be specified: are returns linear, or does the benefit per course decrease as the number of courses taken rises? Do the effects of learning depend on the type of course taken? How do the effects of learning differ depending on the characteristics of the learner? In our first analyses, we do not address these questions, but we return to them subsequently.

\section{Results}

Results are reported in two sections. This section reports the main findings of analyses based upon the whole sample and aggregating across all types of courses. We discuss interpretations of the magnitudes of estimated effects, and to what extent we can interpret these findings as effects of learning. The following section (Section 6) reports the results of many more analyses that investigate in detail the effects of participation in different types of courses for different sub-groups of the population. Key and specific findings (KF and SF) are given throughout the text in bold font, and re-stated at the end of each section.

The results given in this and the following section are based on models that include controls for gender, socio-economic status, and highest academic and vocational qualification at age 33. The decision to include these variables was arrived at following experiments using larger sets of control variables measured up to age 33 . Full details of the control variables used and of the experiments with other sets of controls are given in Appendix 6 and Appendix 7. These experiments show that the results presented below are robust to the inclusion of additional controls.

\subsection{The effects of the number of courses taken}

The measure of participation in learning used in the analyses reported in this subsection is the total number of courses taken between 33 and 42 . This total does not include courses that cohort members were taking at the time of the 2000 survey (i.e., at age 42). Table 5 reports the estimation results for all 12 outcomes. Estimates of the effects of participation in adult learning measured by the total number of courses attended between the ages of 33 and 42 are presented in column 2 and the p-values for these coefficient estimates are given in column $3^{10}$.

\footnotetext{
${ }^{10}$ The $\mathrm{P}$-value is a standard indicator of the statistical significance of the coefficient estimate. A $\mathrm{P}$-value below 0.05 indicates that the result is significant at 95\% confidence, below 0.01 at $99 \%$ confidence.
} 
Table 5: Estimated effects of number of courses taken on the 12 outcomes

\section{Outcome}

(1)

\section{Estimate}

(2)

$\begin{array}{ll}0.003 & 0.197 \\ 0.044 & 0.151 \\ 0.004 & 0.006 \\ 0.007 & 0.007 \\ 0.001 & 0.409 \\ 0.002 & 0.752\end{array}$

\section{Social capital}

7 Change in race tolerance

0.013

0.000

8 Change in political cynicism

$-0.002$

0.150

9 Change in authoritarianism

$-0.009$

0.000

10 Increase in political interest

0.003

0.008

11 Increase in number of memberships

0.003

12 Voted in 1997 having abstained in 1987

0.007

0.000

0.036

NOTE: This table presents the results of 12 regressions, one for each outcome. Each regression controls for gender, qualifications and socio-economic status at age 33 and the lagged dependent variable as discussed in section 4.2.1 and appendix 6. For binary variables probit analysis was used and marginal effects calculated. For continuous variables, the analysis was by ordinary least squares.

The estimates reflect the magnitudes of each effect. The p-value is a measure of statistical significance, that is, the confidence that we can have that an effect would be found if another sample were drawn. It can be seen that statistically significant effects of adult learning are estimated for seven of the 12 outcomes at $95 \%$ confidence. These seven outcomes are changes in level of exercise taken, life satisfaction, three of the measures of change in social attitudes, and both of the measures for change in civic participation, mapping the whole breadth of social and health outcomes considered here.

The results are really quite striking in terms of the range of benefits of adult learning that they suggest.

KF 1: The total number of courses taken between 33 and 42 has effects on a wide range of health and social benefits.

KF 2: Statistically significant effects of the total number of courses taken during midadulthood are estimated for seven of the twelve outcomes at $95 \%$ confidence. These outcomes are changes in exercise taken, life satisfaction, race tolerance, authoritarian attitudes, political interest, number of memberships, and voting behaviour. 


\subsection{Interpretation of effect sizes}

We now clarify the implications of these results in terms of the magnitudes of effects. This involves two steps. The first is to assess whether the impacts of each course taken (first, second, and so on) are the same. If they are, then we can interpret the estimated effects of participation using the linear measure simply as the magnitude of effect associated with each additional course taken. If, on the other hand, the effect size changes as more courses are taken, then we need to consider separately the effect sizes for each level of participation. In other words, we need to use a specification that allows for the different magnitudes of impact associated with, say, the first and the tenth course taken. Once we have established which specification we need to use, we move onto the second step, which is to interpret the magnitudes of estimated effects.

\subsubsection{The effect of level of participation in learning on outcomes}

As explained above, the linear measure of participation assumes that the marginal effect of doing an extra course is the same for the first course as, say, for the tenth course. In order to test whether this is so, we estimate the effects of adult learning using a measure of adult learning that classifies participation into the following four categories chosen to distinguish between no participation and then low, medium and high levels of participation:

- no participation;

- 1 or 2 courses;

- 3 to 10 courses;

- more than 10 courses.

The advantage of this model is that it allows the estimation to distinguish those who take a very large number of courses from those taking a moderate number of courses and relaxes the restriction that the effect of taking ten courses, say, must be ten times greater than the effect of taking one course. Indeed, this model even allows for negative 'effects' of taking large numbers of courses while still facilitating the estimation of positive effects for moderate numbers of courses ${ }^{11}$.

We have experimented with using other categories of participation (e.g. one to three, four to eleven, and more than eleven courses) and results do not change. We have also experimented with other specifications such as a single dummy variable

\footnotetext{
${ }^{11}$ The model used can be described by the following equation:

$\Delta y=\alpha+\sum_{i=1}^{3} \delta_{i} D_{i}+X \mathrm{~B}$

where $y=$ change in outcome, $\alpha=$ constant,$i=$ level of participation, $D_{i}=$ dummy variables indicating whether cohort members have participated at a certain level, $\delta \mathrm{i}=$ estimated coefficients for each level of participation, $\mathrm{X}=$ matrix of control variables, $\hat{\mathrm{A}}=$ matrix of estimated coefficients for control variables.
} 
indicating participation in adult learning and a quadratic specification using the numbers of courses. We find that the form presented here is the most informative, but results do not depend on the specification used.

The results from this model are reported in Table 6 .

Table 6: Estimated effects of three levels of participation in learning

\begin{tabular}{|c|c|c|c|c|c|c|c|}
\hline \multirow[t]{2}{*}{ Outcomes } & \multicolumn{2}{|c|}{1 or 2 courses } & \multicolumn{2}{|c|}{ 3- 10 courses } & \multicolumn{2}{|c|}{$\begin{array}{l}11 \text { or more } \\
\text { courses }\end{array}$} & \multirow{2}{*}{$\begin{array}{l}\text { P-val } \\
\text { for } 3 \\
\text { coeffs. }\end{array}$} \\
\hline & Est & P-val & Est & P-val & Est & P-val & \\
\hline \multicolumn{8}{|l|}{ Health } \\
\hline Gave up smoking & & & & & & & \\
\hline & 0.033 & 0.094 & 0.073 & 0.004 & -0.023 & 0.635 & 0.018 \\
\hline $\begin{array}{l}\text { Change in units } \\
\text { drunk }\end{array}$ & -0.445 & 0.133 & -0.495 & 0.161 & 0.703 & 0.280 & 0.138 \\
\hline $\begin{array}{l}\text { Increase in } \\
\text { exercise }\end{array}$ & 0.015 & 0.258 & 0.071 & 0.000 & 0.049 & 0.108 & 0.000 \\
\hline $\begin{array}{l}\text { Change in life } \\
\text { satisfaction }\end{array}$ & 0.034 & 0.197 & 0.088 & 0.005 & 0.106 & 0.073 & 0.025 \\
\hline & -0.003 & 0.583 & 0.009 & 0.231 & -0.001 & 0.955 & 0.445 \\
\hline $\begin{array}{l}\text { Recovered from } \\
\text { depression }\end{array}$ & 0.036 & 0.447 & 0.023 & 0.726 & -0.020 & 0.884 & 0.881 \\
\hline Social capital & & & & & & & \\
\hline $\begin{array}{l}\text { Change in race } \\
\text { tolerance }\end{array}$ & 0.047 & 0.009 & 0.121 & 0.000 & 0.196 & 0.000 & 0.000 \\
\hline $\begin{array}{l}\text { Change in } \\
\text { political cynicism } \\
\text { Change in }\end{array}$ & -0.046 & 0.028 & -0.050 & 0.049 & -0.049 & 0.304 & 0.094 \\
\hline $\begin{array}{l}\text { authoritarianism } \\
\text { Increase in }\end{array}$ & -0.067 & 0.000 & -0.133 & 0.000 & -0.162 & 0.000 & 0.000 \\
\hline $\begin{array}{l}\text { political interest } \\
\text { Increased }\end{array}$ & 0.018 & 0.061 & 0.021 & 0.079 & 0.063 & 0.009 & 0.025 \\
\hline $\begin{array}{l}\text { memberships } \\
\text { Voted } 1997\end{array}$ & 0.029 & 0.000 & 0.045 & 0.000 & 0.083 & 0.000 & 0.000 \\
\hline abstained 1987 & 0.060 & 0.019 & 0.063 & 0.050 & 0.154 & 0.020 & 0.015 \\
\hline
\end{tabular}

We use these results to assess whether the effects of each course taken are the same. The first point to note is that using this non-linear specification of adult learning, we identify additional effects that are statistically significant at $95 \%$ confidence in relation to two outcomes that were not apparent with the linear specification: increased chances of giving up smoking and reduction in political cynicism. For both these outcomes, effects are found in relation to taking up to but not more than ten courses. Effects of more than ten courses are pernicious for quitting smoking, which 
is why no effects are found using the linear measure of participation. Effects for political cynicism are 'flat', i.e., participation reduces cynicism but there are no returns to taking courses after the tenth course.

Comparison of Table 5 (Column 2) and Table 6 (Column 3) reveals that the estimated effects of taking one or two courses on the probability of giving up smoking and reduced political cynicism using the categorical measure of participation are much larger than the estimated effects per course taken using the linear measure of participation by factors of roughly ten and twenty, respectively. This also applies to changes in alcohol consumption, for which the estimated effect of taking one or two courses is roughly ten times greater using the categorical measure of participation than it is using the linear measure of participation. These comparisons highlight the value of taking just one or two courses, even if no more are taken afterwards, at least in relation to giving up smoking, reducing alcohol consumption, and lower levels of political cynicism.

For changes in level of exercise taken and authoritarian attitudes, for which statistically significant effects are found using the linear measure of participation, the effects of taking over ten courses are not greater than the effects of three to ten courses. In other words, there are no additional returns to taking extra courses at high numbers for these two outcomes.

For the other outcomes for which there are statistically significant effects of learning using the linear measure of participation (i.e., changes in life satisfaction, race tolerance, and the two measures of civic participation), the effects of taking three to ten courses are larger in magnitude than the effects of taking one or two courses, and the effects of taking over ten courses are greater still. This implies that for these outcomes, taking additional courses imparts added value even at numbers of courses above ten. That is, the more courses, the better, though generally at a diminishing rate.

For these outcomes, we compare the values in Table 5 and Table 6 (as before) in order to ascertain whether the estimated effects of taking one or two courses are equivalent using the two specifications of participation. From this comparison, it is evident that in relation to $\underline{\text { all }}$ outcomes, even those where there are returns to extra courses after the tenth, the magnitudes of effects of taking just one or two courses using the categorical measure of participation are greater than one would predict using the linear measure. In other words, the estimated effects of the first and second courses taken appear to be greater than the estimated effects of taking extra courses at higher numbers for all outcomes.

We have already discussed reasons why participation in adult learning might have benefits, but these do not explain why these benefits disappear after nine or ten courses have been taken in relation to changes in smoking behaviour, level of exercise taken, political cynicism, and authoritarian attitudes, and are reduced in relation to the other outcomes. It may be selection bias; perhaps individuals who take more than ten 
courses differ from other members of the sample in relation to their reasons for participation, and therefore, what they derive from it. Another explanation is that taking courses is beneficial, but after a certain number, individuals need to progress either onto different types of learning, or into employment, or some other activity.

We have seen that the results presented in Table 6 differ from those obtained using a linear measure of participation. Since, on theoretical grounds, we do not expect the relationships between participation in adult learning and outcomes to be linear, we conclude that the linear model is not the best fit to the data. The linear measure does, however, have the virtue of simplicity, and so we return to it in Section 6. In the next paragraphs however, we consider separately the impacts of different levels of participation, as opposed to the constant effect of each course taken estimated using the linear specification.

Before doing so, we note that when non-linearity is allowed for, participation in adult learning has significant effects (at 95\% confidence) on all outcomes except becoming depressed, recovery from depression, and change in alcohol consumption. This demonstrates that our finding that participation in adult learning has effects on a wide range of benefits is robust to different specifications of participation. Indeed, as discussed above, we have experimented with a variety of measures of participation and the results remain. These results bring home, therefore, our central conclusion; participation in adult learning has positive effects on a great range of beneficial life course changes.

\subsubsection{Interpretation of effect sizes.}

We now clarify the magnitudes of estimated effects. Given our conclusion that the linear model is not the best fit to the data, we use here the categorical measure of participation in adult learning. Table 7 supports the interpretation.

Column 1 lists the outcome variables. Column 2 reports the predicted outcome for those who took no courses ${ }^{12}$. In the other columns the effect sizes are reported and then presented relative to the baseline change of Column 2. These relative values have different interpretations for binary and continuous variables which are therefore discussed separately.

\footnotetext{
${ }^{12}$ We could have used the observed proportions obtained from simple descriptive analyses of the dataset. These values would be simple to interpret, but they are not strictly comparable with the estimated effects of participation in learning, which apply to individuals with average characteristics for all explanatory and control variables included in the model. It is unlikely that individuals who took no courses between 33 and 42 have the same average characteristics (prior qualification level being an obvious example), and this is why we use the predicted values for comparisons.
} 
Table 7: Interpretation of effect sizes for three levels of participation in learning

\begin{tabular}{|c|c|c|c|c|c|c|c|c|}
\hline & Outcome & $\begin{array}{c}\text { Predicted } \\
\text { change for } \\
\text { no courses } \\
(2) \\
\end{array}$ & $\begin{array}{c}\text { Effect } 1-2 \\
\text { courses } \\
(3) \\
\end{array}$ & $\begin{array}{c}\text { Effect } \\
\text { size/(2) \% } \\
(4) \\
\end{array}$ & $\begin{array}{c}\text { Effect 3-10 } \\
\text { courses } \\
(5) \\
\end{array}$ & $\begin{array}{c}\text { Effect } \\
\text { size/(2) \% } \\
(6) \\
\end{array}$ & $\begin{array}{c}\text { Effect 11+ } \\
\text { courses } \\
(7) \\
\end{array}$ & $\begin{array}{c}\text { Effect } \\
\text { size/(2) \% } \\
(8) \\
\end{array}$ \\
\hline \multicolumn{9}{|c|}{ Health } \\
\hline 1 & Gave up smoking* & 0.244 & 0.033 & 13.5 & 0.073 & 29.9 & -0.023 & -9.4 \\
\hline 2 & Change in units drunk & -0.482 & -0.445 & 92.3 & -0.495 & 102.7 & 0.703 & -145.9 \\
\hline 3 & Increased exercise* & 0.383 & 0.015 & 3.9 & 0.071 & 18.5 & 0.049 & 12.8 \\
\hline 4 & Change in life satisfaction* & -0.251 & 0.034 & -13.5 & 0.088 & -35.1 & 0.106 & -42.2 \\
\hline 5 & Became depressed & 0.067 & -0.003 & -4.5 & 0.009 & 13.4 & -0.001 & -1.5 \\
\hline 6 & Recovered from depression & 0.386 & 0.036 & 9.3 & 0.023 & 6.0 & -0.02 & -5.2 \\
\hline \multicolumn{9}{|c|}{ Social capital } \\
\hline 7 & Change in race tolerance* & 0.140 & 0.047 & 33.6 & 0.121 & 86.4 & 0.196 & 140.0 \\
\hline 8 & Change political cynicism* & 0.470 & -0.046 & -9.8 & -0.050 & -10.6 & -0.049 & -10.4 \\
\hline 9 & Change authoritarianism* & 0.316 & -0.067 & -21.2 & -0.133 & -42.1 & -0.162 & -51.3 \\
\hline 10 & Increased political interest* & 0.153 & 0.018 & 11.8 & 0.021 & 13.7 & 0.063 & 41.2 \\
\hline 11 & Increased memberships* & 0.086 & 0.029 & 33.7 & 0.045 & 52.3 & 0.083 & 96.5 \\
\hline 12 & Voted '97 abstained ' $87 *$ & 0.467 & 0.060 & 12.8 & 0.063 & 13.5 & 0.154 & 33.0 \\
\hline
\end{tabular}

NOTE: * denotes association at $95 \%$ confidence using either the linear or categorical measure of participation 


\section{Interpretation for binary variables}

Seven of the outcomes are binary variables; giving up smoking, increased exercise, onset and recovery from depression, increase in political interest, and the two measures of civic participation. In order to explain the interpretation of values relating to these variables, we use as an example the outcome of giving up smoking.

The predicted rate of quitting for those who took no courses is $24.4 \%$. Columns 4,6 , and 8 give the sizes of estimated effects of participation in learning relative to this baseline. Column 3 gives the estimated effect of taking one or two courses. The marginal effect in relation to quitting smoking is 0.033 . In other words, the estimated effect of taking one or two courses as opposed to none for smokers at age 33 is to increase the chances of giving up smoking by $3.3 \%$ points. This indicates the potential for considerable health care savings, raising the predicted rate of quitting smoking from $24.4 \%$ (for those who took no courses) to $27.7 \%(24.4 \%+3.3 \%)$ for those who took one or two courses. In relative terms, the benefit is an increase in the chance of giving up smoking by $13.5 \%$ (3.3/24.4\%). Columns 5 and 7 give the estimated effects of taking three to ten, and eleven courses compared to the baseline of taking no courses, respectively.

The sizes of these effects for some outcomes may seem small in absolute terms, but compared to overall shifts, as indicated by the baseline changes, they are substantial. In addition, when the findings are grossed up to apply to the whole population, very large numbers of adults are affected. The findings reported above (in Section 3.1) suggest that $58 \%$ of adults born in Britain in 1958 participated in adult learning between 1991 and 2000. When we consider for example the total number of adults who are predicted to give up smoking in connection with taking courses, the implications are important and represent considerable health care savings.

\section{Interpretation for continuous variables}

For continuous variables (changes in alcohol consumption, life satisfaction, and changes in race tolerance, political cynicism, and authoritarian attitudes), the values are less easily interpreted because these variables are for the most part changes in selfreported ratings rather than a natural metric ${ }^{13}$. We take increase in race tolerance as our example. The value in column 3 indicates that the estimated effect of taking one or two courses on race tolerance is 0.047 , which is equivalent to an increase of $4.7 \%$ of a standard deviation in age 33 race tolerance. This is a small change but the value in Column 2 shows that the change for those who took no courses at all (as predicted by the model) was only $14 \%$ of a standard deviation ${ }^{14}$. To put the effect estimate in context, therefore, note that the effect of taking one or two courses as opposed to none

\footnotetext{
${ }^{13}$ The exception is changes in units drunk. The estimate in Column 2 indicates that each course taken is associated with an increase in alcohol consumption of .044 units per week.

${ }^{14}$ Note that for continuous variables this baseline averages across all kinds of actual changes in the population. Positive and negative changes cancel out giving a false appearance of immobility. In future work, we will consider more complex and interesting aspects of the distribution of change than just the mean. We find this simple contextualization useful however, in indicating the average effect for those who took courses relative to that for those who didn't. The results are similar to those for binary variables.
} 
is equivalent to $33.6 \%$ (the figure in Column 4 ) of the predicted change in race tolerance for those who took no courses between 33 and 42, a substantial effect in relative terms.

The values in Columns 5 and 7 indicate that the estimated effects of taking three to ten courses and eleven or more courses as opposed to taking none on increased race tolerance are $12.1 \%$ points and $19.6 \%$ points, respectively. These estimates represent predicted increases in race tolerance 1.86 and 2.40 times greater than for those who took no courses. We conclude that given the inertia in the outcomes, the effect of adult learning is quite strong.

Figures 13 and 14 illustrate effect sizes within the context of predicted changes in outcomes for those who took no courses. The scales used to measure changes are different for binary and continuous variables. That is why we present two figures, one for each type of variable.

We assess the importance of estimated effects of learning on two dimensions, represented by the two axes in each figure. The first dimension, represented by the $y$ axis is the estimated effect of participation relative to no participation. The second dimension, represented by the $\mathrm{x}$ axis is the effect size relative to the predicted change in outcome for those who took no courses. This contextualises the effect size.

As an example, let us consider the importance of estimated effects of taking one or two courses on changes in voting behaviour (Figure 13). This outcome applies only to those members of the sample who did not vote in 1987 . The high value on the $y$ axis for this outcome indicates that the estimated effect of taking one or two courses is high relative to that for the other (binary) outcomes. In fact, the marginal effect of taking one or two courses is $6 \%$ points, i.e., six more people who took one or two courses in one hundred voted in 1997, compared to people who did not take any courses at all. This finding represents a high number of adults in Britain whose voting in 1997 is attributed to taking one or two courses. This finding may have greater policy significance if the predicted level of change for those who took no courses was very small than if most of those who took no courses voted anyway. The former scenario would imply that participation in learning is an important factor in changing adults' voting patterns, whereas the latter suggests that participation in learning is just one amongst many factors that influence voting behaviour.

The position of voting along the $\mathrm{x}$ axis reflects the fact that quite a high proportion ( $47 \%$, see Table 7 , column 2 ) of those who took no courses are predicted to have voted in 1997, in other words, the value in the denominator for the $\mathrm{x}$ axis is quite large. This suggests that other factors besides taking one or two courses are important in changing voting behaviour during mid-adulthood. 
Figure 13: Sizes of estimated effects of taking one to two courses in the context of predicted levels of change for those who took no courses - binary variables



NOTE: The results illustrated here are taken from seven regressions on the seven outcomes. Each regression estimates the effect of taking one or two courses (the value on the y-axis), the effects of higher levels of participation, and also the predicted level of change for those who took no courses. We use this predicted level of change as a baseline to contextualise the importance of the estimated effect of taking one or two courses (the values on the $\mathrm{x}$-axis). * indicates that the estimated effect using either the linear or categorical measure of participation in learning is statistically significant at $95 \%$ confidence 
Figure 14: Sizes of estimated effects of taking one to two courses in the context of predicted levels of change for those who took no courses - continuous variables

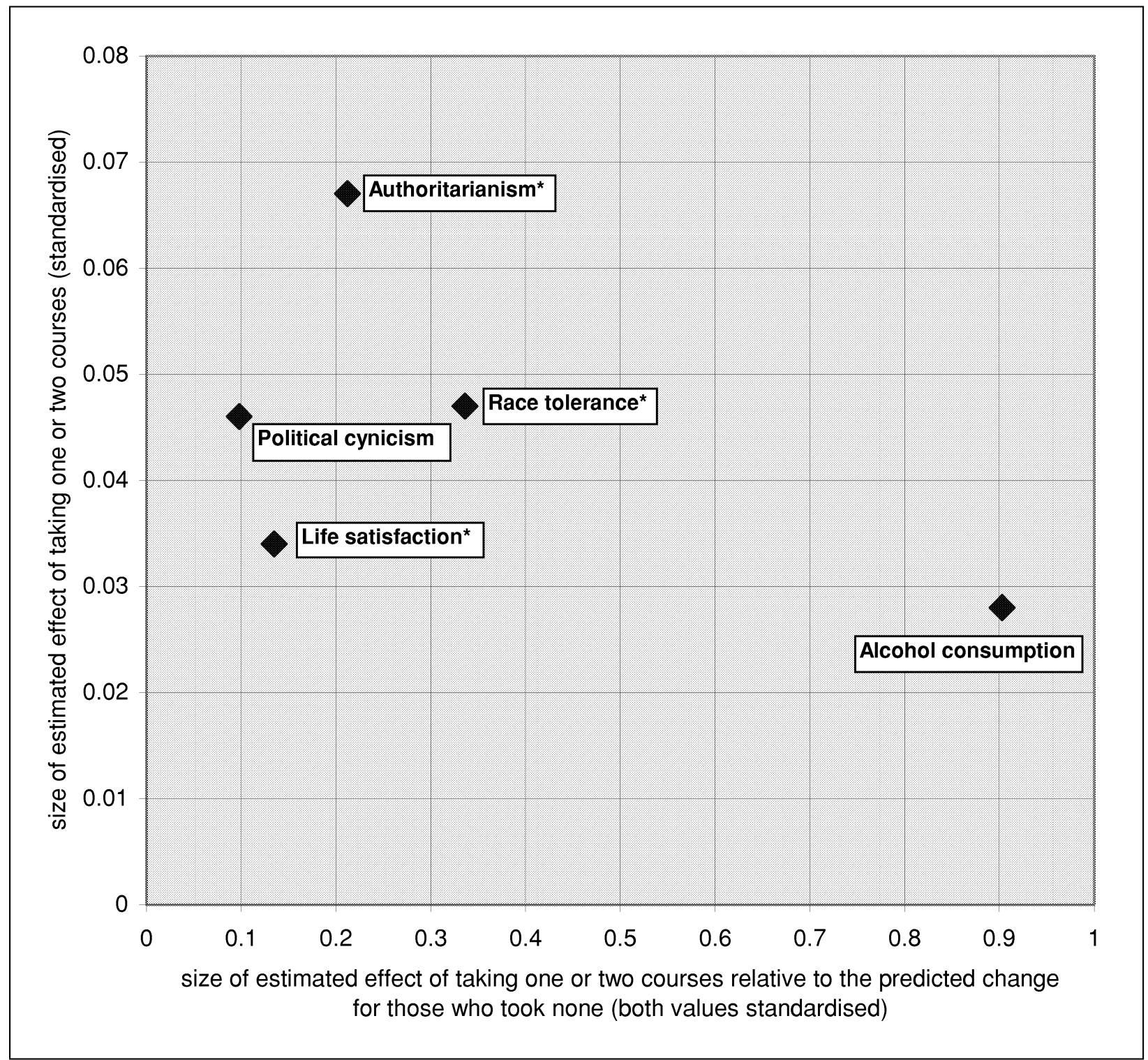

NOTE: The results illustrated here are taken from five regressions on the five outcomes. Each regression estimates the effect of taking one or two courses (the value on the y-axis), the effects of higher levels of participation, and also the predicted level of change for those who took no courses. We use this predicted level of change as a baseline to contextualise the importance of the estimated effect of taking one or two courses (the values on the $\mathrm{x}$-axis). * indicates that the estimated effect using either the linear or categorical measure of participation in learning is statistically significant at $95 \%$ confidence Values for changes in alcohol consumption differ from those given in tables because they are standardised here for comparison with the other continuous variables 
In contrast, consider the position in Figure 13 of the outcome measuring the chances of increased number of memberships. Its value on the y axis is not particularly high. Just under three adults in one hundred increase their number of memberships as a consequence of (or more accurately, in association with) taking one or two courses. But the predicted level of change for those who took no courses is much smaller than it was in relation to voting. Consequently, the denominator in the $\mathrm{x}$ value is smaller, and the size of the estimated effect relative to the predicted level of change for those who took no courses is greater.

The interpretation of Figure 14 is slightly different because it refers to continuous variables. Let us take alcohol consumption as our example. The estimated effect of taking one or two courses on changes in alcohol consumption is not very substantial as illustrated by the position of this outcome on the y axis. However, the predicted level of change in alcohol consumption for those who took no courses, which is the denominator for the $\mathrm{x}$ axis, is also small. This implies that the estimated effect of participation in learning on changes in alcohol consumption is important. The average change in alcohol consumption is not substantial and so the effect size appears large in this context.

In contrast, the estimated effect of participation on changes in authoritarian attitudes is great relative to the estimate for alcohol consumption, but so are the predicted changes in authoritarianism for those who took no courses. Consequently, although change in authoritarianism is located high on the $\mathrm{y}$ axis, its position on the $\mathrm{x}$ axis is much lower than that for alcohol consumption.

Examination of the two figures together suggests that adult learning has greatest impacts on levels of civic participation. The positive impacts of participation on health behaviours and attitudes that contribute to social capital are also important. Of lesser magnitude are the impacts of participation on wellbeing.

Before moving on to the next Section, we summarise the key findings and more specific findings reported in this section.

KF 3: When participation in learning is measured using four separate levels, we find that participation has significant effects (at $95 \%$ confidence) on all outcomes except onset and recovery from depression, and change in alcohol consumption.

KF 4: Generally, the sizes of effects are small in absolute terms but substantial in relation to average shifts, and important when applied to the total number of adults in Britain who participate in learning.

KF 5: Taking one or two courses appears to have important impacts upon adults living in Britain in relation to changing levels of civic participation, health behaviours, and attitudes that contribute to social capital. Of lesser importance are the impacts of participation on wellbeing. 
KF 6: For the whole range of variables examined here ${ }^{15}$, the first and second course taken is associated with changes in outcomes that are greater in magnitude than those associated with taking additional courses. In other words, there is particular value in relation to taking the first few courses.

SF 1: Amongst people who were smokers at age 33, the predicted difference in smoking behaviour between those who took one to two, and three to ten courses and those who took none is that three, and six additional individuals in one hundred, respectively quitted smoking.

SF 2: In relation to life satisfaction, race tolerance, political interest, and civic participation, the more courses the better, albeit with diminishing returns.

SF 3: In relation to health behaviours and two of the four measures of change in social and political attitudes, it appears that there are no or even negative returns to taking high numbers of courses (over ten).

\subsection{Assessing causality}

As discussed in Section 4, the estimates presented here should not be thought of as precise, causal effects of learning. Three possible explanations for these associations are (1) genuine learning effects, (2) confounding bias and (3) reverse causality, as illustrated in Figure 11. In this section, we attempt to assess the extent to which confounding bias or reverse causality might account for the associations found. Two strategies are adopted. First, in Section 5.3.1 we attempt to deal with confounding bias by augmenting the regression with variables that proxy for potentially confounding factors. Secondly, in Section 5.3.2, we use some additional information about participation in adult learning at 42 and consider whether changes in our outcome variables influence this participation. We discuss the method, results and implications of each strategy in more detail below.

\subsubsection{Participation in adult learning, changes in outcome and other life changes.}

The specifications we have used so far to model the effects of participation in adult learning include variables, referred to as controls, which we think may be sources of confounding bias. The control variables included are gender, socio-economic status at age 33 and highest academic and vocational qualifications at age 33 (see Appendix 6 for full details). This control set was chosen in the light of experiments using different model specifications including different combinations of control variables, as described in Appendix 7. All the variables included in these experiments were individual characteristics measured up to but not after the age of 33. In this section, we test whether an additional set of variables that proxy for changes in life circumstances between the ages of 33 and 42 constitutes a source of selection bias. The set of variables is listed a few paragraphs later. Full details are given in Appendix 8.

\footnotetext{
${ }^{15}$ Except for onset and recovery from depression, for which no associations with participation are found.
} 
Because these variables are measures of changes after the age of 33, they are coincident with our measures for participation in learning, and for changes in outcomes. Therefore, if inclusion of changes in life circumstances in the specification attenuates the sizes of associations between participation in learning and changes in outcomes, then two explanations are possible. The first is selection bias - changes in life circumstances lead to both participation in learning and changes in outcomes. Including changes in life circumstances in the model would therefore reduce (i.e. attenuate) the magnitudes of estimated effects of adult learning on changes in outcomes. Second, participation in learning may lead to changes in life circumstances which in turn lead to changes in outcomes. In other words, adult learning has effects but these are to some extent mediated by changes in life circumstances. The two hypotheses are illustrated in Figure 12.

On the basis of our previous fieldwork research reported in Schuller et al. (2002), we think it highly plausible that changes in life circumstances contribute to associations between learning and changes in outcomes. We found that changes in life circumstances led to both participation in adult learning and changes in outcomes. For example, several women with young children reported that having children had prompted them to re-engage in learning as adults and had simultaneously affected their life satisfaction and civic participation. This is an example of changes in life circumstances constituting selection bias. In addition, the fieldwork programme found that participation in adult learning can lead to changes in life circumstances, such as gaining employment, which in turn lead to changes in civic participation and life satisfaction. This is an example of changes in life circumstances mediating the effects of adult learning.

We therefore repeat the analysis described $\mathrm{n}$ Section 5.1, including in the specification additional controls that reflect change in life circumstances between 33 and 42. The changes included relate to socio-economic status, home ownership status, time spent not in education, employment or training (NEET) and family structure. The analyses estimate the effects of the number of courses taken between 33 and 42 on each outcome. Full details are given in Appendix 8.

What is relevant here to interpretation of the results is the extent to which including variables representing changes in life circumstances between 33 and 42 attenuates the magnitudes and precisions of estimated effects of participation in adult learning upon the twelve outcomes. The findings provide no evidence that including these variables in the model specification changes estimates of effects of participation. Therefore, we conclude that there is no evidence that changes in life circumstances between 33 and 42 mediate or drive effects of participation upon outcomes. Neither do they seem to be a source of selection bias for observed associations between participation and outcomes.

This finding is slightly surprising in the light of previous WBL fieldwork. It is possible that our measures for changes in life circumstances between 33 and 42 are 
too gross to pick up the relationships. After all, the measures used apply to changes over a period of nine years. The WBL will continue to investigate this issue.

KF 7: We have included in our models variables measuring characteristics up to the age of 33 in order to control for selection bias, and we have also experimented with including measures of life circumstances between 33 and 42 . The robustness of our estimates is sustained. We are therefore confident that the results reported here reflect effects of participation in learning ${ }^{16}$.

\subsubsection{Attempting to assess the impact of reverse causality}

As stated above, we also have in our data indicators of whether sample members were engaged in adult learning at 42 . We can, therefore, assess whether the changes in outcomes predict current participation. In order to do so, we run a regression to see whether current participation is explained by changes in health behaviours, social and political attitudes and so on. We put health and social changes on the right hand side of the regression as predictors of participation in learning at age 42 . We continue to refer to these changes as outcomes, however, because we consider them as such in the main analyses of the paper.

This additional analysis is helpful because if health and social changes predict participation in learning at age 42 , three interpretations are feasible:

1. the change in the outcome predicts current participation, i.e. there is reverse causality that will bias the results when we estimate of the effects of participation between 33 and 42 on changes in outcomes;

2. the change in the outcome proxies for some third factor that determines participation, i.e. that confounding bias accounts to some extent for the estimated effect of participation between 33 and 42 on changes in outcomes;

3. participation has already had an effect on outcomes.

Both 1 and 2 suggest that when we interpret estimated effects of learning on changes in outcomes, we must allow for selection bias as a possible explanation.

The third explanation is possible because the end point for the change in outcomes is simultaneous to current learning, rather than determined prior to the learning episode as one would wish. Finding that an outcome is associated with participation at age 42, even after including the other variables in the models will, therefore, be somewhat difficult to interpret. It does not necessarily mean that the change in outcome caused participation in learning because the change in outcome may have occurred very recently, possibly as an early consequence of current participation.

\footnotetext{
${ }^{16}$ Nevertheless, it is extremely unlikely that we have successfully excluded every source of confounding bias. The problem of taking into account time-varying unobserved endogeneity remains.
} 
This third possible explanation means that a significant association between a change in outcomes and participation at 42 does not necessarily indicate that selection bias is a problem in estimation of learning effects. However, if no association is found between changes in outcomes and participation in learning at age 42, then it does suggest that when we estimate learning effects on outcomes, selection bias is not a problem.

We therefore undertake 12 regressions; participation at age 42 is regressed separately on each of the 12 outcomes. The specification includes equivalent controls to those used to model the determinants of changes in outcomes (the main analyses), i.e. the value of the appropriate outcome at age 33, gender, socio-economic status and highest levels of academic and vocational qualifications at age 42, plus the number of courses taken between ages 33 and 42. Fuller details of these variables are given in Appendix 9.

The analyses measure participation in adult learning at 42 using a binary indicator. Table 8 reports the estimated effects of changes in outcomes on the probability of participating in learning at age 42 for the whole sample.

The results provide a fascinating insight into the patterns of causality underlying associations between participation in learning and changes in outcomes. Our initial analyses found associations between participation in learning between 33 and 42 and changes in seven of the 12 outcomes. Here, we discuss the results of reciprocal regressions - i.e., changes in health and social capital indicators as determinants rather than outcomes of learning in relation to these seven outcomes only. Considering these seven outcomes only then, we find no evidence that increased political interest, voting in 1997 (for those who abstained in 1987), level of exercise taken, or increased life satisfaction between 33 and 42 lead to taking courses at age 42 .

Change in political interest is just one of four measures of social and political attitudes, and we have found evidence that two of these measures do predict participation in learning at age 42. Similarly, voting behaviour is a measure of civic participation, but there is strong evidence that increased civic participation predicts learning at age 42 when the other measure is used. We therefore conclude that there is no consistent evidence that changes in social and political attitudes or changes in levels of civic participation do not lead to participation in learning.

The findings in relation to exercise and life satisfaction seem more important. They imply that a high proportion of the estimated effects of adult learning on taking more exercise and increased life satisfaction really do reflect positive effects of taking courses. 
Table 8: Estimated effects of each outcome on probability of participation in learning at age 42

\begin{tabular}{lcc}
\multicolumn{1}{c}{ Outcome } & $\begin{array}{c}\text { Estimated } \\
\text { effect }\end{array}$ & P-value \\
\hline \hline & & \\
Health & & \\
Gave up smoking & 0.001 & 0.949 \\
Change in units drunk & -0.001 & 0.024 \\
Increase in exercise & -0.009 & 0.228 \\
Change in life satisfaction & -0.003 & 0.411 \\
Became depressed & -0.007 & 0.551 \\
Recovered from depression & 0.000 & 0.993 \\
& & \\
Social capital & & \\
Change in race tolerance & 0.019 & 0.000 \\
Change political cynicism & -0.002 & 0.650 \\
Change in authoritarianism & -0.019 & 0.000 \\
Increase in political interest & 0.015 & 0.130 \\
Increased memberships & 0.033 & 0.001 \\
Voted 1997 abstained 1987 & 0.014 & 0.282
\end{tabular}

NOTE: Variables included in the model are change in outcome between 33 and 42, outcome at age in 33, number of courses taken between 33 and 42, gender, and socio-economic status and level of qualifications at age 42 .

The dependent variable is a dummy indicator of participation in any type of learning at age 42 . The specification is similar to that used to model effects of participation upon outcomes. Probit regressions used and the estimates are marginal effects.

For three out of the seven outcomes where associations with participation in adult learning are found, we cannot rule out explanations of selection bias. These outcomes are two of the measures of changes in social and political attitudes, and increased numbers of memberships as a measure of change in civic participation. This is hardly surprising, since one would expect processes of psychological, behavioural and social development to relate to learning in a dynamic manner. Our findings suggest that taking courses may be an important driver of this process.

KF 8: Analyses of the determinants of participation in learning at age 42 indicate that changes in most outcomes (but not changes in exercise or life satisfaction) are involved in a process of progression. Participation leads to changes in health and social outcomes, and often these changes lead in turn to (or proxy for other factors leading to) further participation in more learning. 


\subsection{Summary of key and specific findings}

To conclude this section, we restate the key and specific findings (KF and SF).

\section{Evidence for associations between participation in adult learning and changes in} health and social outcomes.

KF1 The total number of courses taken between 33 and 42 has effects on a wide range of health and social benefits.

KF2 Statistically significant effects of the total number of courses taken during midadulthood are estimated for seven of the 12 outcomes at $95 \%$ confidence. These outcomes are changes in exercise taken, life satisfaction, race tolerance, authoritarian attitudes, political interest, number of memberships, and voting behaviour.

KF3 When participation in learning is measured using four separate levels, we find that participation has significant effects (at 95\% confidence) on all outcomes except onset and recovery from depression and change in alcohol consumption.

\section{Effect sizes}

KF4 Generally, the sizes of effects are small in absolute terms but substantial in relation to average shifts, and important when applied to the total number of adults in Britain who participate in learning.

KF5 Taking one or two courses appears to have important impacts upon adults living in Britain in relation to changing levels of civic participation, health behaviours, and attitudes that contribute to social capital. Of lesser importance are the impacts of participation on wellbeing.

SF1 Amongst people who were smokers at age 33, the predicted difference in smoking behaviour between those who took one to two, and three to ten courses and those who took none is that three, and six additional individuals in one hundred, respectively quit smoking.

\section{Does each course have the same added value?}

KF6 For the whole range of variables examined here ${ }^{17}$, the first and second course taken is associated with changes in outcomes that are greater in magnitude than those associated with taking additional courses. In other words, there is particular value in relation to taking the first few courses.

SF2 In relation to life satisfaction, race tolerance, political interest and civic participation, the more courses the better, albeit with diminishing returns.

SF3 In relation to health behaviours and two of the four measures of change in social and political attitudes, it appears that there are no or even negative returns to taking high numbers of courses (over ten).

Evidence for learning effects

KF7 We have included in our models variables measuring characteristics up to the age of 33 in order to control for selection bias, and we have also experimented with including measures of life circumstances between 33 and 42 . The

\footnotetext{
${ }^{17}$ Except for onset and recovery from depression, for which no associations with participation are found.
} 
robustness of our estimates is sustained. We are therefore confident that the results reported here reflect effects of participation in learning ${ }^{18}$.

KF8 Analyses of the determinants of participation in learning at age 42 indicate that changes in most outcomes (but not changes in exercise or life satisfaction) are involved in a process of progression. Participation leads to changes in health and social outcomes, and often these changes lead in turn to (or proxy for other factors leading to) further participation in more learning.

\section{Results by type of adult learning, gender and prior qualifications}

In this section we report the results of additional analyses conducted to investigate the effects of participation in different types of courses and for different sub-groups of the population. Section 6.1 concerns the different effects of participation in four types of learning. Section 6.2 investigates the differences in estimated effects of learning for men and women, and Section 6.3 examines the impact of learning on adults with low levels of qualifications. Key findings and specific findings (KF and SF) are given throughout the text and restated in Section 6.4.

\subsection{Results by type of course}

In this section, we examine the different effects of participation in four types of learning. The four types of learning are academic courses leading to accreditation, vocational courses leading to accreditation, work-related training courses, and leisure courses, as described in section 3.1. The findings reported in this section are summarised in Table 10. Fuller details are given in Appendix 10.

Separate regressions were conducted for each of the 12 outcomes. The specifications included the same controls as before, described in Appendix 6, plus the four measures of participation in learning. Four parameters (relating to each of the four types of learning) were estimated for each of the 12 regressions; 48 parameters in total. ${ }^{19}$

In Section 6.1.1, we present the results of regressions using the linear specification of participation in learning, i.e., total number of courses taken. In Section 6.1.2, we augment these findings using results from analyses in which the categorical measure of participation was used. This section includes interpretations of the magnitudes of estimated effects.

\footnotetext{
${ }^{18}$ Nevertheless, the problem of taking into account time-varying unobserved endogeneity remains.

${ }^{19}$ The model used can be described by the following equation:

$\Delta y=\alpha+\sum_{j} \delta_{j} A_{j}+X \mathrm{~B}$

where $y=$ change in outcome, $a ́=$ constant, $j=$ course type (academic accredited, vocational accredited, work-related training, leisure), $A_{j}=$ total number of courses of each type taken, $\delta_{j}=$ coefficients for effects of participation in each course type, $X=$ matrix of control variables, $\hat{A}=$ vector of coefficients for the controls variables.
} 
We tested for additional sources of selection bias by conducting separate regressions that included changes in life circumstances between the ages of 33 and 42 in the specifications. In addition, we performed regressions of changes in outcomes on participation in learning of each type at age 42, equivalent to the regressions described in section 5.3.2. These investigations revealed no important selection bias additional to that already identified and discussed in Section 5.3. Full results of the regressions are given in Appendices 8 and 9.

\subsubsection{Effects of total numbers of courses}

Initially, we present estimated effects of participation in each type of course using the simple linear measure i.e., the number of courses of each type taken. Although we have found that linearity can be improved upon as a specification for participation in adult learning (see Section 5.2.1) it is a relatively simple specification that enables easy presentation of results and reduces the number of parameters to be estimated. The specification and full estimation results are given in Appendix 10.

As mentioned above, 48 parameters were estimated. When so many parameters are estimated, the chances are that some will be statistically significant, regardless of whether there are associations in the population. For example, if an estimate is statistically significant at $95 \%$ confidence, this means that there is a one in twenty chance that the estimate is zero. If 48 parameters are estimated, the chances are that two or three of them will be statistically significant at $95 \%$. We therefore start this section by reporting that 17 of the 48 parameters estimated are statistically significant at $95 \%$ confidence. This is a much higher number than would be expected by chance. It illustrates the pervasive nature of associations between adult learning and a wide range of health and social benefits.

\section{Academic accredited courses}

Academic accredited courses are not associated with changes in health behaviours, depression, or civic activity. On the other hand, there is a positive effect on life satisfaction and effects on changes in social and political attitudes are greater in magnitude and more consistent than for any other course type. The impact of academic courses on changes in social and political attitudes found here resonates with findings reported by Haegel that academic learning has a much larger impact on racial tolerance than vocational learning (1999).

In the following section, we find that the average difference in level of attitude change between those taking one academic course and those who took none is substantial equivalent to between $37 \%$ and $94 \%$ of the predicted changes for those who took no courses of any type between the ages of 33 and 42 . To assess the importance of these effects, we should bear in mind the number of academic accredited courses taken by adult learners in Britain. The relevant figures are given in Table 9 and illustrated in Figures 1 to 4 . The numbers of academic courses taken by members of our sample are small relative to numbers taking the other three types of courses, but nevertheless, $9 \%$ of the sample took at least one academic course. We should also remember that 
taking an academic course leading to accreditation may demand greater investments in terms of time, energy and money than taking courses of other types.

Table 9: $\quad$ Rates of participation in each type of learning

\begin{tabular}{lcc} 
Type of course & $\begin{array}{l}\text { \% of sample who took } \\
\text { one or more courses }\end{array}$ & $\begin{array}{l}\text { Mean number of } \\
\text { courses taken per } \\
\text { person }\end{array}$ \\
\hline \hline Academic accredited & 9 & 0.14 \\
Vocational accredited & 18 & 0.30 \\
Work-related training & 31 & 1.28 \\
Leisure & 24 & 0.39
\end{tabular}

SF 4: The effects of taking academic accredited courses on social and political attitudes are greater in magnitude and more consistent than for any other course type.

\section{Vocational accredited courses}

Participation in vocational courses only has an effect on race tolerance and the magnitude of the effect is much smaller than that for taking academic accredited courses. Nevertheless, it is substantial, and we should remember that more vocational accredited courses were taken by more individuals than academic accredited ones. $18 \%$ of the sample took at least one vocational accredited course between the ages of 33 and 42, and the average number of courses taken per person is 0.3. (See Table 9, which compares rates of participation in each course type.)

We should be wary of concluding from these findings that participation in courses resulting in qualifications do not lead to other wider benefits. This is because the category of vocational accredited courses encompasses a wide range of learning experiences - in a range of contexts and using different pedagogies. If outcomes depend on the type of learning process, then we can expect these to be different also. However, this categorisation aggregates over these effects, and where these do not operate in the same direction, they will be masked. These findings will be further investigated in the future work of the Centre.

\section{SF 5: Taking vocational courses has positive effects on race tolerance}

\section{Work-related training}

Participation in all types of courses changes wellbeing and social attitudes. But it is participation in work-related (and, as we shall see later leisure courses) as opposed to accredited academic or vocational courses that changes the behaviours that we measure: increased numbers of memberships and the adoption of health behaviours.

SF 6: Taking work-related training courses has positive effects on the whole range of health and social outcomes

Taking work-related training courses is associated with a substantial increase in alcohol consumption, which is probably a normatively bad effect. On a slightly more 
positive note, taking work-related courses increases life satisfaction and race tolerance, decreases authoritarian attitudes and raised numbers of memberships.

A plausible explanation for the effects of taking work-related training courses on increased exercise and civic participation is that taking this type of course is accompanied by socialising and leads to people going out more. It may be this socialising aspect of work-related training that leads to the changes in outcomes.

In contrast, it is less obvious why taking work-related training leads to increased alcohol consumption, whereas taking vocational accredited and leisure courses does not.

When we consider the importance of these findings and compare the roles of different types of learning in relation to wider health and social outcomes, we should note that more members of our sample took work-related courses than any other type of course. $31 \%$ of the sample took at least one work-related training course, and the average number of courses taken by each individual was 1.28 (Table 9).

\section{Leisure courses}

Participation in leisure courses has positive effects on the chances of giving up smoking, taking more exercise, increased levels of civic participation and a reduction in authoritarian attitudes. Interestingly, only participation in work-related training and leisure courses increases civic participation, leisure courses being much more important in this respect. Indeed, the effects of taking leisure courses on increased levels of civic participation are consistent and substantial.

On a less positive note, participation in leisure courses is not associated with changes in life satisfaction, and is positively associated with becoming depressed. This is slightly surprising in the light of our fieldwork findings (Schuller et al., 2002), which found that participation in learning as an adult often has a very positive impact on wellbeing. On the other hand, the fieldwork findings also suggest that some adults start to take courses at times of difficulty or when they feel at a low ebb. Leisure courses in particular were taken because they provided a distraction or outlet without being too demanding. The accounts of those individuals interviewed provide convincing evidence that taking leisure courses at such times can both sustain psychological health and transform lives.

We begin by addressing the finding in relation to life satisfaction. Participation in leisure courses may have positive impacts on the life satisfaction of some individuals (as evidenced in our fieldwork project) but for others the effect may be negative so that the average effect across the sample is zero. This implies that the fieldwork sample was not representative of the population of adult learners. Indeed it never claimed to be. It does, however, suggest that there are positive effects for some individuals. In Section 6.1.2, below, we report that taking high numbers of leisure courses (over ten) is associated with reduced life satisfaction. One explanation for this finding, therefore, is that there are positive effects for some, but on average these are 
cancelled out by the negative effects for those who took many courses. Individuals taking high numbers of leisure courses may need help in order to progress to other activities.

In relation to depression, it seems that leisure courses either lead to depression or are taken by individuals who are becoming depressed and who are not helped out of depression by participation in leisure courses. Again, this raises important questions for those delivering leisure courses. We will address these issues more directly and in substantially more detail in future work at the WBL.

SF 7: Taking leisure courses has strong effects of the whole range of health and social capital outcomes, although not wellbeing. Effects are particularly strong in relation to civic participation. In fact, the effects of taking leisure courses on civic participation are more consistent and substantial than for any other course type.

SF 8: Participation in leisure courses is not associated with changes in life satisfaction, and is positively associated with becoming depressed.

KF 9: Taking work-related and leisure courses has effects on a much broader range of health and social capital outcomes than taking academic or vocational courses leading to accreditation.

\subsubsection{Different effects for different levels of participation in learning}

We now explore these findings further by considering the results when the non-linear measure of participation is used. The level of participation in work-related training and leisure courses is coded into four categories as shown previously:

- no participation;

- one or two courses;

- three to ten courses;

- more than ten courses.

We recode the academic and vocational accredited courses variables into four groups reflecting their long duration and hence the lower average number of accredited courses taken:

- no participation;

- one course;

- two courses;

- more than two courses.

Therefore, for each course type we have a set of three dummy variables and a baseline of no participation reflecting the extent of participation in adult learning. With four such sets (one for each type of course) we now have twelve parameters to be estimated for each outcome. All are estimated simultaneously in models including the 
control variables described previously ${ }^{20}$. The full results are given in Appendix 10. The estimated effects of participation in each type of course (using either measure) are summarised in Table 10.

This subsection reports additional substantive findings that emerge from this analysis, summarising first what we already know, and augmenting these findings with new results, including some interpretations of the sizes of estimated effects.

\section{Academic accredited courses}

The results of analyses using the linear measure of participation indicated that academic courses have positive effects on increases in life satisfaction and the attitudinal measures of social capital and cohesion. The results of analyses using the non-linear measure of participation suggest that there are positive returns to taking courses at all levels of participation, albeit with diminishing returns.

Using the non-linear measure of participation, two additional associations emerge. Taking just one academic course as opposed to none has a positive and substantial effect on the chances of increasing levels of exercise, raising this probability by $6 \%$ points. There is only very weak evidence however, that taking more than one academic course brings additional returns in terms of taking more exercise. The results suggest that there are diminishing returns to taking additional academic courses in relation to the chances of taking more exercise. These findings provide an example of our more general finding that the first course taken is associated with changes in outcomes that are greater in magnitude than those associated with taking additional courses (KF 6), and with our more specific finding, that in relation to health behaviours there is no evidence for additional returns to taking high numbers of courses (SF 3).

We also find that taking just one academic course is associated with a substantial increase in the chances of becoming depressed. $6.7 \%$ of those members of the sample who were not depressed at age 33 and who took no courses of any type were depressed at age 42 . The estimated effect of taking one academic accredited course as opposed to none is that two additional people in every hundred becoming depressed. The finding is not quite statistically significant at $95 \%$ confidence, but the size of the sample is not as large as for other types of courses. The number of individuals who were not depressed at age 33 and who took just one academic accredited course is 630. We return to this finding in Section 6.4.

\footnotetext{
${ }^{20}$ The model specification can be described by the following equation:$$
\Delta y=\alpha+\sum_{i=1}^{3} \sum_{j} \delta_{i j} D_{i j}+X \mathrm{~B}
$$

where $y=$ change in outcome, á = constant, $i=$ level of participation, $j=$ course type (academic accredited, vocational accredited, work-related training, leisure), $D_{\mathrm{ij}}=$ dummies for different levels of participation in each course type, $\delta_{\mathrm{ij}}=$ coefficients for effects of each level of participation in each course type, $\mathrm{X}=$ matrix of control variables, $\hat{\mathrm{A}}=$ vector of coefficients for the controls variables.
} 
Table 10: Interpretation of effect sizes for each course type

\begin{tabular}{|c|c|c|c|c|c|c|c|}
\hline & Outcome & All & $\begin{array}{l}\text { Acad. } \\
\text { accred. }\end{array}$ & $\begin{array}{l}\text { Vocatnl. } \\
\text { accred. }\end{array}$ & $\begin{array}{l}\text { Work- } \\
\text { related }\end{array}$ & Leisure & $\begin{array}{l}\text { Reverse } \\
\text { causality }\end{array}$ \\
\hline & Health & & & & & & \\
\hline 1 & $\begin{array}{l}\text { Gave up } \\
\text { smoking }\end{array}$ & & & & & & No \\
\hline 2 & $\begin{array}{l}\text { Change in units } \\
\text { drunk }\end{array}$ & & & & & & Yes \\
\hline 3 & $\begin{array}{l}\text { Increased } \\
\text { exercise }\end{array}$ & 4 & & & 4 & & No \\
\hline 4 & $\begin{array}{l}\text { Change in life } \\
\text { satisfaction }\end{array}$ & & 4 & & & & No \\
\hline 5 & $\begin{array}{l}\text { Became } \\
\text { depressed }\end{array}$ & & & & & 4 & No \\
\hline 6 & $\begin{array}{l}\text { Recovered } \\
\text { depression }\end{array}$ & & & & & & No \\
\hline & Social capital & & & & & & \\
\hline 7 & $\begin{array}{l}\text { Change race } \\
\text { tolerance }\end{array}$ & & & 444 & & 4 & Yes \\
\hline 8 & $\begin{array}{l}\text { Change in pol. } \\
\text { cynicism }\end{array}$ & & & & & & No \\
\hline 9 & $\begin{array}{l}\text { Change in } \\
\text { authoritarian }\end{array}$ & & & $\downarrow \downarrow \downarrow$ & 11 & 11 & Yes \\
\hline 10 & $\begin{array}{l}\text { Change in pol. } \\
\text { interest }\end{array}$ & & & & & & No \\
\hline 11 & $\begin{array}{l}\text { Increased } \\
\text { memberships }\end{array}$ & & 44 & & $\uparrow$ & & Yes \\
\hline 12 & $\begin{array}{l}\text { Voting '97 } \\
\text { abstained ' } 87\end{array}$ & & & & & & No \\
\hline
\end{tabular}

NOTE: Associations shown that are statistically significant at $95 \%$ confidence using either linear or categorical measure of participation.

Arrows reflect magnitudes of estimated effects of taking 1-2 courses (work-related and leisure) or one course (academic and vocational) relative to average shifts for those who took no courses of any type: one small arrow $0-9.9 \%$, two small arrows $10.0-19.9 \%$, three small arrows $20.0-29.9 \%$, one additional large arrow $30.0-100 \%$, two additional large arrows $100 \%+$

\section{Vocational accredited courses}

The linear results indicated that taking vocational courses increases race tolerance but has no effects on other outcome at the $95 \%$ level of statistical significance. We now see that participation in vocational accredited courses has effects on other outcomes as well, but not in a linear manner. For example, taking one vocational course decreases alcohol consumption and reduces authoritarian attitudes. There is no clear evidence for returns in these outcomes to taking a second, third, or subsequent vocational courses. However, the parameter estimates (reported in Appendix 10) suggest that there may be diminishing returns in relation to changes in authoritarian attitudes, and pernicious returns in relation to alcohol consumption. 
When interpreting these findings, we need to remember that the numbers taking different numbers of courses may be too small to estimate reliable effects. In our sample, 1,151 individuals took just one vocational course leading to accreditation between the ages of 33 and 42 . The results are not easy to interpret and more detailed investigations are required before any firm conclusions should be drawn.

\section{Work-related training courses}

These results show that in terms of effects on life satisfaction, race tolerance, less authoritarian attitudes, increased number of memberships, and alcohol consumption, the more courses the better (or perhaps worse in the case of alcohol consumption). In addition, we now see that taking work-related training courses leads to taking more exercise, but the effect disappears when more than ten courses are taken.

\section{Leisure courses}

The analyses using the linear specification found evidence for positive returns to participation in learning in relation to smoking, exercise, onset of depression, authoritarian attitudes, membership of organisations, and voting. Examination of the estimated effects of different levels of participation (in Appendix 10) suggests that there are positive $\mathrm{e}^{21}$ but diminishing returns to taking higher numbers of courses for all of these outcomes except for giving up smoking. Thus, for most of the outcomes for which effects are found, the more leisure courses taken the better (or worse in the case of onset of depression), although apparently with diminishing returns to taking high numbers of courses.

In relation to smoking, there is no evidence for positive returns to taking more than ten leisure courses, and the indication from the parameter estimate is that there are no or even negative returns to taking eleven or more leisure courses. This is another example of the finding reported earlier that in relation to health behaviours, there are no or negative returns to taking high numbers of courses (SF 3).

Another example of this finding is that taking just one or two leisure courses reduces alcohol consumption, but there appear to be no returns to taking three to ten courses, and negative returns (i.e. increased alcohol consumption) in relation to taking more than ten leisure courses.

Taking more than ten leisure courses is also associated with a very substantial decrease in levels of life satisfaction. We should be wary about interpreting this finding because it is based on a very small number of individuals ( 31 in total) who took more than ten leisure courses. Nevertheless, the finding is statistically significant at $95 \%$ confidence, which is reflects both the magnitude of the estimated effect and its consistency.

\footnotetext{
${ }^{21}$ Positive here does not mean normatively good. It applies equally to taking more exercise and to increased chances of onset of depression, which would be regarded as normatively good and bad, respectively.
} 
The negative relationship between taking high numbers of leisure courses and life satisfaction may tie in with the findings using the linear measure that taking leisure courses is not associated with increases in life satisfaction (as might be predicted from our fieldwork study), and is associated with increased chances of becoming depressed (see Section 6.1.1 and SF8). The explanation is unclear. It seems unlikely that participating in high numbers of courses undermines life satisfaction, but it might be that dissatisfaction motivates some individuals to take leisure courses, and those who continue taking more and more leisure courses are those who continue to be dissatisfied. These findings suggest that adults who take many leisure courses may need to progress, for example to other forms of learning or employment, and this throws the relevance of guidance and advice into relief.

SF 9: In relation to life satisfaction, social attitudes and civic participation, and participation in each of the four types of learning, returns are for the most part diminishing but still positive at high levels. In other words, the more courses the better.

SF 10: We have seen that the effects of participation in learning on the adoption of healthy behaviours hold only for taking fewer rather than more courses. We now see that this finding applies to each type of course, the only exception being the additive effect of each leisure course taken upon exercise.

SF 11: Taking just one academic accredited course increases levels of exercise, and taking just one vocational accredited course reduces alcohol consumption. The magnitudes of both effects are substantial.

SF 12: Countering the generally positive benefits of learning, taking leisure courses is associated with increased chances of becoming depressed and taking more than ten leisure courses is associated with reduced life satisfaction. It appears that some adults may require more support, or benefit from moving on from taking additional leisure courses. More research is required.

\subsection{Differences in results for men and women ${ }^{22}$}

We now consider the issue of whether results are different for different groups. The Centre's fieldwork findings provide evidence that the impact of learning varies according to the characteristics of the learner. We look here at different estimates of effects of participation in learning for men and women. In the next section, we investigate the effects of participation amongst individuals with low levels of qualifications.

Initially we examine the relative take up in adult learning by men and women (6.2.1). We then report findings relating to gender differences in estimated effects of participation aggregating across all types of learning (6.2.2), followed by Section 6.2.3, which deals with gender differences by course type.

\footnotetext{
${ }^{22}$ This section and the following one report summary results from extensive analyses, details of which are available from the authors.
} 


\subsubsection{Take-up of adult learning}

The first step in these investigations is to examine take-up of adult learning for men and women. Overall, the participation rates were the same for men and women. Figure 15 shows that more men than women took work-related training courses, whilst more women than men took academic, vocational, and leisure courses.

Figure 15: Proportions taking at least one course of each type by gender

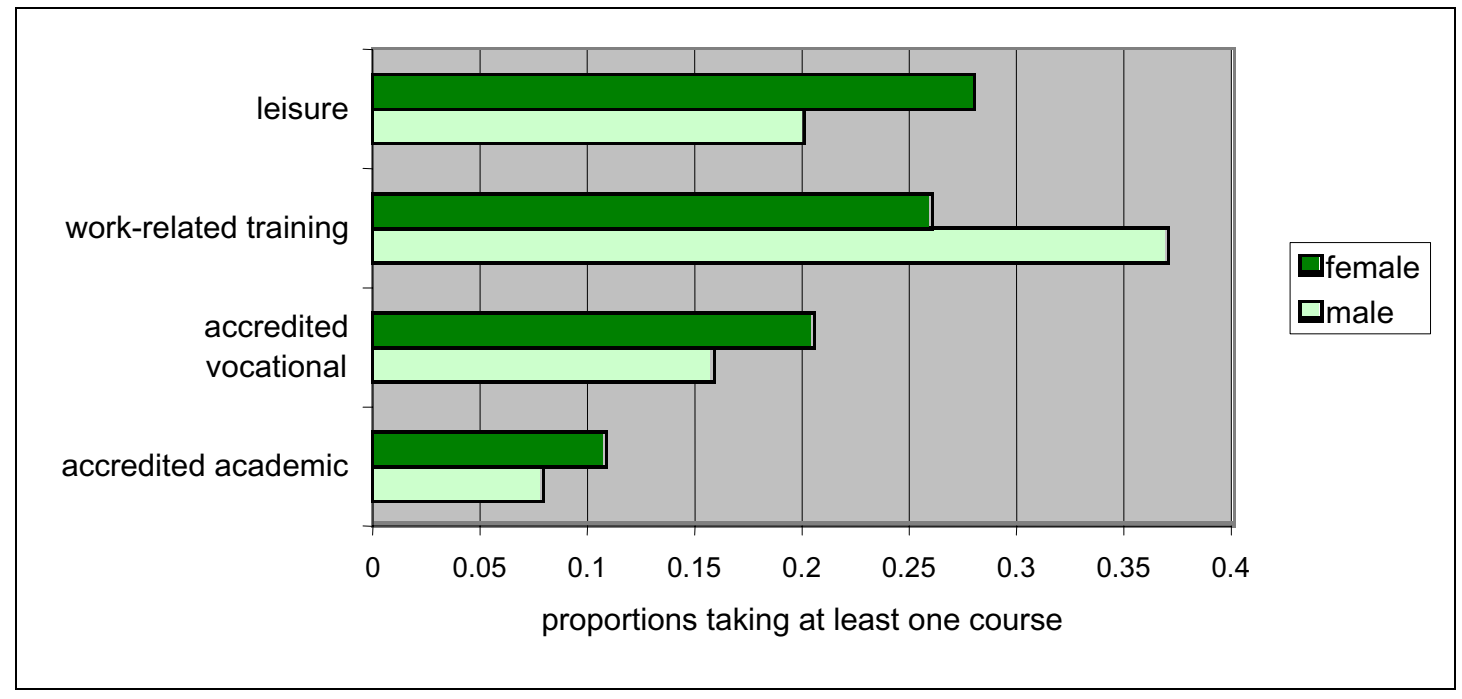

\subsubsection{Gender differences in effects of number of courses taken}

We now examine the gender differences in the estimated effects of participation in learning aggregating over course type.

In earlier sections, we estimated effects of learning using separate regressions that model the effects of participation in learning (specified in various ways) upon change in each outcome. The control set used in these regressions comprised gender, the outcome at age 33, socio-economic status, and highest academic and vocational qualifications, all at age 33. Full details of these control variables are given in Appendix 6. Experiments conducted with other sets of controls, which produced similar results are described in Appendix 7.

In this section, we extend our basic model by including an interaction term between participation and gender ${ }^{23}$. The coefficient on this interaction indicates the difference in learning effects for men and women. This enables us to test the relative effects of adult learning for men and women. Table 11 reports these coefficients.

\footnotetext{
${ }^{23}$ The model can be described by the following equation: $\mathrm{y}=\alpha+\delta_{1} \mathrm{~A}+\delta_{2} \mathrm{~g}+\delta_{3}\left(\mathrm{~A}^{*} \mathrm{~g}\right)+\mathrm{XA}$ where $\mathrm{y}=$ change in outcome, $\alpha=$ constant, $\mathrm{A}=$ number of courses taken, $\mathrm{g}=\operatorname{gender},\left(\mathrm{A}^{*} \mathrm{~g}\right)=$ interaction between gender and participation in each type of course, $\delta_{1}$ to $\delta_{3}=$ estimated coefficients, $\mathrm{X}=$ matrix of control variables, $\hat{\mathrm{A}}=$ matrix of estimated coefficients for control variables. $\delta_{3}$ is therefore the difference in effect across gender.
} 


\begin{tabular}{|c|c|c|c|c|c|c|}
\hline \multirow[b]{2}{*}{$\begin{array}{c}\text { Outcome } \\
\text { (1) }\end{array}$} & \multicolumn{2}{|c|}{ Men } & \multicolumn{2}{|c|}{ Women } & \multicolumn{2}{|c|}{$\begin{array}{c}\text { Interaction } \\
\text { term }\end{array}$} \\
\hline & $\begin{array}{c}\text { Effect } \\
(2)\end{array}$ & $\begin{array}{c}\text { P-val } \\
\text { (3) }\end{array}$ & $\begin{array}{c}\text { Effect } \\
(4)\end{array}$ & $\begin{array}{c}\text { P-val } \\
\text { (5) }\end{array}$ & $\begin{array}{c}\text { Effect } \\
(6)\end{array}$ & $\begin{array}{c}\text { P-val } \\
(7)\end{array}$ \\
\hline \multicolumn{7}{|l|}{ Health } \\
\hline 1 Gave up smoking & 0.000 & 0.878 & 0.006 & 0.064 & 0.006 & 0.186 \\
\hline 2 Change in units drunk & 0.043 & 0.247 & 0.047 & 0.384 & 0.004 & 0.955 \\
\hline 3 Increased level of exercise & 0.004 & 0.012 & 0.003 & 0.112 & 0.000 & 0.693 \\
\hline 4 Change in life satisfaction & 0.012 & 0.001 & 0.000 & 0.934 & -0.012 & 0.037 \\
\hline 5 Became depressed & 0.001 & 0.137 & -0.001 & 0.576 & -0.002 & 0.183 \\
\hline 6 Recovered depression & 0.006 & 0.484 & -0.005 & 0.651 & -0.011 & 0.443 \\
\hline \multicolumn{7}{|l|}{ Social capital } \\
\hline 7 Change in race tolerance & 0.015 & 0.000 & 0.009 & 0.007 & -0.006 & 0.109 \\
\hline 8 Change political cynicism & -0.003 & 0.223 & -0.003 & 0.432 & 0.000 & 0.931 \\
\hline 9 Change in authoritarianism & -0.008 & 0.000 & -0.011 & 0.001 & -0.003 & 0.500 \\
\hline 10 Increased political interest & 0.002 & 0.137 & 0.004 & 0.013 & 0.002 & 0.290 \\
\hline 11 Increased memberships & 0.003 & 0.004 & 0.005 & 0.000 & 0.002 & 0.111 \\
\hline 12 Voted '97 abstained '87 & 0.007 & 0.050 & 0.005 & 0.385 & -0.003 & 0.697 \\
\hline
\end{tabular}

The first column lists the outcome variables. The second column gives the estimated effect for each additional course taken on each outcome for men. The third column gives the p-value, i.e., the probability that these estimates are zero when one takes account of sampling bias. The fourth and fifth columns give the estimated effects and p-values for women. The sixth column gives the interaction term: the additional impact of each course taken for women as opposed to men. Where the value is negative, this indicates that the impact of taking courses is greater for men than for women. The final column indicates the probability that this coefficient is zero, i.e., that there is no gender difference. In our discussion, we reject the null hypothesis that there are no gender differences in the impact of adult learning only when this probability falls below 0.050 .

The figures in the table suggest that when participation is measured by total number of courses taken, irrespective of course type, the effects for men and women only differ at a $95 \%$ level of confidence in relation to change in life satisfaction. Separate regressions for each sex also reveal that the association between participation and improved life satisfaction is statistically significant for men but not for women. The effects of participation on all other outcomes are not different for men and women.

The finding that adult learning has no effect on the life satisfaction of women is slightly perplexing in the light of our fieldwork findings, and findings from other qualitative studies (e.g. McGivney 1999, 1997, 1990), which report that participation in adult learning, particularly for women, enhances their self-esteem, self-efficacy, and feelings of wellbeing. One explanation lies in our measure of life satisfaction, 
and its relationship to empowerment. As mentioned in Section 3, life satisfaction is measured by levels of agreement with two statements, one of which is satisfaction with the way that one's life has turned out so far. It could be that for some women, participation in learning enables them to realise that they are not, after all satisfied with their lives so far. This can be seen as a form of empowerment, albeit one that carries with it an element of risk.

KF 10: The effects of participation in learning, aggregating across all types of courses, are broadly similar for men and women. This means that the pervasive effects of participation in learning on health and social capital outcomes apply to both men and women.

SF 13: A gender difference is found in relation to life satisfaction. The association between participation and improved life satisfaction is statistically significant for men but not present for women. More research is required to understand why this is so.

\subsubsection{Effects of participation in each course type by gender ${ }^{24}$}

Although we have found little evidence for gender differences in effects of learning when we aggregate across all types of learning, we hypothesise that there may nevertheless be gender differences in relation to taking particular types of courses. We therefore estimate gender differences in the effects of participation in adult learning by type of course. In order to do so, we performed 12 regressions (one for each outcome) using an extension of the model described in the previous section. This model included four interaction terms, one for participation in each of the four types of course. The linear specification of participation in adult learning was used ${ }^{25}$.

\footnotetext{
${ }^{24}$ In order to test for reverse causality, we modeled the effects of changes in outcomes on participation in each of type of learning for men and for women. The results of these analyses are presented in Appendix 8. They find evidence for reverse causality in relation to all outcomes except for life satisfaction and political cynicism. No evidence for reverse causality was found for these outcomes aggregating across course type and participants either.
}

In addition, we investigated whether changes in life circumstances had any impacts upon the estimated effects of each type of course for men and for women by including in the specifications changes in life circumstances measured using the variables described in Table learning by including in regressions conducted. The results are in Appendix 7. In line with findings of similar tests but aggregating over course type and participants, including these variables in the model specification does not changes estimates of effects of participation. We therefore conclude that there is no evidence that changes in life circumstances between 33 and 42 mediate or magnify effects of participation upon outcomes. Neither do they seem to be a source of selection bias for observed associations between participation and outcomes.

${ }^{25}$ The model can be described as follows:

$\Delta y=\alpha+\sum_{j} \delta_{j} A_{j}+\sum_{j} \gamma_{j}\left(A^{*} g\right)_{j}+\eta g+X \mathrm{~B}$

where $y=$ change in outcome, $\mathrm{j}=$ course type (academic ac credited, vocational accredited, workrelated training, leisure), $A_{j}=$ total number of courses of each type taken, $\delta_{j}=$ coefficients for effects of participation in each course type, $g=$ gender, $\left(A^{*} g\right)_{j}=$ interactions between gender and participation in each type of course, $\tilde{\mathrm{a}}_{\mathrm{j}}=$ coefficients for interactions in effects between gender and participation in each type of course, $\mathrm{X}=$ matrix of control variables, $\hat{\mathrm{A}}=$ vector of coefficients for the controls variables. 
In total, 48 interaction parameters were estimated. The full results are given in Appendix 11. By chance we would expect two or three of them to be statistically significant at $95 \%$ confidence. In fact, we identified three statistically significant gender differences. We therefore conclude that are few if any gender differences that apply specifically to one type of course ${ }^{26}$.

The only gender difference in the estimated effects of participation that we found aggregating over course type related to changes in life satisfaction. Examination of gender differences by course type reveals that this difference is driven by effects of taking work-related and academic courses, for which the sizes and consistencies of the estimates are much greater for men than for women. We also found that participation in vocational accredited courses reduces life satisfaction for men, but not for women.

\section{SF 14: Taking work-related training and academic courses leading to accreditation are associated with increases in life satisfaction for men but not for women. In contrast, taking vocational accredited courses is associated with reduced life satisfaction for men but not for women. Further research is required.}

The explanations for these gender differences must lie in the different life circumstances and motivations of men and women during mid-adulthood, a stage in the life course when changes in family life are particularly prominent. For example, taking academic courses may increase life satisfaction for both men and women. But this positive effect may be offset for women more than for men (on average) by the stress associated with juggling demands of coursework, employment and family responsibilities. The positive estimated effect of taking work-related courses found for men but not women may reflect gender differences in the meaning and importance attached to occupational success by parents of young families. The finding that taking vocational accredited courses are associated with reduced life satisfaction for men but not women may be a consequence of selection bias. More men than women may be motivated to take such courses because they are unemployed or dissatisfied with their working lives, in contrast to changed circumstances and opportunities occasioned by childbirth, which might more often be motivating factors for women.

\subsection{Differences in results for individuals with low levels of qualification $^{27}$}

In order to examine the effects of participation in learning between the ages of 33 and 42 for individuals with different levels of prior qualifications, we divide the sample into two groups, a high qualification group and a low qualification group. Those falling into the low qualification group had, at the age of 33, no qualifications, CSE qualifications up to and including grade 2, RSA stage 1, and any other qualifications

\footnotetext{
${ }^{26}$ Analyses using the categorical specification for participation in each course type produce similar results.

${ }^{27}$ The findings reported here summarise the results of extensive analyses. Details are available from the authors.
} 
below Level 2 as defined by the Qualifications and Curriculum Authority ${ }^{28}$. Those falling into the higher qualification group had qualifications above this level at the age of 33 . $39 \%$ of the sample fall into the former category, constituting 3,821 adults, which we consider a large enough sub-sample for the purposes of our analyses.

As with the previous section, we divide this one into four subsections. The first examines relative rates of take up of adult learning. The second reports findings relating to differences when the impacts of learning are considered aggregating over course type. The third section presents more detailed results pertaining to four different types of course.

\subsubsection{Take-up of adult learning}

The first stage of the investigation is to examine take-up of adult learning for the two educational groups. In line with evidence from other sources (see Section 3.1), we find that a much higher proportion of those with higher as opposed to lower levels of qualification at 33 took at least one course, the percentages participating being $64 \%$ and $49 \%$ respectively. Similarly, the average number of courses taken by the higher educational group was 2.5 as opposed to 1.7 for group with no qualifications or qualification below Level 2. These differences apply to participation in each of the four different types of course considered here.

\subsubsection{Effect of participation in adult learning by prior level of education}

To test the relative importance of adult learning for individuals with higher and lower levels of qualifications, we include in our basic model the interaction between participation in adult learning and prior qualification level ${ }^{29}$. Its estimated effect on each outcome indicates whether learning effects are different for the two educational groups. We conducted twelve regressions, one for each outcome.

The results, which are given in Appendix 11, suggest that when participation is measured by total number of courses taken, irrespective of course type, the effects for each education group are very similar. The only exception is in relation to changes in

\footnotetext{
${ }^{28}$ This does not include any GCSEs with grades A*-C or their academic equivalent. Subsequent analyses will include up to four such qualifications in this group, but it was not possible to do so within the timescale of this phase of the research.

${ }^{29}$ The model used is equivalent to that used to estimate gender differences, and can be described as follows:$$
\mathrm{y}=\alpha+\delta_{1} \mathrm{~A}+\delta_{2} \mathrm{q}+\delta_{3}(\mathrm{~A} * \mathrm{q})+\mathrm{XA}
$$$$
\text { where } \mathrm{y}=\text { change in outcome, } \alpha=\text { constant, } \mathrm{A}=\text { total number of courses taken, } \mathrm{q}=\mathrm{a} \text { dummy }
$$
variable indicating whether cohort members had below Level 2 qualifications at age 33, $\left(A^{*} q\right)=$ interaction between prior level of qualification and total number of courses taken, $\delta_{1}$ to $\delta_{3}=$ estimated coefficients, $\mathrm{X}=$ matrix of control variables, $\hat{\mathrm{A}}=$ matrix of estimated coefficients for control variables. $\quad \delta_{3}$ is therefore the difference in effect across prior qualification level.
} 
political interest, for which the estimated effects of participation in learning is greater for those with below Level 2 qualifications at age 33 .

\section{KF 11: Aggregating across all course types, the effects of participation in learning are similar for each education group. This means that the pervasive effects of participation in learning already found on health and social capital outcomes apply regardless of prior qualification levels.}

\subsubsection{Effects of participation in each course type by previous level of education}

Although we have found little evidence for differences in effects of learning for the two education groups when we aggregate across all types of learning, we hypothesise that there may nevertheless be education differences in relation to taking particular types of courses. We therefore estimate differences between the two groups in the effects of participation in adult learning by type of course. In order to do so, we performed 12 regressions (one for each outcome) using an extension of the model described in the previous section. This model included four interaction terms, one for participation in each of the four types of course. The linear specification of participation in adult learning was used ${ }^{30}$. The results are reported in Table 12.

The first column of this table lists the outcomes. The second column gives the additional effect for those with below Level 2 qualifications at age 33 over and above the effect estimated for those with Level 2 and above qualifications at the same age of each academic course taken. The third column gives the probability that the value in the second column is zero, i.e., the probability that there is no difference in the estimated effects of taking academic courses between the two education groups. The values in the subsequent pairs of columns are equivalent to those in columns 2 and 3 , but refer to other types of courses as indicated by the headings.

${ }^{30}$ The model can be described as follows:
$\Delta y=\alpha+\sum_{j} \delta_{j} A_{j}+\sum_{j} \gamma_{j}\left(A^{*} q\right)_{j}+\eta q+X \mathrm{~B}$

where $y=$ change in outcome, $\mathrm{j}=$ course type (academic accredited, vocational accredited, work related training, leisure), $A_{j}=$ total number of courses of each type taken, $\delta_{j}=$ coefficients for effects of participation in each course type, $q=a$ dummy variable indicating whether cohort members had below Level 2 qualifications at age $33,\left(\mathrm{~A}^{*} \mathrm{q}\right)_{\mathrm{j}}=$ interactions between prior level of qualification and participation in each type of course, $\tilde{a}_{j}=$ coefficients for interactions in effects between prior qualification level and participation in each type of course, $X=$ matrix of control variables, $\hat{A}=$ vector of coefficients for the controls variables. 
Table 12: Differences between the two education groups in the marginal effects of participation in each type of course

\begin{tabular}{|c|c|c|c|c|c|c|c|c|c|}
\hline \multirow{2}{*}{\multicolumn{2}{|c|}{ Outcome }} & \multicolumn{2}{|c|}{ Academic } & \multicolumn{2}{|c|}{ Vocational } & \multicolumn{2}{|c|}{ Work-related } & \multicolumn{2}{|c|}{ Leisure } \\
\hline & & Beta & $\mathbf{P}$ & Beta & $\mathbf{P}$ & Beta & $\mathbf{P}$ & Beta & $\mathbf{P}$ \\
\hline \multicolumn{10}{|c|}{ Health } \\
\hline 1 & Gave up smoking & 0.020 & 0.545 & 0.011 & 0.625 & 0.001 & 0.857 & 0.001 & 0.974 \\
\hline 2 & $\begin{array}{l}\text { Change in units } \\
\text { drunk }\end{array}$ & -0.829 & 0.109 & -0.642 & 0.067 & -0.002 & 0.983 & -0.061 & 0.793 \\
\hline 3 & Increased exercise & -0.023 & 0.296 & 0.010 & 0.501 & 0.006 & 0.101 & -0.012 & 0.267 \\
\hline 4 & $\begin{array}{l}\text { Change in life } \\
\text { satisfaction }\end{array}$ & 0.081 & 0.081 & 0.015 & 0.619 & -0.005 & 0.503 & 0.025 & 0.242 \\
\hline 5 & Became depressed & 0.023 & 0.015 & -0.012 & 0.081 & -0.002 & 0.334 & 0.001 & 0.852 \\
\hline 6 & $\begin{array}{l}\text { Recovered from } \\
\text { depression }\end{array}$ & -0.025 & 0.774 & -0.041 & 0.460 & 0.004 & 0.839 & -0.033 & 0.388 \\
\hline \multicolumn{10}{|c|}{ Social capital } \\
\hline 7 & $\begin{array}{l}\text { Change in race } \\
\text { tolerance }\end{array}$ & -0.002 & 0.951 & 0.005 & 0.802 & 0.003 & 0.496 & 0.011 & 0.462 \\
\hline 8 & $\begin{array}{l}\text { Change in political } \\
\text { cynicism }\end{array}$ & 0.003 & 0.940 & 0.007 & 0.766 & -0.004 & 0.469 & -0.025 & 0.150 \\
\hline 9 & $\begin{array}{l}\text { Change in } \\
\text { authoritarianism }\end{array}$ & 0.020 & 0.521 & 0.002 & 0.930 & 0.001 & 0.844 & 0.000 & 0.999 \\
\hline 10 & $\begin{array}{l}\text { Increase in political } \\
\text { interest }\end{array}$ & 0.007 & 0.652 & -0.002 & 0.829 & 0.003 & 0.180 & 0.007 & 0.369 \\
\hline 11 & $\begin{array}{l}\text { Increased } \\
\text { memberships }\end{array}$ & 0.002 & 0.838 & 0.008 & 0.339 & -0.002 & 0.299 & 0.010 & 0.042 \\
\hline 12 & $\begin{array}{l}\text { Voted } 1997 \\
\text { abstained } 1987\end{array}$ & -0.094 & 0.059 & -0.010 & 0.726 & 0.006 & 0.375 & 0.090 & 0.019 \\
\hline
\end{tabular}

In total, 48 interaction parameters were estimated. By chance we would expect two or three of them to be statistically significant at $95 \%$ confidence, and in fact we find just three are statistically significant at this level. Nevertheless, some interesting results do emerge.

The first is that taking leisure courses have generally stronger positive impacts on the social capital outcomes for those with below Level 2 qualifications at age 33. This is indicated by the figures in the final two columns of the table relating to outcomes 7 to 12. We see that in relation to changes in authoritarian attitudes there is no difference between the education groups, but in relation to the other five outcomes, the additional effect estimated for those with below Level 2 qualifications is positive (except in relation to changes in political cynicism, where the negative sign represents a change in the direction which is normatively good). The additional effect of participation is particularly marked in relation to civic participation outcomes; the 
interaction term is statistically significant at a $95 \%$ level of confidence for both measures used.

\section{SF 15: Taking leisure courses appears to have stronger positive impacts for those with below Level 2 qualifications at age 33 in relation to the range of social capital outcomes, particularly in relation to increased civic participation.}

Since those with low levels of education may face exclusion in various forms, this finding implies that leisure courses may be an important stepping stone for those who wish to take a more active part in civic life. This resonates with findings from our qualitative fieldwork (e.g. Schuller et al., 2002), and with the informal accounts of practitioners.

Other interesting findings relate to differences between the education groups in the estimated effects of participation on onset of depression. This variable only applies to adults who were not depressed at age 33. Aggregating across prior education groups, we have already found that taking leisure courses was associated with increased chances of becoming depressed (Section 6.1.1). We can now report that this finding applies to both education groups equally. However, for those with below Level 2 qualifications only, taking academic accredited courses is associated with increased chances of becoming depressed, and taking vocational accredited courses is associated with decreased chances of becoming depressed. No effects are found for those with Level 2 and above qualifications at age 33 .

SF 16: For those with below Level 2 qualifications at age 33, taking vocational accredited courses appears to protect against onset of depression, whereas taking academic accredited courses increases the chances of becoming depressed. The effect of taking leisure courses on increased chances of becoming depressed which is found for the whole sample applies regardless of prior qualification level.

It may not surprise the reader that taking vocational courses during mid-adulthood protects those with lower levels of qualifications from becoming depressed. Cohort members who report taking vocational courses obtained qualifications, and additional vocational qualifications widen opportunities, are likely leading to improved life circumstances, and probably enhance self-esteem and self-efficacy - all of which would protect psychological health. The impact appears to be greater for those with lower levels of qualifications to start with.

The normatively positive effect of taking vocational courses for those with below Level 2 qualifications at 33 contrasts with the normatively negative effect of taking academic courses for the same group. The size of this estimated effect is substantial. For those with below Level 2 qualifications at age 33, taking each academic course between the ages of 33 and 42 is associated with two additional adults in one hundred becoming depressed between the ages of 33 and 42. This proportion can be compared to the proportion of adults who took no courses at all between 33 and 42 who are predicted to become depressed over the same period: seven in one hundred. 
Both vocational and academic courses may have the potential to benefit all groups. Indeed, evidence from the Centre's fieldwork programme suggests that this is so. However, it appears that these benefits are more readily experienced in relation to vocational than academic courses for those with low levels of qualifications to start with. In addition for this group, taking academic courses may undermine psychological health, possibly as a consequence of the stress associated with high demands that outstrip participants' skills and knowledge, and with fears of failure. Many of those with below Level 2 qualifications at age 33 will have experienced academic failure already during their initial education.

\subsection{Summary of key and specific findings.}

We now restate the key and specific findings (KF and SF) from this section.

\begin{tabular}{|c|c|}
\hline \multicolumn{2}{|c|}{ Different effects for different types of course } \\
\hline KF9 & $\begin{array}{l}\text { Taking work-related and leisure courses has effects on a much broader range } \\
\text { of health and social capital outcomes than taking academic or vocational } \\
\text { courses leading to accreditation. }\end{array}$ \\
\hline SF4 & $\begin{array}{l}\text { The effects of taking academic accredited courses on social and political } \\
\text { attitudes are greater in magnitude and more consistent than for any other } \\
\text { course type. }\end{array}$ \\
\hline SF5 & Taking vocational courses has positive effects on race tolerance. \\
\hline SF6 & $\begin{array}{l}\text { Taking work-related training courses has positive effects on the whole range } \\
\text { of health and social outcomes }\end{array}$ \\
\hline SF7 & $\begin{array}{l}\text { Taking leisure courses has strong effects of the whole range of health and } \\
\text { social capital outcomes, although not wellbeing. Effects are particularly } \\
\text { strong in relation to civic participation. In fact, the effects of taking leisure } \\
\text { courses on civic participation are more consistent and substantial than for any } \\
\text { other course type. }\end{array}$ \\
\hline SF8 & $\begin{array}{l}\text { Participation in leisure courses is not associated with changes in life } \\
\text { satisfaction, and is positively associated with becoming depressed. }\end{array}$ \\
\hline SF9 & $\begin{array}{l}\text { In relation to life satisfaction, social attitudes and civic participation, and } \\
\text { participation in each of the four types of learning, returns are for the most part } \\
\text { diminishing but still positive at high levels. In other words, the more courses } \\
\text { the better. }\end{array}$ \\
\hline SF10 & $\begin{array}{l}\text { We have seen that the effects of participation in learning on the adoption of } \\
\text { healthy behaviours hold only for taking fewer rather than more courses. We } \\
\text { now see that this finding applies to each type of course, the only exception } \\
\text { being the additive effect of each leisure course taken upon exercise. }\end{array}$ \\
\hline SF11 & $\begin{array}{l}\text { Taking just one academic accredited course increases levels of exercise, and } \\
\text { taking just one vocational accredited course reduces alcohol consumption. } \\
\text { The magnitudes of both effects are substantial. }\end{array}$ \\
\hline SF12 & $\begin{array}{l}\text { Countering the generally positive benefits of learning, taking leisure courses } \\
\text { is associated with increased chances of becoming depressed and taking more } \\
\text { than ten leisure courses is associated with reduced life satisfaction. It appears }\end{array}$ \\
\hline
\end{tabular}




\begin{tabular}{|c|c|}
\hline & $\begin{array}{l}\text { that some adults may require more support, or benefit from moving on from } \\
\text { taking additional leisure courses. More research is required. }\end{array}$ \\
\hline \multicolumn{2}{|c|}{ Different effects for men and women } \\
\hline KF10 & $\begin{array}{l}\text { The effects of participation in learning, aggregating across all types of } \\
\text { courses, are broadly similar for men and women. This means that the } \\
\text { pervasive effects of participation in learning on health and social capital } \\
\text { outcomes apply to both men and women. }\end{array}$ \\
\hline SF13 & $\begin{array}{l}\text { A gender difference is found in relation to life satisfaction. The association } \\
\text { between participation and improved life satisfaction is statistically significant } \\
\text { for men but not present for women. Again, more research is required. }\end{array}$ \\
\hline SF14 & $\begin{array}{l}\text { Taking work-related training and academic courses leading to accreditation } \\
\text { are associated with increases in life satisfaction for men but not for women. } \\
\text { In contrast, taking vocational accredited courses is associated with reduced } \\
\text { life satisfaction for men but not for women. }\end{array}$ \\
\hline \multicolumn{2}{|r|}{$\begin{array}{l}\text { Different effects for those with below Level } 2 \text { qualifications at age } 33 \text { and those } \\
\text { with Level } 2 \text { qualifications at age } 33\end{array}$} \\
\hline KF11 & $\begin{array}{l}\text { Aggregating across all course types, the effects of participation in learning are } \\
\text { similar for each education group. This means that the pervasive effects of } \\
\text { participation in learning already found on health and social capital outcomes } \\
\text { apply regardless of prior qualification levels. }\end{array}$ \\
\hline SF15 & $\begin{array}{l}\text { Taking leisure courses appears to have stronger positive impacts for those } \\
\text { with below Level } 2 \text { qualifications at age } 33 \text { in relation to the range of social } \\
\text { capital outcomes, particularly in relation to increased civic participation. }\end{array}$ \\
\hline SF16 & $\begin{array}{l}\text { For those with below Level } 2 \text { qualifications at age 33, taking vocational } \\
\text { accredited courses appears to protect against onset of depression, whereas } \\
\text { taking academic accredited courses increases the chances of becoming } \\
\text { depressed. The effect of taking leisure courses on increased chances of } \\
\text { becoming depressed which is found for the whole sample applies regardless } \\
\text { of prior qualification level. }\end{array}$ \\
\hline
\end{tabular}

\section{Conclusions, interpretations, and policy implications}

The analyses described here generated numerous estimates of the effects of learning. We have estimated effects of adult learning on a wide range of outcomes, broken down participation in learning in a number of ways and assessed the different impacts of participation on different groups. The primary objective is to assess the nature and extent of wider effects of adult learning. More detailed findings relating to specific outcomes, types of courses taken and groups of learners are extremely interesting and indicate directions for further research. We therefore conclude by discussing our findings in two sections. Section 7.1 offers interpretations and policy implications relating to main findings, and Section 7.2 discusses interpretations and policy implications relating to detailed findings. Main findings are summarised at the ends 
of Sections 5 and 6, and illustrated in Figure 13 and Figure 14 in Section 5.2.2, and Table 13 below $^{31}$.

\subsection{Main findings}

Consistent evidence for positive effects of adult learning on health and social capital outcomes

Other studies have provided evidence of effects of education on health and social capital outcomes. These previous findings suggest that staying on and achieving success during initial education play a crucial part in promoting positive health and social capital. The research reported here is the first study that uses large sample data to test whether participation in learning during mid-adulthood also has effects on health and social capital outcomes. We find consistent evidence for effects of participation in learning during this period of the life course on health and social capital. Effects are found with most outcomes, and this finding is robust to changes in the specification of participation in learning. ${ }^{32}$

\section{Small effects that are important in relative terms}

The sizes of estimated effects of participation in adult learning are small in absolute terms, but they are nevertheless important. They are substantial relative to the stability of attitudes, behaviours, and levels of wellbeing during mid-adulthood. Adult learning appears to play an important role in promoting a positive process of personal and social development.

The sizes of estimated effects in the context of changes in attitudes and behaviours amongst adults are illustrated in Figure 13 and Figure 14 in Section 5.2.2, where a full explanation of the figures is also given. In addition, we summarise estimate sizes that are statistically significant at 95\% level of confidence in words in Box 1.

Figure 16: Some examples of the sizes of estimated effects of participation in learning during mid-adulthood

Taking one to two courses between ages 33 and 42 increases the probability of giving up smoking by $3.3 \%$ points. $24 \%$ of smokers who took no courses are predicted ${ }^{33}$ to quit by 42 . Therefore, the effect of taking one or two courses is to increase this probability to just over $27 \%(24 \%+3.3 \%)$, representing an increase in the chances of giving up by a factor of over one eighth.

The effect of taking three to ten courses is that seven additional individuals in 100

\footnotetext{
${ }^{31}$ Table 13 is a repeat of Table 10.

${ }^{32}$ The specifications of learning used were the linear measure of participation (i.e. total number of courses taken), a categorical measure consisting of three dummies to indicate four levels of participation, a single dummy indicator of participation vs. non-participation, and a quadratic function for number of courses taken.

${ }^{33}$ We do not make comparisons with all adults who took no courses because adults who took courses and adults who did not are likely to be different. Instead we make comparisons with adults who have similar characteristics to learners, but who took no courses.
} 
increase their level of exercise between 33 and 42 . We predict that $38 \%$ of those who took no courses increase their level of exercise. The change attributed to taking three to ten courses is to raise this proportion by almost $20 \%$.

Taking three to ten courses between 33 and 42 offsets the predicted decline in life satisfaction for those who took no courses by $35 \%$.

Social and political attitudes are fairly stable during mid-adulthood for this cohort, but participation in adult learning nevertheless has substantial effects. Taking one or two courses changes three of the four measures of social and political attitudes in ways that are normatively beneficial by between 2 and 5\% points. These changes represent increases of between $12 \%$ and $34 \%$ from the baseline level predicted for those who took no courses.

Taking one or two courses raises the proportion of adults in the sample who increased their number of memberships by $3 \%$ points. The proportion of adults who took no courses who are predicted to increase their memberships is $8.6 \%$. The predicted proportion for those who took one or two courses is therefore $11.6 \%(8.6 \%+3 \%)$, which is an increase over those who took no courses by a factor of more than one third.

Participation in adult learning is a significant factor in positive processes of psychological and social development

Our results do suggest that there are effects of adult learning. However, we also find evidence that changes in health and social capital sometimes precede participation in adult learning. Consequently, we see participation in learning during mid-adulthood as a significant factor in a positive process of psychological, behavioural, and social development.

Previous fieldwork research conducted at the WBL Centre and reported in Schuller et al. (2002) suggests that psychosocial outcomes of learning often motivate further learning. Thus, we see a progression from learning in more supportive contexts to more challenging learning, which is enmeshed with a more general progression in terms of personal and social development. Taking courses appears to be an important driver of this process.

In contrast, we find no evidence that changes in life satisfaction or level of exercise taken lead to participation in adult learning. We are therefore particularly confident that the estimated effects of participation in adult learning on these outcomes reflect pure effects of adult learning.

What aspects of participation may be important in generating wider benefits?

The question arises as to why participation in learning should produce these effects. In our theoretical introduction, we suggest six channels through which adult learning may produce wider benefits. These are:

- effects due to the development of specific skills;

- generic cognitive development;

- personal development;

- $\quad$ peer group and other interactional effects inside and outside the classroom; 
- positional benefits;

- economic effects.

Clearly wider benefits arise beyond the confines of the subject matter of courses, which suggests it is the learning environment itself, which may provide the answer. The situation of adults engaging in the common pursuit of learning under the direction of an experienced teacher, committed to making their learning a success, appears to have all the ingredients of confidence building and rising social awareness. Although we can have no direct evidence of this from our analysis, it is hard to imagine that learning through books or exclusively through distance measures would have anything like the same effect.

Distance learning and learning from books may, however, be a starting point for adults who are disengaged from the education system or who have little social confidence. Or conversely, they may be the means of carrying on learning when the use of classroom opportunities is no longer feasible. In other words, they may suit some individuals better than others. But notably, the Open University places much emphasis on the role of summer schools in its foundation courses.

We found in our case studies individuals whose engagement in learning in the middle thirties had been a long process of getting back to education from a position of having abandoned it relatively early in life. The main message that comes therefore from these findings is that opportunities for learning are not necessarily sufficient to ensure engagement and classes that are not sensitive to learners' needs are not necessarily going to generate the wider benefits. The provision of facilities and encouragement for interaction would also appear to be essential components. This makes the case for the advancement of a lifelong learning agenda on all fronts.

Though early moves in the direction of the lifelong learning scenario were driven by concerns with upgrading skills and meeting qualification targets, the wider agenda of enhancing quality of life both personally and in the community, suggests the need for a broader set of learning options. These need to build on the best traditions of nonvocational adult education emphasising accessibility and learner-centeredness in the provision and delivery of courses. They will also address more explicitly the health, community awareness and citizenship functions of adult learning that our analysis demonstrates.

Of course, such courses may well involve progression out of unaccredited learning into accredited courses and back again to unaccredited courses. The main point is that when participation is occurring, life course shifts are likely to follow. These shifts are reflected in enhanced quality of life and through enhanced motivation to take advantage of further learning opportunities. Labour market prospects may also be enhanced through both vocational and non-vocational routes. 
Our research shows that as high a proportion as $58 \%$ of the sample took part in some kind of course between the ages of 33 and 42 . The fact remains, however, that $42 \%$ of the sample had not participated and are therefore classified in some statistics as "nonlearners". Wider appreciation of the personal and social benefits to be gained from learning might help to transform more of them into active learners.

\subsection{Detailed findings}

This section concerns the different effects of participation in adult learning depending on the level of participation, the type of course taken and the characteristics of those participating. Key and specific findings are summarised at the ends of Sections 5 and 6. See also Table 13, which is a repeat of Table 10 and summarises effect sizes for each course type. We discuss interpretations of these findings and their policy implications below.

\section{Greater returns to the first few courses taken}

We report above that the health and social capital benefits of the first few courses taken are greater than those generated from higher numbers of courses. Depending on the type of course taken and the outcomes under consideration, there are diminishing, zero, and even negative returns to taking high numbers of courses. These findings provide evidence for the value of interventions designed to widen participation in adult learning. They also highlight the importance of advice, guidance and other forms of support that help adults learning to move on to other forms of activity - for example, employment, voluntary work, or other types of courses.

We suggest that participation in adult learning plays an important and in some cases possibly crucial role in processes of personal and social development during midadulthood. Clearly, the individual's learning needs will change alongside their development in other areas and our findings suggest that progression in (or from) learning is important if progression in other areas is to continue. The importance of progression in learning is also illustrated by the accounts of respondents interviewed as part of the WBL fieldwork programme, reported in Schuller et al. (2002).

\section{Effects of participation in different types of courses}

Table 13 below illustrates the magnitudes of estimated effects of participation in four types of course: academic courses leading to accreditation, vocational courses leading to accreditation, work-related training and leisure courses. The column headed 'All' gives effect sizes when participation is aggregated over course type. The following four columns illustrate effect sizes for participation in each type of course. The final column states whether we found evidence that change in the outcome precedes participation in learning at age 42 .

Work-related and leisure courses are important in terms of generating wider benefits It is striking that taking work-related and leisure courses, which do not lead to accreditation, appears not only to change social and political attitudes and affect wellbeing, but also has a positive impact on the behavioural outcomes: increased civic 
Table 13: Interpretation of effect sizes for each course type

\begin{tabular}{|c|c|c|c|c|c|c|c|}
\hline & Outcome & All & $\begin{array}{l}\text { Acad. } \\
\text { accred. }\end{array}$ & $\begin{array}{l}\text { Vocatnl. } \\
\text { accred. }\end{array}$ & $\begin{array}{l}\text { Work- } \\
\text { related }\end{array}$ & Leisure & $\begin{array}{l}\text { Reverse } \\
\text { causality }\end{array}$ \\
\hline & Health & & & & & & \\
\hline 1 & $\begin{array}{l}\text { Gave up } \\
\text { smoking }\end{array}$ & $\uparrow \uparrow$ & & & & & No \\
\hline 2 & $\begin{array}{l}\text { Change in } \\
\text { units drunk }\end{array}$ & & & $\downarrow \downarrow$ & & & Yes \\
\hline 3 & $\begin{array}{l}\text { Increased } \\
\text { exercise }\end{array}$ & $\uparrow$ & & & 4 & 4 & No \\
\hline 4 & $\begin{array}{l}\text { Change in life } \\
\text { satisfaction }\end{array}$ & & 4 & & & & No \\
\hline 5 & $\begin{array}{l}\text { Became } \\
\text { depressed }\end{array}$ & & & & & 4 & No \\
\hline 6 & $\begin{array}{l}\text { Recovered } \\
\text { depression }\end{array}$ & & & & & & No \\
\hline & Social capital & & & & & & \\
\hline 7 & $\begin{array}{l}\text { Change race } \\
\text { tolerance }\end{array}$ & & & 444 & & 4 & Yes \\
\hline 8 & $\begin{array}{l}\text { Change pol. } \\
\text { cynicism }\end{array}$ & & & & & & No \\
\hline 9 & $\begin{array}{l}\text { Change in } \\
\text { authoritarian }\end{array}$ & $\downarrow \downarrow \downarrow$ & & $\downarrow \downarrow \downarrow$ & $\downarrow$ & $\downarrow \downarrow$ & Yes \\
\hline 10 & $\begin{array}{l}\text { Change in } \\
\text { pol. interest }\end{array}$ & 44 & & & & & No \\
\hline 11 & $\begin{array}{l}\text { Increased } \\
\text { memberships }\end{array}$ & & $\uparrow \uparrow$ & & $\uparrow$ & & Yes \\
\hline 12 & $\begin{array}{l}\text { Voting '97 } \\
\text { abstained '87 }\end{array}$ & 44 & $\perp$ & & & & No \\
\hline
\end{tabular}

NOTE: Associations shown that are statistically significant at 95\% confidence using either linear or categorical measure of participation.

Arrows reflect magnitudes of estimated effects of taking 1-2 courses (work-related and leisure) or one course (academic and vocational) relative to average shifts for those who took no courses of any type: one small arrow $0-9.9 \%$, two small arrows $10.0-19.9 \%$, three small arrows $20.0-29.9 \%$, one additional large arrow 30.0-100\%, two additional large arrows $100 \%+$.

participation and the adoption of health practices. The wider benefits of taking workrelated and leisure courses are a strong argument for continuing investment in them.

The impact of participation in leisure courses on social exclusion

Our research suggests that leisure courses may have particular value in combating social exclusion. Work-related courses are usually funded by employers, but they are only available to adults in the workforce. Leisure courses on the other hand are available to those outside the labour market as well as those within it. We find that leisure courses are particularly important in relation to increasing civic participation, especially for those with below Level 2 qualifications at age 33. This finding resonates with informal reports from practitioners teaching and co-ordinating leisure 
courses. For those without many qualifications, who are often at greatest risk of social exclusion, leisure courses are said to provide a stepping stone to inclusion.

Unaccredited courses do not generate Level 2 qualifications, but they may equip adults with the personal and social confidence as well as other necessary skills to progress to more challenging accredited courses, especially if appropriate guidance is available.

\section{Wider benefits of academic and vocational courses leading to accreditation}

Although we find little evidence for health and social capital returns to taking vocational courses, the economic returns to participation are likely to be relatively more important than the wider benefits for these courses. It is worrying, then, that the recent research from the Centre for the Economics of Education (Jenkins et al., 2002) did not find supporting evidence for such returns to vocational courses. In contrast, taking academic courses is associated with substantial changes in social and political attitudes that positively contribute to social capital. Haegel similarly reports that academic learning has a much larger impact on racial tolerance than vocational learning (1999).

Although positive changes in social and political attitudes contribute to social capital, we should not make inferences about how changed attitudes translate into behaviour changes. For example, we find that taking academic courses increases political interest and reduces political cynicism, but taking the same courses is not associated with joining more organisations or positive voting behaviour. Roedigger (2002, pp.12-13) suggests that shifts in attitudes towards race tolerance may not be reflected by changes in racist practices. He cites segregated housing as one example. The economic advantages and social status that may come with academic success may be associated with choices to live in areas that are predominantly white, to send children to predominantly white schools, and to work in occupations that are also predominantly white.

More work is required in order to clarify the relationship between our assessments of race tolerance and behaviour. That said, although expressed attitudes are not the only element of racist behaviour and apparently tolerant attitudes may mask institutional racism, nonetheless attitudes are also fundamental to creating change and so this finding should not be underplayed.

\section{Effects of participation in adult learning on wellbeing}

Our findings suggest a very complex and interesting pattern of associations in relation to wellbeing. We find positive and negative effects, but these vary depending on the course type and the characteristics of the participant. We suggest that participation in adult learning has the potential to sustain and improve wellbeing, but that it also carries an element of risk. In order to maximise the benefits and minimise the risks, adequate support must be available, especially for those who face obstacles to success and who enrol as a result of programmes designed to widen participation. This point was also made by practitioners surveyed by the Centre in collaboration with the LSDA (Preston \& Hammond 2002, 2003). 
It may seem surprising that we find a positive effect of taking leisure courses on the chances of becoming depressed, for all members of the cohort, regardless of previous qualifications. The WBL's earlier fieldwork programme reported in Schuller et al. (2002) found that many respondents took leisure courses at times when they were psychologically at a low ebb. They took leisure courses as a form of distraction or escape. Participation, particularly in leisure courses, provided structure and routine without high levels of investment or commitment. Those who chose to take part in the fieldwork programme gave very positive accounts of participation sustaining and often transforming their psychological health and consequently other areas of their lives. Our findings suggest that the fieldwork findings were not representative in a statistical sense. Indeed, they never claimed to be. Although it may be the case that there is a selection bias in who takes leisure courses (those tending towards depression being more likely to participate), on average, participants do not benefit in terms of protecting their mental health. Taking leisure courses may be particularly effective in providing a stepping stone for those in danger of social exclusion, but it appears that they are less effective in terms of protecting mental psychological health.

Another interesting finding is the contrast between i) the normatively negative effect of taking academic courses for those with below Level 2 qualifications, and ii) the normatively positive effect of taking vocational courses for the same group. The size of the normatively negative effect is substantial. For those with below Level 2 qualifications at age 33, taking each academic course between the ages of 33 and 42 is associated with two additional adults in one hundred becoming depressed between the ages of 33 and 42. This proportion can be compared to the proportion of adults who took no courses at all between 33 and 42 who are predicted to become depressed over the same period - seven in one hundred.

A plausible explanation may follow from issues of perceived success and failure. All those who report having taken an accredited academic course achieved a qualification. However, evidence from the Centre's fieldwork programme suggests that not all those who achieve qualifications feel positive about their experience because the level of success achieved does not meet their expectations (Schuller et al., 2002). The accounts of respondents also demonstrated that for those who had previously failed in education, repeated failure in adulthood had very negative effects upon confidence in most areas of respondents' lives. Such an experience is probably more common amongst those with low levels of qualification to start with, and may be particularly common in relation to academic as opposed to vocational courses because they are more reminiscent of early experiences of school.

If perceived failure is the channel through which academic learning leads to depression, then this highlights the need for support for those with low levels of qualifications, who are often the target for initiatives aimed at widening participation. In addition, the difference between the estimated effects of vocational and academic courses also suggests that pedagogies and curricula that differ markedly from those experienced during early schooling may be more effective in terms of sustaining and 
improving psychological health for adults who did not achieve qualifications during their initial education. We hope to investigate these hypotheses in future work of the Centre. 


\section{References}

Adorno, T.W., Frenkel-Brunswik, E., Levinson, D.J. \& Sanford, R.N. (1950) The authoritarian personality. (New York: Harper)

Aldridge F., Tuckett, A. (2001) Winners and losers in an expanding system. (Leicester: NIACE)

Alexander, T. and Clyne, P. (1995) Riches Beyond Price: Making the Most of Family Learning, NIACE : Leicester

Becker, G.S. (1964) Human Capital, Chicago, IL: University of Chicago Press

Becker, G.S. \& Becker, G.N. (1996) The Economics of Life. (McGraw-Hill)

Behrman, J. \& Stacey, N. (1997), The Social Benefits of Education, Ann Arbor: University of Michigan Press.

Beinart, S. \& Smith, P. (1998) 'National Adult Learning Survey 1997'. DfES Research Report 49.

Bourdieu,P. (1973) Cultural reproduction and social reproduction, in: R.Brown (ed.) Knowledge, Education and Cultural Change, (London, Tavistock).

Bynner, J., Dolton, P., Feinstein, L., Makepeace, G., Malmberg, L., Woods, L. (2003) Revisiting the Benefits of Higher Education. London: The Smith Institute.

Downloadable from http://www.hefce.ac.uk/Pubs/RDreports/Downloads/report25.htm

Bynner, J. and Ashford, S. (1994) Politics and Participation : Some Antecedents of Young People's Attitudes to the Political System and Political Activity, European Journal of Social Psychology, 24 : 223-236

Bynner, J. \& Egerton, M. (2001) 'The wider benefits of higher education', London: HEFCE Report, 01/46

Campbell, C. and Mzaidume, Z. (2001) 'Grassroots participation, peer education, and HIV prevention by sex workers in South Africa' Amerian Journal of Public Health, 91(12): 1978-86.

Campinelli, P. and Channell, J. (1996) The Conceptualisation of Qualifications by Individuals, DfES Research Studies, 9 : HMSO

Clarke, Harold, and Alan C. Acock. (1989). National elections and political attitudes: the case of political efficacy. British Journal of Political Science, 19, 551-562 
Coare, P. and Thomson, A. (1996) Through the Joy of Learning : Diary of 10,000 Adult Learners, NIACE : Leicester

Côté, J.E (2002) The role of identity capital in the transition to adulthood: The individualisation thesis examined. Journal of Youth Studies, 5(2), 2002, 117-134

Cox, R. and Pascall, G. (1994) 'Individualism, self-evaluation and self-fulfilment in the experience of mature women students'. International Journal of Lifelong Education, 13 (2), 159-173.

Dench, S. and Regan, J. (1998) 'Learning in Later Life: Motivation and Impact.' Institute for Employment Studies.

Department for Education and Employment (1998) The Learning Age, Cm 3790. London: The Stationery Office

Diener, E. (2000) "Subjective well-being: The science of happiness and a proposal for a national index", American Psychologist, 55,34-43.

Dore, R. (1976) Human Capital Theory: the Diversity of Societies and the Problem of Quality in Education, Higher Education, 5 : 79-102

Ellison, G. (1999) 'Is there more to the 'relative income hypothesis' than simply a statistical artifact?" Social Biology and Human Affairs, 64(1), 12-23.

Emler, N. and Fraser, E. (1999) "Politics, the education effect". Oxford Review of Education. 25 (1\&2), 251-273

Evans, K. and Rainbird, H. (2002) The Significance of Workplace Learning for a 'Learning Society' in Evans,K., Hodkinson,P. and Unwin,L. (2002) Working to Learn : Transforming Learning in the Workplace (London : Kogan Page)

Feinstein, L. (2002) "Quantitative estimates of the social benefits of learning, 2: Health (depression and obesity)" Wider Benefits of Learning Research Report No.6. London: Centre for Research on the Wider Benefits of Learning.

Foster, P., Howard, U. and Reisenberger, A. (1997) A Sense of Achievement: Outcomes of Learning. London: LSDA

Green, F. (1999) "Training the Workers", in P.Gregg \& J.Wadsworth, "The State of Working Britain," Manchester University Press.

Hagendoorn, L. (1999) Introduction, in Hagendoorn, L. and Nekuee, S. (1999) Education and Racism: A Cross National Inventory of Positive Effects of Education on Ethnic Tolerance (Aldershot : Ashgate) 
Hall, P. (1999) Social capital in Britain, British Journal of Political Science, 29 : 417461

Haegel, F. (1999) The Effect of Education on the Expression of Negative Views Towards Immigrants in France: The Influence of the Republican Model Put to the Test, in Hagendoorn, L. and Nekuee, S. (1999) op. cit. Hall

Hammond, Cathie (2002a) "Learning to be Healthy", Wider Benefits of Learning Papers: No.3, London: Institute of Education.

Hammond, Cathie (2002b) "What is it about education that makes us healthy? Exploring the education-health connection", International Journal of Lifelong Education, 21(06), pp.551-571.

Hammond, Cathie (2003) "How education makes us healthy", London Review of Education, 1(1), pp.61-78.

Hillage, J., Uden, T., Aldridge, F., Eccles, J. (2000) Adult Learning in England: A Review, IES Report 369, Institute of Employment Studies.

Jenkins, A., Vignoles, A., Wolf, A. and Galindo-Rueda, F. (2002) The Determinants and Effects of Lifelong Learning, CEE Discussion Paper No. 19

Kickbusch, I. (1990) “A Strategy for Health Promotion”. Copenhagen: WHO Regional Office for Europe.

Kohn, Melvin L. (1990) "Unsolved Issues in the Relationship Between Work and Personality." Pp. 36-68 in The Nature of Work, edited by K. Erikson and S.P. Vallas, New Haven, CT: Yale University Press.

Kohn, Melvin L. and C. Schooler, in collaboration with J. Miller, K.A. Miller, C. Schoenbach, and R. Schoenberg. (1983) "Work and Personality: An Inquiry into the Impact of Stratification". Norwood, NJ: Ablex.

La Valle, Ivana; Blake, Margaret "National Adult Learning Survey, 2001." Downloadable from the DFES website.

Lines, A., Sims, D., Powell, R., Mann, P., Dartnell, L., Spielhofer. (2003) 'Bigger Pictures, Broader Horizons: Widening Access to Adult Learning in the Arts and Cultural Sectors' DfES Research Report 394

MacMahon, W. (2002) Conceptual Framework for the Analysis of the Social Benefits of Lifelong Learning, Education Economics, 6:3, pp.309-345

McGivney, V. (1990), The Women's Education Project: An evaluation, Women's Education Project, Belfast and NIACE REPLAN. 
McGivney, V. (1997), Evaluation of the Gloucester Primary Health Care Project, GLOSCAT, unpublished report.

McGivney, V. (1999) Informal Learning in the Community : A Trigger for Change and Development (Leicester : NIACE)

Monks, J., Bie Nio Ong (2002) "Social Capital and Organisations: A Survey of Nottingham SARP. Process Evaluation”, Keele University, downloadable from www.phel.gov.uk/sarpdocs/nott_eval_org.pdf

Montgomery, S.M. and Schoon, I. (1997) "Health and Health Behaviour", In J. Bynner, E. Ferri and P. Shepherd (eds), Getting on, getting by, getting nowhere. Aldershot: Dartmouth

Nie, N., Junn, J., Stehlik-Barry, K, (1996). Education and Democratic Citizenship in America. (University of Chicago Press)

Preston, J. and Hammond, C. (2002) "The Wider Benefits of FE : Practitioner Views" Wider Benefits of Learning Research Report No.1. London: Centre for Research on the Wider Benefits of Learning.

Preston, John; Hammond, Cathie (2003) "Practitioner views on the Wider Benefits of Further Education", Journal of FE and HE, 27(2), pp.211-222.

Putnam, R.D. (2000) Bowling alone: the collapse and revival of American community. New York: Simon \& Schuster.

Roedigger, D.R. (2002) Colored White (University of California Press, Berkeley, Los Angeles, London)

Rutter, M., Tizard, J. \& Whitmore, K. (1970) "Education, health and behaviour". London: Longmans.

Sargant, N. (2000) "The Learning Divide Revisited: A Report on the Findings of a UK-wide Survey on Adult Pariticpation in Education and Learning". NIACE

Schuller, T., Brassett-Grundy, A., Green, A., Hammond, C. and Preston, J. (2002) Learning, Continuity and Change in Adult Life, Wider Benefits of Learning Research Report No.3. Centre for Research on the Wider Benefits of Learning.

Shepherd, P. (1993) “Appendix 1: Analysis of response bias”. In Ferrie, E. (ed) Life at 33: the fifth follow-up of the National Child Development Study. Pp.184-187.

National Children's Bureau, City University, Economic and Social Research Council. 
Thompson, J. (2002) Community Education and Neighbourhood Renewal, NIACE : Leicester

Unwin, L. (1999) "Flower Arranging's Off but Floristry is On” : Lifelong Learning and Adult Education in Further Education Colleges' in Green,A. and Lucas,N. (eds.) FE and Lifelong Learning : Realigning the Sector for the Twenty-First Century (London : Institute of Education)

Variyam, J.N., Blaycock, J., Smallwood, D. (2002) "Characterizing the distribution of macronutrient intake among U.S. adults: a quantile regression approach", American Journal of Agricultural Economics, 84(2), 454-466.

Verbeck, G. and Scheepers, P. (1999) Education, Attitudes towards Ethnic Minorities and Opposition to Affirmative Action, in Hagendoorn,L. and Nekuee,S. (1999) op cit

Wagner, U. and Zick, A. (1995) "The relation of formal education to ethnic prejudice: its reliability, validity and explanation". European Journal of Social Psychology, 25 (1), 41-56.

Wilkinson, R.G. (1996) “Unhealthy societies : the afflictions of inequality.” London: Routledge.

Wolfe, Alan. "Developing Civil Society: Can the Workplace Replace Bowling?" The Responsive Community (Spring 1998): 41-47. 


\section{Appendices}

Appendix 1

Response bias $\quad 87$

Appendix 2

The adult learning variables $\quad 88$

Appendix 3

The Malaise Inventory

93

Appendix 4

Raw differences in outcomes by academic

educational level 94

Appendix 5

Dealing with selection bias 95

Appendix 6

Control variables used in regression analysis

Appendix 7

Results from regressions using different control sets 100

Appendix 8

Estimating the impact of shocks between 33 and $42 \quad 104$

Appendix 9

Estimating the impact of selection bias

105

Appendix 10

Regression results, not including interaction terms

Appendix 11

Regression results with interaction term for gender

and prior qualifications included

\section{List of Appendix Tables and Figures}

Appendix Table 2.1 Definitions of adult learning variables

Appendix Table 4.1

Raw differences in outcomes at 33, by academic education

Appendix Table 6.1

Summary statistics for control variables included in the regressions

Appendix Figure 6.1

The level of alcohol consumption at 33 graphed against the change between 33 and 42

Appendix Table 6.2

Lagged dependent variable control set

Appendix Table 7.1

Summary statistics for potential controls

101

Appendix Table 7.2

Change in effect estimates as control set variables are introduced

Appendix Table 7.3 Change in effect estimates as control set variables are introduced step-wise

Appendix Table 8.1 Variables used to measure changes in life circumstances between 33 and 42

Appendix Table 8.2 Estimated effects of participation - model includes life changes between 33 and 42

Appendix Table 9.1 Description of variables used to model the determinants of participation in learning at age 42

Appendix Table 10.1 The separate effects of different course types

Appendix Table 10.2

Sizes of estimated effects of taking one or two courses relative to predicted changes for those who took no courses

Appendix Table 10.3

Non-linear effects of academic accredited courses

Appendix Table 10.4 Non-linear effects of vocational accredited courses 
Appendix Table 11.2 Estimated effects of participation in different types of courses by gender

Appendix Table 11.3 Estimated effects of participation by level of highest qualification at age 33

Appendix Table 11.4 Estimated effects of participation in different types of courses by qualifications at age 33 


\section{Appendix 1: Response bias}

For the analyses presented here we use data relating only to those individuals who participated in the two most recent sweeps of the NCDS, that is, sweeps 5 and 6. These individuals comprise just $57 \%$ of the original sample of babies surveyed in 1958. We must therefore ask to what extent our sample represents this cohort growing up in Britain.

The Centre for Longitudinal Studies, which is responsible for the NCDS has assessed the impact of response bias for recent sweeps, including the fifth. These analyses have not yet been completed for the most recent sweep (the sixth).

Shepherd (1993) compares the characteristics of those participating in the fifth sweep of the NCDS with the characteristics of adults born during the same time period who participated in other surveys such as the General Household Study and the National Expenditure Survey. He concludes that characteristics - relating to marital status, gross weekly pay, housing tenure and ethnicity - of those who responded to each survey are broadly similar. We can conclude from this finding that those sampled in the fifth sweep of the NCDS are similar to those sampled in other national surveys, but we should not infer that these surveys are therefore free from response bias. It is more likely that the surveys suffer from similar patterns of response.

Comparisons between participants in the fifth sweep of the NCDS and cohort members not participating in the fifth sweep but participating in earlier sweeps provide additional information about the nature of response bias ${ }^{34}$. These comparisons reveal a pattern similar to that reported in analyses of response bias for earlier sweeps. Shepherd concludes that differences between the characteristics of participants and non-participants in the fifth sweep are for the most part very small, although for those characteristics that are rare to start with, response bias may nevertheless be important. He summarises the most important aspects of response bias in the fifth sweep as follows:

"Losses are greatest for the ethnic minority and immigrant groups, appearing to be most marked for those reported as Afro-Caribbean in appearance and immigrants from the West Indies. They [results of analyses] also suggest an under-representation of: low-achievement groups (for example, those with low test scores); those with low aspirations (for example, those who did not intend to stay on at school, or to engage in post-school study); those who are 'handicapped'; those with origins in the lower social classes; and those brought up under poorer housing conditions" (Shepherd, 1993: 186).

\footnotetext{
${ }^{34}$ This is an advantage of longitudinal datasets. The potential to measure the effects of response bias apply directly to the longitudinal dataset, but can also be applied indirectly to assess the impact of response bias in other survey data. Note however that there remains an element of response bias which we cannot investigate because a proportion of individuals who fall within the sampling frame may never have responded. For the NCDS, this proportion is actually very small indeed: $98 \%$ of the original sampling frame responded to the first sweep of the NCDS.
} 
The issue that we need to consider here is whether participants in sweeps 5 and 6 of the NCDS differ systematically from non-participants who were nevertheless in the sampling frame in terms of learning effects on health and social capital. Results reported in Section 6.3 suggest that the impact of adult learning on those with below Level 2 qualifications at age 33 are on the whole the same as or perhaps slightly greater than they are for the rest of the sample. One of the effects of response bias is to exclude cohort members most likely to fall into this category. This suggests that the result of any response bias may be that we slightly underestimate the effects of participation in adult learning on health and social capital, as applied to the total population of adults born in 1958 and growing up in Britain.

\section{Appendix 2: The adult learning and outcome variables}

\section{A2.1 Adult learning variables}

The measure of adult learning available in our data is a self-report of participation in adult learning between the ages of 33 and 42 for individuals aged 42 in 2000. This excludes participation in learning at the time of the survey. The data include information on participation in adult learning in terms of seven categories as shown in Appendix Table 2.1.

Note that the first two categories, which refer to taking courses leading to qualifications include only participation that resulted in qualifications. Taking courses designed to lead to qualifications but which did not result in the cohort member obtaining a qualification is not included in our measures of participation in learning. The effects of participation where cohort members fail to obtain a qualification may be very different from the effects of participation where they do, and will be investigated further by the WBL Centre.

Note that courses leading to vocational qualifications include both national vocational qualifications (NVQs) and vocationally related qualifications (VRQs). This distinction is made in a DfES briefing on vocational qualifications (Green, 2003). What is relevant here is that the processes involved in obtaining the two types of vocational qualifications are different and therefore we might expect the personal and social benefits of taking these courses to differ also. Typically, NVQs are obtained on the basis of a portfolio of evidence demonstrating competence in a particular occupation, which may be gathered by the learner in isolation from his or her peers. In contrast, VRQs usually give a broader preparation for a wider occupational area and are normally obtained through participation in classes at a Further Education College. The categorisation of vocational accredited courses used here means that our we average the effects of each type of learning. Thus, effects specific to one type of vocational qualification may be masked.

The questions about participation in work-related training and leisure courses follow questions prompting for participation in academic and vocational courses that led to a 
Appendix Table 2.1: Definitions of adult learning variables

Type

Accredited academic

Accredited vocational

Work-based

Leisure

Access

Basic skills

Other govt. training

\section{Source question}

"Have you obtained any of the following qualifications since 1991?,35

"Have you obtained any of the following qualifications since 1991?"36

“Apart from anything else you've already told me about have you done any work-related training provided by an employer which lasted for three days or more since 1991?"

"Have you done any other courses for leisure or interest since 1991?"

"Have you done any courses to improve reading since 1991?"

"Have you done any courses to improve writing since 1991?"

"Have you done any courses to improve maths since 1991?"

"Have you done any Government courses since 1991?"

"Have you done any modern apprenticeships since 1991?"

\section{No of courses}

No of individuals

1354

918

2922

12636

“Have you done any access courses since 1991?”

\footnotetext{
${ }^{35}$ The qualifications listed are: “GCSE, GCSE O Level, CSE, A/S Level, GCE A Level (or S Level), Scottish School Certificate, Higher School Certificate or Scottish School Qualification, Diploma of Higher Education, Degree (e.g. BA, BSc), Other degree level qualification such as graduate membership of professional institutes, Higher degree (e.g. $\mathrm{PhD}, \mathrm{MSc}$ ), Other degree level qualification such as graduate membership of professional institutes, Higher degree (e.g. PhD, MSc), Nursing or other para-medical qualification not yet mentioned, PGCE - Post - graduate Certificate of Education, Other teaching qualification".

${ }^{36}$ The qualifications listed are: "BTEC, BEC, TEC, SCOTTEC, or SCOTVEC First / General Certificate, First / General Dipoloma, National certificate diploma, Higher certificate diploma, Other BTEC qualification; City \& Guilds Part1, Part2/Craft/Intermediate, Part3/Final/Advanced Craft, Part4/Career Extension/Full technological certificate, Other C\&G qualification; RSA Certificate, First Diploma, Advanced Diploma or certificate, Higher diploma, Other RSA qualification; Pitmans' Level1, Level2, Level3, Other Pitmans qualification; NVQ Level1, Level2, Level3, Level4, Level5, Level6, Trusts towards NVQ/SVQ, Other NVQ; GNVQ Foundation, Intermediate, Advanced, Other GNVQ qualification; ONC/OND; HNC/HND; recognized trade apprenticeships; HGV license; other qualifications".
} 
qualification. For vocational but not academic accredited courses, this includes a category of "Other". Our definitions of work-related training and leisure courses therefore exclude participation in courses that led to vocational qualifications, and most courses leading to academic qualifications.

\section{A2.2 Outcome variables}

\section{Giving up smoking}

At age 33, cohort members were asked the following two questions about their smoking behaviour:

"Do you smoke cigarettes at all nowadays?" (Yes/No)

"How many cigarettes do you smoke every day?"

Those who smoke fewer than one cigarette each day are classified as non-smokers.

At age 42, the following question was asked:

"Would you say that:

1. you've never smoked cigarettes;

2. you used to smoke cigarettes but don't at all now;

3. you now smoke cigarettes occasionally but not every day;

4. you smoke cigarettes every day?"

Those who give answers 1 to 3 are classified as non-smokers.

Those who smoked at both ages are classified as not giving up, and those who smoked at age 33 and not at age 42 were classified as giving up.

\section{Change in alcohol consumption}

At age 33, respondents were asked:

"In the last seven days, that is not counting today but starting from last (NAME PRESENT DAY OF WEEK) how much beer, stout, lager, ale or cider have you had? Spirits or liqueurs? Glasses of wine? Glasses of martini, vermouth, sherry, or similar drinks?"

At age 42, they were asked:

"In the last seven days, that is not counting today but starting from last Day7 Ago how much beer, stout, lager, ale or cider have you had? Gin, whiskey, rum, brandy, vodka or advocate? Glasses of wine? Glasses of martini, vermouth, sherry, port or similar drinks? Bottles of alcopops?" 
Change in alcohol consumption was calculated by subtracting the number of units given at age 42 from the number of units given at age 33 .

\section{Increase in level of exercise taken.}

At age 33, respondents were asked:

"How often do you take part in any activity of this type?(Take part in competitive sport of any sort, go to 'keep fit' or aerobics classes, take part in circuit training, weight training or other repeated exercises - at home or at a gym, go running or jogging, go swimming, go cycling, go for walks, take part in water sports, take part in outdoor sports, go dancing, take part in any other sport or leisure activity which involves physical exercise):

1. every day or most days;

2. 4-5 days a week;

3. 2-3 days a week;

4. once a week;

5. 2-3 times a month;

6. less often."

At age 42, they were asked:

"How often do you take part in any activity of this type? Competitive sport of any kind, go to 'keep fit' or aerobics classes, go running or jogging, go swimming, go cycling, go for walks, take part in water sports, take part in outdoor sports, go dancing, take part in any other sport or leisure activity which involves physical exercise?

$$
\begin{array}{ll}
\text { 1. } & \text { every day; } \\
\text { 2. } & \text { 4-5 days a week; } \\
\text { 3. } & \text { 2-3 days a week; } \\
\text { 4. } & \text { once a week; } \\
\text { 5. } & \text { 2-3 times a month; } \\
\text { 6. } & \text { less often." }
\end{array}
$$

This variable does not apply to respondents who reported exercising most days or every day at age 33 , because it is impossible for this group to report an increase in exercise at age 42 .

\section{Life satisfaction}

As explained in the main text, the measure used for life satisfaction is based upon two items that were asked to respondents at the ages of 33 and 42 . They were asked to give a score between 0 and 10 for : 
- how satisfied they are about "the way their life has turned out so far";

- how satisfied they "expect to be in ten years time".

In each case the score ranged from 0 for completely dissatisfied to 10 for completely satisfied. Life satisfaction at each age is calculated as the mean of the two scores. Change in life satisfaction is taken to be the difference between these scores at ages 33 and 42 . This is then standardised on the norm of the age 33 scores, providing a change variable whose metric is standard deviations of age 33 life satisfaction.

\section{5. and 6. Onset and recovery from depression}

The instrument used to measure depression is the malaise inventory, given in Appendix 3. We define depression as a score of eight or more in this index.

\section{Change in race tolerance}

Our variable for support for race equality is based upon measures at ages 33 and 42 of self-reported agreement on a five-point scale with the following statements:

- "It is alright for different races to get married";

- "I would not mind if a family from another race moved in next door to me";

- "I would not mind if my child went to a school where half the children were of another race";

- "I would not mind working with other races";

- "I would not want a person from another race to be my boss".

\section{Change in political cynicism}

Political cynicism is measured by the level of reported agreement (again on a fivepoint scale) with the statements:

- "None of the political parties would do anything to benefit me";

- "It does not really make much difference which political party is in power in Britain";

- "Politicians are mainly in politics for their own benefit and not for the benefit of the community”.

\section{Change in authoritarian attitudes}

Level of agreement with authoritarian attitudes is measured using level of agreement (along the same five point scale as the previous measures) to six statements, the same at both ages:

- "The law should be obeyed even if a particular law is wrong";

- "For some crimes death penalty is the most appropriate sentence"; 
- "Censorship of films and magazines is necessary to uphold moral standards";

- "People who break the law should be given stiffer sentences";

- "Young people today don't have enough respect for traditional British values";

- "Schools should teach children to obey authority".

\section{Increase in political interest}

Increase in political interest is measured using the difference between self-rated interest at ages 42 and 33 using the following question:

\section{"How interested would you say you are in politics?"}

Answers are given on a scale from 1 (very interested) to 4 (not at all interested). Those who report the maximum score of 1 at age 33 are excluded for this outcome.

\section{Increased memberships}

Increase in civic participation was recorded as 1 (otherwise 0 ) if there had been an increase in the total number of memberships. (Political party, charity/voluntary group (environment), charity/voluntary group (other), women's group, townswomen's guild / women's institute, parents / school organisations, tenants / residents associations). The question asked, which was the same at both sweeps is:

"Are you currently a member of any..."

\section{Voting in $\mathbf{1 9 9 7}$ having abstained in $\mathbf{1 9 8 7}$}

Voting is measured using the same question in each sweep, which is:

"Did you vote in the last general election (DATE)?"

\section{Appendix 3: The Malaise Inventory}

Do you often have a backache?

Do you feel tired most of the time?

Do you often feel miserable or depressed?

Do you often have bad headaches?

Do you often get worried about things?

Do you usually have great difficulty in falling or staying asleep?

Do you usually wake up unnecessarily early in the morning?

Do you wear yourself out worrying about your health?

Do you often get into violent rage?

Do people often annoy or irritate you?

Have you at times had twitching of the face, head or shoulders?

Do you often suddenly become scared for no reason? 
Are you scared to be alone when there are no friends near you?

Are you easily upset or irritated?

Are you frightened of going out alone or meeting people?

Are you constantly keyed up and jittery?

Do you suffer from indigestion?

Do you suffer from an upset stomach?

Is your appetite poor?

Does every little thing get on your nerves and wear you out?

Does your heart often race like mad?

Do you often have bad pains in your eyes?

Are you troubled with rheumatism or fibrosis?

Have you ever had a nervous breakdown?

\section{Appendix 4: Raw differences in outcomes by academic educational level}

Appendix Table 4.1 gives the differences in outcomes between those with qualifications and those without qualifications at age 33. Column 1 lists the outcomes. Column 2 gives the differences for each outcome between those with Level 2 and below qualifications and those with no qualifications. Column 3 gives the probabilities that each estimate is zero. The values in columns 4 and 5 are equivalent to those in columns 2 and 3 , but the comparisons are between those with no qualifications and those with Level 3 and above at age 33 .

Appendix Table 4.1: Raw differences in outcomes at 33, by academic education

\begin{tabular}{|llcccc|}
\hline \multicolumn{1}{|c}{$\begin{array}{c}\text { Level 2 and below } \\
\text { Outcome }\end{array}$} & $\begin{array}{c}\text { Level 3 and above } \\
\text { Difference, } \\
\text { \% points } \\
\text { (1) }\end{array}$ & $\begin{array}{l}\text { P- } \\
\text { value } \\
(3)\end{array}$ & $\begin{array}{l}\text { Difference, } \\
\text { \% points } \\
(4)\end{array}$ & $\begin{array}{l}\text { P- } \\
\text { value } \\
(5)\end{array}$ \\
\hline \hline & Health & & & & \\
1 & Smoker & -0.19 & 0.000 & -0.29 & 0.000 \\
2 & Above median alcohol consumption & -0.01 & 0.611 & 0.06 & 0.000 \\
3 & Exercises at least once per week & 0.08 & 0.000 & 0.17 & 0.000 \\
4 & Above median life satisfaction & -0.01 & 0.687 & -0.04 & 0.008 \\
5 & Depressed & -0.05 & 0.000 & -0.07 & 0.000 \\
& Social capital & & & & \\
7 & Above median race tolerance & 0.00 & 0.929 & 0.21 & 0.000 \\
8 & Above median political cynicism & -0.22 & 0.000 & -0.38 & 0.000 \\
9 & Above median support for authority & 0.00 & 0.759 & -0.21 & 0.000 \\
10 & Interested in politics & 0.17 & 0.000 & 0.38 & 0.000 \\
11 & At least one associational membership & 0.11 & 0.000 & 0.32 & 0.000 \\
12 & Voted in 1987 & 0.10 & 0.000 & 0.16 & 0.000 \\
\hline
\end{tabular}

NOTE: Baseline for comparison is level of outcome for those with no qualifications 


\section{Appendix 5: Dealing with selection bias}

\section{The fixed effects approach}

We are concerned to obtain valid estimates of the effects of adult learning from nonexperimental data. In this context, selection bias is an inherent problem.

This is usefully shown in equation 1 .

$y=\alpha+\delta A+f+u$

where $y$ denotes the outcome that is potentially affected by adult learning and A denotes the experience of adult learning. The terms $f$ and $u$ denote crucial, unobserved determinants of the outcome that we will discuss shortly. It would be standard to also include in this equation a matrix of observed background characteristics that determine the outcome, commonly denoted by X. We exclude this matrix for now to keep the analysis simple but it is straight-forward to extend the analysis to the multivariate case.

The important distinction between $\mathrm{f}$ and $\mathrm{u}$ is that the effect of the former on the outcome (y) is time-invariant, known in the econometrics literature as a fixed effect. It can be thought of as akin to a permanent character trait, for example. The latter component of the error is random and unsystematic, i.e. noise. Whereas the random error can be thought of as uncorrelated with the adult learning variable, the fixed effect cannot. It is likely that a feature of personality that has an impact on an outcome such as voting, may also be correlated with the choice to participate in adult learning.

Failure to deal with the fixed effect will cause confounding bias. To see this imagine that the analyst assumes that equation 2 is the correct model:

$y=\alpha+\delta A+v$

where $v=f+u$

The estimate of $\delta, \hat{\delta}$, that we obtain by ordinary least squares estimation will, by the application of the normal equations, be:

$$
\begin{aligned}
& \hat{\delta}=\delta+\frac{\operatorname{cov}(A, v)}{\operatorname{var}(A)} \\
& =\delta+\frac{\operatorname{cov}(A, f+u)}{\operatorname{var}(A)}=\delta+\text { bias }
\end{aligned}
$$

Since $\operatorname{cov}(A, f) \neq 0$ and $\operatorname{cov}(A, u)=0$, the resulting bias will be given by:

$$
\text { bias }=\frac{\operatorname{cov}(A, f)}{\operatorname{var}(A)} \neq 0
$$


As stated in the text, the correlation of the participation in adult learning and the unobserved fixed effect causes bias to the estimated adult learning coefficient. This follows from the three causes of confounding bias, all three of which are necessary in combination if confounding bias is to occur:

1. A variable is omitted. In our example it is the fixed effect, $\mathrm{f}$, that is omitted because it is unobserved;

2. The omitted variable is correlated with the outcome, $\operatorname{cov}(y, f) \neq 0$;

3. The omitted variable is correlated with the treatment variable, in our case the adult learning variable $A, \operatorname{cov}(A, f) \neq 0$.

These three features must occur in combination if confounding bias is to result. Since we have assumed that the fixed effect enters the outcome equation and is unobserved, confounding bias will result if the third cause holds and the fixed effect is correlated with adult learning. It is this feature of participation that makes selection bias hold ${ }^{37}$. A standard treatment of the fixed effect is to take first differences. If the outcome is observed at two points in time, at age 33 and 42 in our data we can write, reintroducing background characteristics:

$\mathrm{y}_{33}=\alpha+\beta \mathrm{X}+\mathrm{f}+\mathrm{u}_{33}$

$\mathrm{y}_{42}=\alpha+\beta \mathrm{X}+\delta \mathrm{A}+\mathrm{f}+\mathrm{u}_{42}$

Taking first differences gives:

$$
\begin{aligned}
\mathrm{y}_{42}-\mathrm{y}_{33}=\Delta \mathrm{y}= & \left(\alpha+\beta \mathrm{X}+\delta \mathrm{A}+\mathrm{f}+\mathrm{u}_{42}\right)-\left(\alpha+\beta \mathrm{X}+\mathrm{f}+\mathrm{u}_{33}\right) \\
& =\delta \mathrm{A}+\mathrm{u}_{42}-\mathrm{u}_{33} \\
& =\delta \mathrm{A}+\varepsilon
\end{aligned}
$$

We introduce a new error term notation, $\varepsilon$, for simplicity. It is random noise, as before.

By taking first differences we remove the fixed effect and subject to the assumptions of the model have dealt with selection bias. We can now estimate an unbiased version of $\hat{\delta}$ by regressing the change in outcomes on the level of experience of adult learning between the ages of 33 and 42 .

\section{Remaining selection bias}

The key assumption made was that the fixed effect on the outcome (y) was timevariant. If the unobserved aspect actually changes over time then it will not be removed by taking first differences and bias will remain. This is important in the

\footnotetext{
${ }^{37}$ In this discussion, we describe the bias sometimes as confounding bias and sometimes as selection bias. As the analysis should make clear, the two are one and the same in this case.
} 
context of the estimation of the effects of adult learning. It may be, for example, that an individual's motivation undergoes some increase for unobserved reasons. If that increase leads to participation in adult learning and to benefits in terms of the outcome variable then selection bias will result even if the analysis is undertaken in first differences. That is because rather than a fixed effect, we now have an unobserved, time-varying covariate ${ }^{38}$. Denoting this attitudinal variable by $z$, the true model becomes:

$\mathrm{y}_{33}=\alpha+\beta \mathrm{X}+\mathrm{z}_{33}+\mathrm{u}_{33}$

$\mathrm{y}_{42}=\alpha+\beta \mathrm{X}+\delta \mathrm{A}+\mathrm{z}_{42}+\mathrm{u}_{42}$

Taking first differences now gives:

$\Delta \mathrm{y}=\delta \mathrm{A}+\Delta \mathrm{z}+\varepsilon$

and estimating $\Delta y=\delta \mathrm{A}+\varepsilon$ as before gives bias as follows:

$=\delta+\frac{\operatorname{cov}(A, \Delta z+\varepsilon)}{\operatorname{var}(A)}=\delta+$ bias

where

bias $=\frac{\operatorname{cov}(A, \Delta z)}{\operatorname{var}(A)}$

To the extent that the change in attitude (motivation) is correlated with the participation decision as well as changes in outcomes, bias will result in the first difference model.

\section{Appendix 6: Control variables used in regression analysis}

Appendix Table 6.1 summarises the control variables included in the models used to estimate effects of adult learning on the twelve outcome variables.

\footnotetext{
${ }^{38}$ In addition to changing personality traits, permanent characteristics may also have effects on the outcomes that vary over time. For example, the effect of gender (a permanent characteristic) on civic participation may be different before and after parenthood.
} 
Appendix Table 6.1: Summary statistics for control variables included in the regressions.

\begin{tabular}{lcc} 
Variable & $\begin{array}{c}\text { \% for binary, mean for } \\
\text { continuous variables }\end{array}$ & $\begin{array}{l}\text { Some totals } \\
\%\end{array}$ \\
\hline Lagged dependent variables (see & & \\
Appendix Table 6.2) & 52 & 100 \\
\hline Male & 48 & \\
Female & 0 & \\
Gender missing & 14 & \\
\hline No academic qualifications at 33 & 18 & \\
Academic level 1 at 33 & 41 & \\
Academic level 2 at 33 & 11 & \\
Academic level 3 at 33 & 2 & \\
Academic level 4 at 33 & 11 & \\
Academic level 5 at 33 & 2 & \\
Academic level 6 at 33 & & \\
\hline Academic and vocational levels & 1 & \\
missing at 33 & 44 & \\
\hline No vocational qualifications at 33 & 13 & \\
Vocational nvq1 at 33 & 14 & \\
Vocational nvq2 at 33 & 11 & \\
Vocational nvq3 at 33 & 17 & \\
Vocational nvq4 at 33 & 3 & \\
\hline Social class v at 33 & 15 & \\
Social class iv at 33 & 18 & \\
Social class iiim at 33 & 22 & \\
Social class iii nm at 33 & 31 & \\
Social class ii at 33 & 5 & \\
Social class i at 33 & 6 & \\
Social class missing at 33 & & \\
\hline \hline
\end{tabular}

\section{Lagged dependent variables}

The specifications used to model effects of adult learning are fixed effects models, i.e., the outcome variables are differences between outcomes at ages 33 and 42 . The rationale for this approach is explained in Appendix 5.

In addition, we control for the starting value of the outcome at age 33, what economists call the lagged dependent variable. The one exception is for outcome 12, voting, for which the prior value is subsumed into the outcome. For example, in the regression for outcome 2 , the change in the number of units of alcohol, we include the number of units drunk at 33 as a control in the regression. The importance of this can be seen in Appendix Figure 6.16.1, which graphs the level of units at 33 against the change between 33 and 42 . 


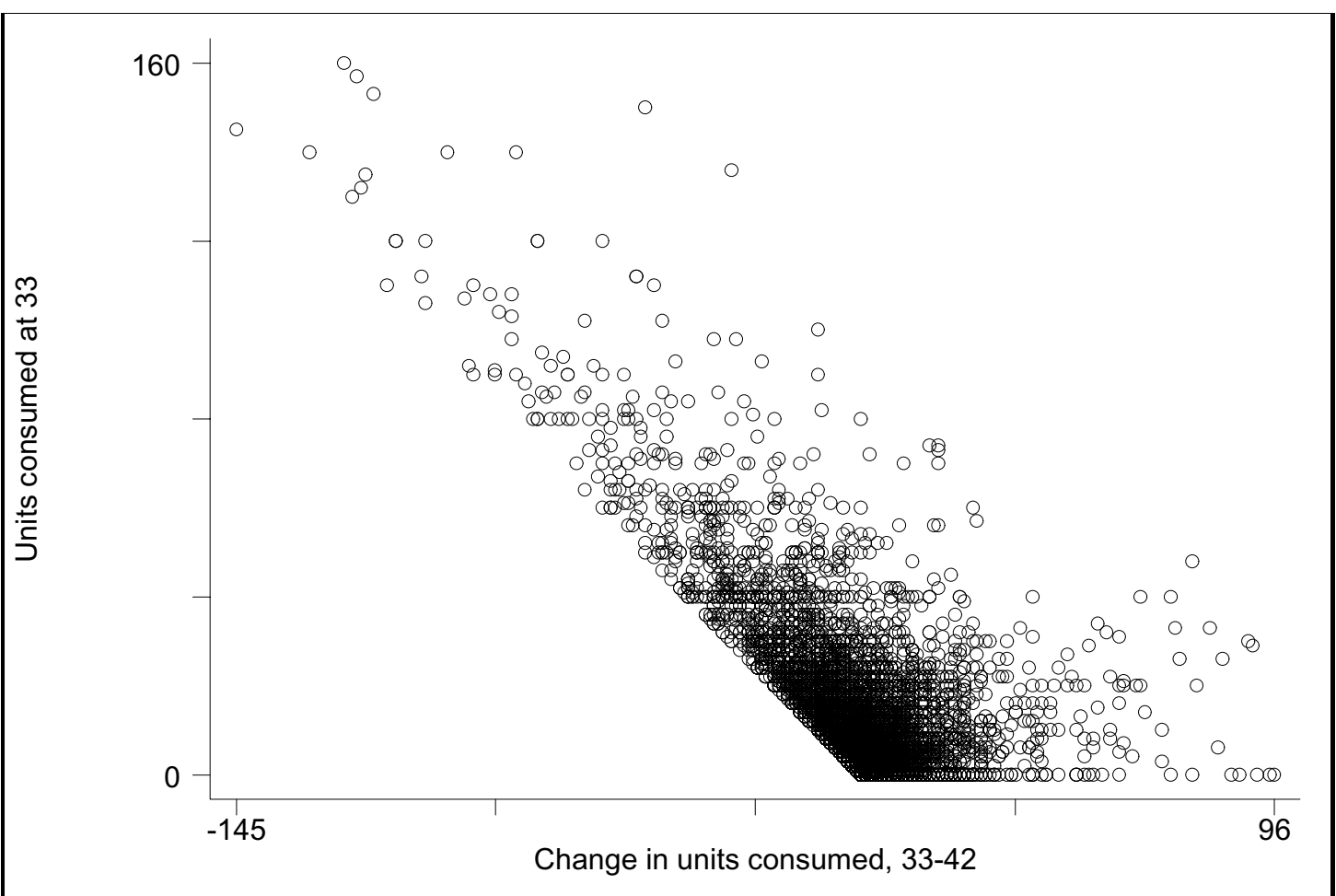

The graph shows the constraint exercised by the fact that the number of units drunk cannot be negative. Therefore, if the number drunk at 33 is low, the change cannot take a highly negative value. This systematic constraint is clearly visible in Appendix Figure 6.1 from the marked 90 degree stratification from the point $[0,0]$; there can be no observations to the left of this line.

Given that our concern is with unbiased estimation of the effects of adult learning, this systematic relation would not matter of itself unless it was correlated with the adult learning variable ${ }^{39}$. If the lagged dependent variable and adult learning were correlated then confounding bias would result in the manner discussed in Section 4 and Appendix 5. By introducing the lagged dependent variable we take account of this enforced constraint, taking out this systematic variation in the data and removing the risk of this kind of bias ${ }^{40}$. The interpretation of effect estimates becomes the effect of adult learning on the change in units consumed given the starting point.

Descriptive statistics for this control set are reported in Appendix Table 6.2.

\footnotetext{
${ }^{39}$ In a multivariate context, this bias-inducing relationship would have to be one conditional on all other covariates.

${ }^{40}$ Some potential bias remains due to possible measurement error in the lagged dependent variable but this is trivial in magnitude.
} 
Health

1 Number of cigarettes smoked per week at 33

$\begin{array}{rrr}16.96 & 1 & 70 \\ 11.06 & 0 & 160 \\ 3.97 & 1 & 7 \\ 8.00 & 0 & 10 \\ 2.37 & 0 & 22\end{array}$

Social capital

7 Race tolerance at 33

$\begin{array}{lll}3.79 & 1 & 5\end{array}$

8 Political cynicism at 33

$\begin{array}{lll}2.82 & 1 & 5\end{array}$

9 Support for authority at 33

$\begin{array}{lll}3.56 & 1 & 5\end{array}$

10 Political interest at 33

2.38

11 Number of memberships at 33

0.26

$1-4$

12 Voting

n.a. n.a. n.a.

\section{Appendix 7: Results from regressions using different control sets}

Sections 5 and 6 summarise the regression findings from the 12 regressions on the 12 outcomes, but they do not include information about the overall fit of the model or the importance of the different control variable sets. In this appendix we give the results of additional regressions used to inform the choice of control variables in our final model.

Appendix Table 7.1 gives details of six sets of variables that we considered including in our model to control for confounding bias.

Appendix Table 7.2 reports the changing values of estimated effects of participation in adult learning as different sets of control variables are introduced into the models. The standard errors associated with each are given in smaller font in rows beneath each estimated effect. Model 1 includes no controls, Model 2 includes the lagged dependent variables. For most outcomes, introducing the lagged dependent variable changes the value of the estimate and increases its precision. Therefore, in subsequent models, we include the lagged dependent variables. Model 3 introduces the variable for gender. We include gender in the final specification because it is highly plausible that gender affects changes in most of the outcome variables. Models 4, 5, 6, and 7 include the lagged dependent variable, the gender variable, plus in each case one additional set of controls. We can see from the results, that each set of controls makes a difference to the estimates and their precision, and that the differences made by each control group are quite similar in magnitude. However, control set 3 reduces the magnitude of the estimates more than any other control set for 10 out of the 12 outcomes. 
Appendix Table 7.1: Summary statistics for potential controls

\begin{tabular}{|c|c|c|c|}
\hline $\begin{array}{l}\text { Control } \\
\text { set }\end{array}$ & Variable & $\begin{array}{l}\text { \% binary, } \\
\text { mean } \\
\text { continuous }\end{array}$ & $\begin{array}{l}\text { Some } \\
\text { totals }\end{array}$ \\
\hline 1 & Lagged dependent variables & $\begin{array}{l}\text { see App.Table } \\
6.2\end{array}$ & \\
\hline 2 & Gender (female) & $48 \%$ & \\
\hline 3 & $\begin{array}{l}\text { Academic \& vocational qualifications } \\
\text { and SES at age } 33\end{array}$ & $\begin{array}{l}\text { See App.Table } \\
6.2 \\
\end{array}$ & \\
\hline 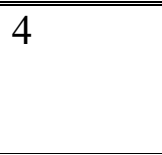 & $\begin{array}{l}\text { Homeowner at } 33 \\
\text { Not homeowner at } 33 \\
\text { Homeowner at } 33 \text { missing }\end{array}$ & $\begin{array}{l}65 \% \\
15 \% \\
20 \%\end{array}$ & $10100 \%$ \\
\hline & $\begin{array}{l}\text { Family income at } 33 \\
\text { Family income at } 33 \text { missing }\end{array}$ & $\begin{array}{l}0.35 \\
30 \%\end{array}$ & \\
\hline 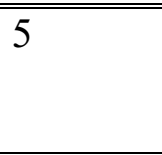 & $\begin{array}{l}\text { Living with partner at } 33 \\
\text { Not living with partner at } 33 \\
\text { Partner at } 33 \text { missing }\end{array}$ & $\begin{array}{l}82 \% \\
18 \% \\
0 \% \\
\end{array}$ & $100 \%$ \\
\hline & $\begin{array}{l}\text { Living with dep child at } 33 \\
\text { Not living with child at } 33 \\
\text { Dependent child } 33 \text { missing }\end{array}$ & $\begin{array}{c}69 \% \\
31 \% \\
0 \% \\
\end{array}$ & $100 \%$ \\
\hline 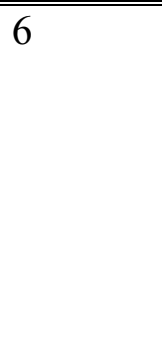 & $\begin{array}{l}\text { Social class v at birth } \\
\text { Social class iv at birth } \\
\text { Social class iiim at birth } \\
\text { Social class iiinm at birth } \\
\text { Social class ii at birth } \\
\text { Social class I at birth } \\
\text { Social class at birth missing }\end{array}$ & $\begin{array}{c}8 \% \\
12 \% \\
46 \% \\
11 \% \\
13 \% \\
4 \% \\
6 \%\end{array}$ & $100 \%$ \\
\hline & $\begin{array}{l}\text { Hardship at age } 11 \\
\text { Hardship at } 11 \text { missing }\end{array}$ & $\begin{array}{c}24 \% \\
0 \%\end{array}$ & \\
\hline & $\begin{array}{l}\text { Hostility at } 11 \text { (standardised) } \\
\text { Hostility at } 11 \text { missing }\end{array}$ & $\begin{array}{l}-0.06 \\
13 \%\end{array}$ & \\
\hline & $\begin{array}{l}\text { Reading score at } 11 \text { (standardised) } \\
\text { Reading score at } 11 \text { missing } \\
\text { Maths score at } 11 \text { (standardised) } \\
\text { Maths score at } 11 \text { missing }\end{array}$ & $\begin{array}{l}0.09 \\
14 \% \\
0.10 \\
13 \%\end{array}$ & \\
\hline & Father not interested child's educn 11 & $16 \%$ & \\
\hline & Father interested child's educn at 11 & $22 \%$ & $100 \%$ \\
\hline & Father v. Interested child's educn 11 & $25 \%$ & \\
\hline & Father over-concerned child's educn 11 & $\begin{array}{l}2 \% \\
35 \%\end{array}$ & \\
\hline & Mother not interested child's educn 11 & $11 \%$ & \\
\hline & Mother interested child's education 11 & $29 \%$ & $100 \%$ \\
\hline & Mother v. Interested child's educn 11 & $33 \%$ & \\
\hline & Mother over-concerned child's educn 11 & $3 \%$ & \\
\hline & Mother's interest child's educn missing & $24 \%$ & \\
\hline
\end{tabular}


Appendix Table 7.2: Change in effect estimates as control set variables are introduced

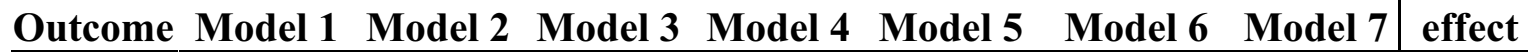

\begin{tabular}{|c|c|c|c|c|c|c|c|c|}
\hline \multirow[t]{2}{*}{1} & 6.75 & 5.84 & 5.31 & 2.92 & 4.05 & 5.08 & 4.18 & 3 \\
\hline & & 2.19 & & & & & & \\
\hline \multirow[t]{2}{*}{2} & 128.78 & 72.28 & 41.73 & 44.23 & 52.71 & 43.08 & 33.97 & 7 \\
\hline & 40.64 & 30.39 & 30.25 & 30.79 & 30.41 & 30.23 & 30.57 & \\
\hline \multirow[t]{2}{*}{3} & -0.32 & 4.52 & 4.61 & 3.78 & 4.18 & 4.57 & 4.15 & 3 \\
\hline & 1.2 & 1.25 & 1.26 & 1.28 & 1.26 & 1.26 & 1.27 & \\
\hline \multirow[t]{2}{*}{4} & 7.62 & 8.57 & 9.62 & 7.44 & 8.62 & 9.51 & 8.43 & 3 \\
\hline & 3.04 & 2.73 & 2.74 & 2.79 & 2.75 & 2.74 & 2.76 & \\
\hline \multirow[t]{2}{*}{5} & -1.29 & -0.25 & -0.14 & 0.54 & 0.3 & -0.02 & 0.23 & 5 \\
\hline & 0.78 & 0.66 & 0.66 & 0.65 & 0.65 & 0.66 & 0.65 & \\
\hline \multirow[t]{2}{*}{6} & 5.4 & 4.97 & 4.95 & 2.13 & 4.16 & 4.67 & 4.48 & 3 \\
\hline & 6.32 & 6.32 & 6.37 & 6.73 & 6.5 & 6.47 & 6.65 & \\
\hline \multirow[t]{2}{*}{7} & 9.5 & 15.54 & 16.01 & 12.94 & 15.42 & 16.04 & 13.62 & 3 \\
\hline & 2.16 & 1.9 & 1.91 & 1.93 & 1.92 & 1.91 & 1.92 & \\
\hline \multirow[t]{2}{*}{8} & 1.42 & -6.32 & -7.66 & -3.25 & -6.58 & -7.54 & -5.06 & 3 \\
\hline & 2.58 & 2.23 & 2.24 & 2.26 & 2.25 & 2.24 & 2.25 & \\
\hline \multirow[t]{2}{*}{9} & -7.89 & -14.52 & -14.86 & -9.2 & -13.53 & -14.55 & -10.96 & 3 \\
\hline & 2.09 & 1.87 & 1.88 & 1.87 & 1.88 & 1.88 & 1.86 & \\
\hline \multirow[t]{2}{*}{10} & 1.06 & 4.24 & 4 & 2.71 & 3.76 & 3.97 & 3.44 & 3 \\
\hline & 1.05 & 1.01 & 1.01 & 1.02 & 1.01 & 1.01 & 1.01 & \\
\hline \multirow[t]{2}{*}{11} & 4.5 & 4.87 & 5.4 & 3.43 & 5.04 & 5.33 & 4.09 & 3 \\
\hline & 0.71 & 0.7 & 0.71 & 0.69 & 0.71 & 0.71 & 0.69 & \\
\hline \multirow[t]{2}{*}{12} & 10.11 & 10.11 & 10.1 & 6.58 & 8.93 & 10.02 & 7.22 & 3 \\
\hline & 3.06 & 3.06 & 3.07 & 3.13 & 3.09 & 3.06 & 3.12 & \\
\hline
\end{tabular}

NOTE: All values multiplied by 1000 for easier comparisons

Model 1: no controls, Model 2: ldv, Model 3: ldv and female,

Model 4: model $3+$ control set 3 (qualifications and SES at 33)

Model 5: model $3+$ control set 4 (home ownership and family income at 33)

Model 6: model $3+$ control set 5 (family status at 33 )

Model 7: model $3+$ control set 6 (childhood indicators)

We include in our final model only the lagged dependent variable, gender, and control set 3, which comprises measures of educational qualifications and socio-economic status at age 33. On the basis of previous research, we would expect this set of controls to affect the outcome variables, and our findings bear this out. We also find that adding additional control sets leads to no substantial change in the estimates of adult learning effects. This is shown in Appendix Table 7.3, which adds control sets step-wise. 
Appendix Table 7.3: Change in effect estimates as control set variables are introduced step-wise

Outcome Model 1 Model 2 Model 3 Model 4 Model 5 Model 6 Model 7

Control set that makes most difference to estimated

\begin{tabular}{c|cccccccc|c}
\hline \hline 1 & 6.75 & 5.84 & 5.31 & 2.92 & 4.05 & 5.08 & 4.18 & $\mathbf{3}$ \\
& $\mathbf{2 . 1 8}$ & $\mathbf{2 . 1 9}$ & $\mathbf{2 . 1 9}$ & $\mathbf{2 . 2 6}$ & $\mathbf{2 . 2 1}$ & $\mathbf{2 . 1 9}$ & $\mathbf{2 . 2 2}$ & \\
\hline 2 & 128.78 & 72.28 & 41.73 & 44.23 & 52.71 & 43.08 & 33.97 & $\mathbf{7}$ \\
& $\mathbf{4 0 . 6 4}$ & $\mathbf{3 0 . 3 9}$ & $\mathbf{3 0 . 2 5}$ & $\mathbf{3 0 . 7 9}$ & $\mathbf{3 0 . 4 1}$ & $\mathbf{3 0 . 2 3}$ & $\mathbf{3 0 . 5 7}$ & \\
\hline \multirow{2}{*}{3} & -0.32 & 4.52 & 4.61 & 3.78 & 4.18 & 4.57 & 4.15 & $\mathbf{3}$ \\
& $\mathbf{1 . 2}$ & $\mathbf{1 . 2 5}$ & $\mathbf{1 . 2 6}$ & $\mathbf{1 . 2 8}$ & $\mathbf{1 . 2 6}$ & $\mathbf{1 . 2 6}$ & $\mathbf{1 . 2 7}$ & \\
\hline 4 & 7.62 & 8.57 & 9.62 & 7.44 & 8.62 & 9.51 & 8.43 & $\mathbf{3}$ \\
& $\mathbf{3 . 0 4}$ & $\mathbf{2 . 7 3}$ & $\mathbf{2 . 7 4}$ & $\mathbf{2 . 7 9}$ & $\mathbf{2 . 7 5}$ & $\mathbf{2 . 7 4}$ & $\mathbf{2 . 7 6}$ & \\
\hline \multirow{2}{*}{5} & -1.29 & -0.25 & -0.14 & 0.54 & 0.3 & -0.02 & 0.23 & $\mathbf{5}$ \\
& $\mathbf{0 . 7 8}$ & $\mathbf{0 . 6 6}$ & $\mathbf{0 . 6 6}$ & $\mathbf{0 . 6 5}$ & $\mathbf{0 . 6 5}$ & $\mathbf{0 . 6 6}$ & $\mathbf{0 . 6 5}$ & \\
\hline 6 & 5.4 & 4.97 & 4.95 & 2.13 & 4.16 & 4.67 & 4.48 & $\mathbf{3}$ \\
& $\mathbf{6 . 3 2}$ & $\mathbf{6 . 3 2}$ & $\mathbf{6 . 3 7}$ & $\mathbf{6 . 7 3}$ & $\mathbf{6 . 5}$ & $\mathbf{6 . 4 7}$ & $\mathbf{6 . 6 5}$ & \\
\hline 7 & 9.5 & 15.54 & 16.01 & 12.94 & 15.42 & 16.04 & 13.62 & $\mathbf{3}$ \\
& $\mathbf{2 . 1 6}$ & $\mathbf{1 . 9}$ & $\mathbf{1 . 9 1}$ & $\mathbf{1 . 9 3}$ & $\mathbf{1 . 9 2}$ & $\mathbf{1 . 9 1}$ & $\mathbf{1 . 9 2}$ & \\
\hline \multirow{2}{*}{8} & 1.42 & -6.32 & -7.66 & -3.25 & -6.58 & -7.54 & -5.06 & $\mathbf{3}$ \\
& $\mathbf{2 . 5 8}$ & $\mathbf{2 . 2 3}$ & $\mathbf{2 . 2 4}$ & $\mathbf{2 . 2 6}$ & $\mathbf{2 . 2 5}$ & $\mathbf{2 . 2 4}$ & $\mathbf{2 . 2 5}$ & \\
\hline 9 & -7.89 & -14.52 & -14.86 & -9.2 & -13.53 & -14.55 & -10.96 & $\mathbf{3}$ \\
& $\mathbf{2 . 0 9}$ & $\mathbf{1 . 8 7}$ & $\mathbf{1 . 8 8}$ & $\mathbf{1 . 8 7}$ & $\mathbf{1 . 8 8}$ & $\mathbf{1 . 8 8}$ & $\mathbf{1 . 8 6}$ & \\
\hline 10 & 1.06 & 4.24 & 4 & 2.71 & 3.76 & 3.97 & 3.44 & $\mathbf{3}$ \\
& $\mathbf{1 . 0 5}$ & $\mathbf{1 . 0 1}$ & $\mathbf{1 . 0 1}$ & $\mathbf{1 . 0 2}$ & $\mathbf{1 . 0 1}$ & $\mathbf{1 . 0 1}$ & $\mathbf{1 . 0 1}$ & \\
\hline 11 & 4.5 & 4.87 & 5.4 & 3.43 & 5.04 & 5.33 & 4.09 & $\mathbf{3}$ \\
& $\mathbf{0 . 7 1}$ & $\mathbf{0 . 7}$ & $\mathbf{0 . 7 1}$ & $\mathbf{0 . 6 9}$ & $\mathbf{0 . 7 1}$ & $\mathbf{0 . 7 1}$ & $\mathbf{0 . 6 9}$ & \\
\hline 12 & 10.11 & 10.11 & 10.1 & 6.58 & 8.93 & 10.02 & 7.22 & $\mathbf{3}$ \\
& $\mathbf{3 . 0 6}$ & $\mathbf{3 . 0 6}$ & $\mathbf{3 . 0 7}$ & $\mathbf{3 . 1 3}$ & $\mathbf{3 . 0 9}$ & $\mathbf{3 . 0 6}$ & $\mathbf{3 . 1 2}$ & \\
\hline
\end{tabular}

NOTE: All values multiplied by 1000 for easier comparisons

Model 1 - no controls

Model 2 - lag dependent variable for each outcome

Model 3 - Model 2 plus gender

Model 4 - Model 3 plus socio-economic class and qualifications at 33

Model 5 - Model 4 plus additional income variables at 33

Model 6 - Model 5 plus family structure at 33

Model 7 - Model 6 plus early years variables

Standard errors are given beneath estimates in small font.

See Appendix Table 7.1 for full description of control sets.

As we have already noted, for most outcomes, introducing the lagged dependent variable increases the magnitude and precision of the effect estimate. These are further changed as gender and the first additional control set are added (Model 4). As additional control sets are added, the estimates and their standard errors are not on the whole very much affected. This suggests that the additional controls included in Models 5, 6, and 7 do not constitute sources of confounding bias remaining after control set 3 has been added to the model and can be excluded from our model. The 
final model, which we use for the regressions described in Sections 5 and 6 is, therefore, Model 4.

\section{Appendix 8: Estimating the impact of shocks between 33 and 42}

We have found evidence that participation in learning between 33 and 42 has effects on changes in outcomes over the same period. We include in our models controls for sources of selection bias up to the age of 33. However, it is also possible that changes in life circumstances after the age of 33 are a source of selection bias. In order to test whether this is so, we repeat some of our analyses including in the specification changes in life circumstances between 33 and 42. The changes included relate to socio-economic status, home ownership status, time spent not in education, employment or training (NEET), and family structure. Full descriptions of these variables are given in Appendix Table 8.1.

Appendix Table 8.1: Variables used to measure changes in life circumstances between 33 and 42

\begin{tabular}{|l|c|}
\hline Variable & \% falling into this category \\
\hline 1-12 months of NEET in last 4 years & 4.4 \\
\hline 13-47 months of NEET in last 4 years & 6.7 \\
\hline 48 months of NEET in last 4 years & 6.3 \\
\hline Partner at 33, no partner at 42 & 8.4 \\
\hline No partner at 33, partner at 42 & 8.0 \\
\hline Child at 33, not at 42 & 5.5 \\
\hline No child at 33, child at 42 & 12.0 \\
\hline SES promotion 33-42 & 15.8 \\
\hline SES demotion 33-42 & 21.3 \\
\hline Not home owner at 33 - home owner at 42 & 6.4 \\
\hline Home owner at 33 - not home owner at 42 & 3.5 \\
\hline
\end{tabular}

We compare estimated effects of participation in learning using two models. The first includes control variables up to the age of 33 only. The second model is an extension of the first and includes additional controls for changes in circumstances between 33 and 42. The results of this comparison are given in Appendix Table 8.2 below.

Column 1 lists the outcome variables. Column 2 gives the estimated effects of participation in adult learning on each outcome predicted by the model that includes only control variables up to the age of 33 . Column 3 gives the $p$-values - the probabilities that these estimates are zero. The values in columns 4 and 5 are equivalent to those in columns 2 and 3 but for the model that includes additional controls for changes in life circumstances between 33 and 42 . 


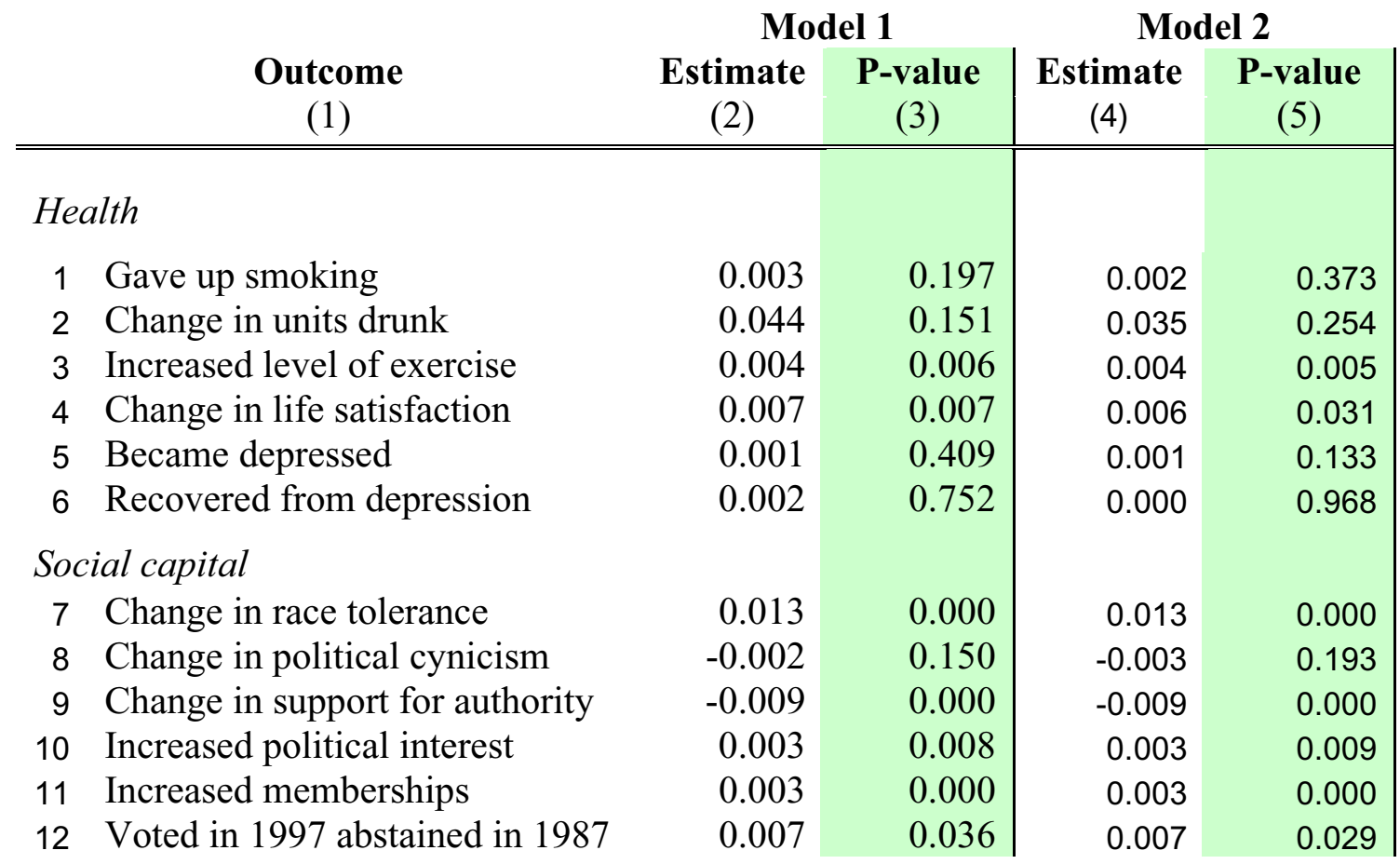

NOTE: Control set for Model 1 includes variables measured up to age 33

Controls set for Model 2 includes all controls in Model 1 with additional variables for changes in life circumstances between 33 and 42

Comparisons of the estimates and their p-values indicate that including in the model changes in life circumstances between 33 and 42 makes very little difference to our results. Therefore, we conclude that there is no evidence that changes in life circumstances between 33 and 42 are a source of selection bias. Neither do they appear to mediate effects of adult learning on health and social capital outcomes.

\section{Appendix 9: Estimating the impact of selection bias}

In this appendix we describe the model specification used to investigate the antecedents of participation in adult learning at 42 . The objective of these investigations is to see whether changes in our outcome variables do indeed precede participation. This would be predicted if one believed that changes in outcomes are not caused by adult learning but in fact precede adult learning. In order to make the analysis compatible with that when we take the outcomes as dependent variables, we control here for the same background characteristics. Details of the variables included are given in Appendix Tables 9.1. The results of the regressions are presented and discussed in Section 5.3.2, where there is also more discussion of the methodological issues. 
Appendix Table 9.1: Descriptions of variables used to model the determinants of participation in learning at age 42

\begin{tabular}{|l|l|}
\hline Variable & $\begin{array}{l}\text { Mean or \% falling into this } \\
\text { category }\end{array}$ \\
\hline Change in outcome & See Tables 1 to 4 \\
\hline Outcome at age 33 & See Appendix Table 6.2 \\
\hline Female & 48.0 \\
\hline No. courses taken between 33 and 42 & 2.19 \\
\hline $\begin{array}{l}\text { No. courses taken between 33 and 42 of type used as } \\
\text { dependent variable }\end{array}$ & See Figure 4 \\
\hline No academic quals at age 42 (baseline) & 16.0 \\
\hline GCSEs below C grade at 42 & 16.3 \\
\hline GCSEs A*-C, AS levels, one A-level at 42 & 37.8 \\
\hline Two or more A-levels at 42 & 9.2 \\
\hline Sub-degree or degree at 42 & 17.7 \\
\hline Higher degree at 42 & 2.8 \\
\hline No vocational quals at 42 (baseline) & 40.2 \\
\hline Vocational level 1 at 42 & 16.6 \\
\hline Vocational level 2 at 42 & 9.7 \\
\hline Vocational level 3 at 42 & 14.4 \\
\hline Vocational level 4 at 42 & 18.8 \\
\hline Social class I at 42 & 4.9 \\
\hline Social class ii at 42 & 34.8 \\
\hline Social class iii manual at 42 & 20.7 \\
\hline Social class iii non-manual at 42 & 18.7 \\
\hline Social class iv at 42 & 12.1 \\
\hline Social class v at 42 (baseline) & 3.4 \\
\hline
\end{tabular}

\section{Appendix 10: Regression results, not including interaction terms}

This appendix presents results not given in the main text relating to the effects of taking four different types of courses: academic, vocational, work-related and leisure.

Appendix Table 10.1 presents results for the four types of course using the linear measure of participation in learning between ages 33 and 42 (total number of courses taken). Appendix Table 10.2 gives the sizes of effects relative to the predicted levels of change for those who took no courses. These values are illustrated in the main text in Tables 10 and 13. Twelve regressions, one for each outcome, were run to generate the results. The model used can be described by the following equation: 
Appendix Table 10.1: The separate effects of different course types

\begin{tabular}{|c|c|c|c|c|c|c|c|c|c|}
\hline $\begin{array}{c}\text { Outcomes } \\
(1) \\
\end{array}$ & \multicolumn{2}{|c|}{ Academic } & \multicolumn{2}{|c|}{ Vocational } & \multicolumn{2}{|c|}{ Work-related } & \multicolumn{2}{|c|}{ Leisure } & $\begin{array}{c}\text { P-value } \\
\text { (10) }\end{array}$ \\
\hline \multicolumn{10}{|l|}{ Health } \\
\hline Gave up smoking & 0.020 & 0.239 & 0.016 & 0.122 & 0.000 & 0.975 & 0.023 & 0.013 & 0.027 \\
\hline Change in units drunk & -0.013 & 0.958 & -0.319 & 0.056 & 0.079 & 0.020 & -0.103 & 0.352 & 0.051 \\
\hline Increased exercise & 0.019 & 0.070 & 0.008 & 0.250 & 0.001 & 0.203 & 0.016 & 0.002 & 0.026 \\
\hline Recovery from depression & 0.015 & 0.738 & 0.036 & 0.174 & 0.001 & 0.882 & -0.014 & 0.495 & 0.474 \\
\hline \multicolumn{10}{|l|}{ Social capital } \\
\hline Change in race tolerance & 0.086 & 0.000 & 0.023 & 0.018 & 0.010 & 0.000 & 0.013 & 0.064 & 0.000 \\
\hline Change pol. cynicism & -0.043 & 0.015 & 0.006 & 0.624 & -0.002 & 0.449 & -0.010 & 0.233 & 0.089 \\
\hline Change authoritarianism & -0.118 & 0.000 & -0.018 & 0.057 & -0.004 & 0.031 & -0.022 & 0.001 & 0.000 \\
\hline
\end{tabular}




$$
\begin{gathered}
\Delta y=\alpha+\sum_{j} \delta_{j} A_{j}+X \mathrm{~B} \\
\text { where: } \quad \begin{array}{c}
\mathrm{y}=\text { change in outcome, } \\
\mathrm{a}=\text { constant, } \\
\mathrm{j}=\text { course type }(\mathrm{ac}, \mathrm{vc}, \mathrm{wk}, \mathrm{s}), \\
\mathrm{A}_{\mathrm{j}}=\text { total number of courses of each type taken, } \\
\delta_{\mathrm{j}}=\text { coefficients for effects of participation in each course type, } \\
\mathrm{X}=\text { matrix of control variables, } \\
\hat{\mathrm{A}}=\text { vector of coefficients for the controls variables. }
\end{array}
\end{gathered}
$$

Column 1 of Appendix Table 10.1 lists the outcomes. Column 2 gives the estimated effects of taking an additional academic course leading to accreditation on each outcome. Column 3 gives the p-values. Columns 4 to 9 give the estimated effects

\begin{tabular}{|c|c|c|c|c|c|c|}
\hline & Outcome & All \% & $\begin{array}{l}\text { Academic } \\
\text { accred. } \\
\% \\
\text { \% } \\
\end{array}$ & $\begin{array}{l}\text { Voc. } \\
\text { accred. } \\
\% \text { (4) } \\
\end{array}$ & $\begin{array}{l}\text { Work- } \\
\text { related \% } \\
(5) \\
\end{array}$ & $\begin{array}{l}\text { Leisure } \\
\% \\
\quad(6) \\
\end{array}$ \\
\hline & \multicolumn{6}{|l|}{ Health } \\
\hline 1 & Gave up smoking & 13.5 & 21.7 & 15.2 & 4.5 & 25.0 \\
\hline 2 & Change in units drunk & 92.3 & -140.7 & 296.7 & 48.5 & 150.2 \\
\hline 3 & Increase in exercise & 3.9 & 15.1 & 1.6 & 3.4 & 14.9 \\
\hline 4 & Change life satisf. & -13.5 & -0.8 & -5.6 & -15.1 & -5.6 \\
\hline 5 & Became depressed & -4.5 & 31.3 & -6.0 & -14.9 & 1.5 \\
\hline 6 & Recovered depression & 9.3 & 19.9 & 26.4 & 9.1 & -13.7 \\
\hline & Social capital & & & & & \\
\hline 7 & Change race toler. & 33.6 & 94.3 & 20.0 & 32.1 & 8.6 \\
\hline 8 & Change pol. cynicism & -9.8 & -2.6 & -5.5 & -7.9 & -3.0 \\
\hline 9 & Change authoritarian & -21.2 & -64.2 & -21.2 & -14.9 & -16.5 \\
\hline 10 & Increased pol. interest & 11.8 & 36.6 & 6.5 & -5.2 & 15.7 \\
\hline 11 & Increased mmbrships & 33.7 & 10.5 & 3.5 & 3.5 & 62.8 \\
\hline 12 & Voted '97 abstained '87 & 12.8 & -6.4 & 5.1 & 10.1 & 12.2 \\
\hline
\end{tabular}
and $p$-values for each vocational accredited, work-related, or leisure course taken. Column 10 gives the p-values that the effects of participation on each outcome are the same regardless of course type. We can see from the values in this column that for all outcomes except recovery from depression we can reject the null hypothesis that the effects of participation are the same for each type of course.

Appendix Table 10.2: Sizes of estimated effects of taking one or two courses ${ }^{41}$ relative to predicted changes for those who took no courses

Appendix Table 10.2 gives the values which are used to generate Table 10 and Table 13. The first column lists the outcomes. Column 2 gives the estimated effect of

41 One course for academic and vocational courses leading to accreditation, one or two courses for work-related training and leisure courses. 
taking one or two courses of any type divided by the predicted level of change for those who took no courses. The proportions are expressed as percentages. Columns 3 to 7 give equivalent percentages for taking one academic or vocational accredited course, and for taking one or two work-related training and leisure courses.

Appendix Tables 10.3 to 10.6 present results for each type of course using the categorical measure of participation. For ease of presentation we report these results in four separate tables but it should be remembered that they have been estimated simultaneously. The model used to generate these results can be described by the following equation:

$$
\begin{aligned}
& \Delta y=\alpha+\sum_{i=1}^{3} \sum_{j} \delta_{i j} D_{i j}+X \mathrm{~B} \\
& \text { where: } \quad \begin{array}{l}
\mathrm{y}=\text { change in outcome, } \\
\dot{\mathrm{a}}=\text { constant, } \\
\mathrm{i}=\text { level of participation, } \\
\mathrm{j}=\text { course type }(\mathrm{ac}, \mathrm{vc}, \mathrm{wk}, 1 \mathrm{~s}), \\
\mathrm{D}_{\mathrm{ij}}=\text { dummies for different levels of participation in each course type, } \\
\delta_{\mathrm{ij}}=\text { coefficients for effects of each level of participation in each course type, } \\
\mathrm{X}=\text { matrix of control variables, } \\
\hat{\mathrm{A}}=\text { vector of coefficients for the controls variables. }
\end{array}
\end{aligned}
$$

Appendix Table 10.3 gives the estimated effects of taking one, two or three and more academic accredited courses. It also gives the p-values for each estimated effect. The final column of the table gives a p-value accumulated over all three levels of participation.

Appendix Tables 10.4, 10.5, and 10.6 give equivalent results for the effects of participation in the other three types of learning. 
Appendix Table 10.3: Non-linear effects of academic accredited courses

\begin{tabular}{|c|c|c|c|c|c|c|c|}
\hline \multirow[b]{2}{*}{ Outcome } & \multicolumn{2}{|c|}{1 course } & \multicolumn{2}{|c|}{2 courses } & \multicolumn{2}{|c|}{$3+$ courses } & \multirow{2}{*}{$\begin{array}{l}\text { P-val no } \\
\text { learning } \\
\text { effect }\end{array}$} \\
\hline & Effect & P-val & Effect & P-val & Effect & P-val & \\
\hline \multicolumn{8}{|l|}{ Health } \\
\hline Gave up smoking & 0.053 & 0.190 & 0.000 & 0.996 & 0.081 & 0.349 & 0.475 \\
\hline Change in units drunk & 0.678 & 0.185 & -0.693 & 0.482 & -0.036 & 0.978 & 0.498 \\
\hline Increased exercise & 0.058 & 0.014 & 0.038 & 0.421 & 0.072 & 0.215 & 0.051 \\
\hline Change life satisfaction & 0.002 & 0.957 & 0.134 & 0.129 & 0.174 & 0.129 & 0.210 \\
\hline Became depressed & 0.021 & 0.069 & 0.031 & 0.184 & -0.005 & 0.856 & 0.181 \\
\hline Recovery depression & 0.077 & 0.465 & -0.088 & 0.678 & -0.006 & 0.973 & 0.863 \\
\hline \multicolumn{8}{|l|}{ Social capital } \\
\hline Changed race tolerance & 0.132 & 0.000 & 0.225 & 0.000 & 0.247 & 0.002 & 0.000 \\
\hline Change pol. cynicism & -0.012 & 0.744 & -0.146 & 0.040 & -0.171 & 0.066 & 0.059 \\
\hline Change authoritarianism & -0.203 & 0.000 & -0.231 & 0.000 & -0.342 & 0.000 & 0.000 \\
\hline Increased pol. interest & 0.056 & 0.002 & 0.125 & 0.001 & 0.106 & 0.025 & 0.000 \\
\hline Increased memberships & 0.009 & 0.462 & 0.006 & 0.802 & 0.030 & 0.338 & 0.677 \\
\hline Voted '97 abstained '87 & -0.030 & 0.551 & 0.113 & 0.281 & 0.169 & 0.198 & 0.355 \\
\hline
\end{tabular}

Appendix Table 10.4: Non-linear effects of vocational accredited courses

\begin{tabular}{|c|c|c|c|c|c|c|c|}
\hline \multirow[b]{2}{*}{ Outcome } & \multicolumn{2}{|c|}{1 course } & \multicolumn{2}{|c|}{2 courses } & \multicolumn{2}{|c|}{$3+$ courses } & \multirow{2}{*}{$\begin{array}{l}\text { P-val no } \\
\text { learning } \\
\text { effect }\end{array}$} \\
\hline & Effect & P-val & Effect & P-val & Effect & P-val & \\
\hline \multicolumn{8}{|l|}{ Health } \\
\hline Gave up smoking & 0.037 & 0.177 & -0.033 & 0.455 & 0.082 & 0.125 & 0.189 \\
\hline Change in units drunk & -1.430 & 0.000 & -0.085 & 0.896 & -0.468 & 0.560 & 0.005 \\
\hline Increased exercise & 0.006 & 0.753 & 0.005 & 0.862 & 0.031 & 0.385 & 0.843 \\
\hline Change life satisfaction & 0.014 & 0.699 & -0.067 & 0.250 & -0.078 & 0.265 & 0.429 \\
\hline Became depressed & -0.004 & 0.644 & 0.011 & 0.416 & -0.010 & 0.548 & 0.724 \\
\hline Recovered depression & 0.102 & 0.109 & 0.132 & 0.221 & 0.043 & 0.756 & 0.280 \\
\hline \multicolumn{8}{|l|}{ Social capital } \\
\hline Changed race tolerance & 0.028 & 0.244 & -0.062 & 0.126 & 0.132 & 0.006 & 0.010 \\
\hline Change pol. cynicism & -0.026 & 0.371 & -0.011 & 0.816 & 0.049 & 0.380 & 0.628 \\
\hline Change authoritarianism & -0.067 & 0.004 & -0.036 & 0.355 & -0.033 & 0.481 & 0.032 \\
\hline Increased pol. interest & 0.010 & 0.450 & 0.056 & 0.013 & 0.002 & 0.934 & 0.090 \\
\hline Increased memberships & 0.003 & 0.974 & 0.009 & 0.792 & 0.038 & 0.514 & 0.923 \\
\hline Voted '97 abstained '87 & 0.024 & 0.498 & 0.027 & 0.651 & -0.030 & 0.670 & 0.835 \\
\hline
\end{tabular}


Appendix Table 10.5: Non-linear effects of work-related courses

\begin{tabular}{|c|c|c|c|c|c|c|c|}
\hline \multirow[b]{2}{*}{ Outcome } & \multicolumn{2}{|c|}{1 or 2 courses } & \multicolumn{2}{|c|}{$\begin{array}{l}3 \text { to } 10 \\
\text { courses }\end{array}$} & \multicolumn{2}{|c|}{$11+$ courses } & \multirow{2}{*}{$\begin{array}{l}\text { P-val no } \\
\text { learning } \\
\text { effect }\end{array}$} \\
\hline & Effect & P-val & Effect & P-val & Effect & P-val & \\
\hline \multicolumn{8}{|l|}{ Health } \\
\hline Gave up smoking & 0.011 & 0.634 & 0.029 & 0.356 & -0.056 & 0.277 & 0.495 \\
\hline Change in units drunk & -0.234 & 0.475 & 0.658 & 0.131 & 1.301 & 0.070 & 0.092 \\
\hline Increased exercise & 0.013 & 0.400 & 0.054 & 0.008 & 0.024 & 0.467 & 0.061 \\
\hline Change life satisfaction & 0.038 & 0.188 & 0.086 & 0.031 & 0.190 & 0.004 & 0.006 \\
\hline Became depressed & -0.010 & 0.149 & 0.004 & 0.662 & 0.014 & 0.362 & 0.441 \\
\hline Recovered depression & 0.035 & 0.546 & 0.089 & 0.367 & 0.028 & 0.893 & 0.790 \\
\hline \multicolumn{8}{|l|}{ Social capital } \\
\hline Changed race tolerance & 0.045 & 0.026 & 0.082 & 0.003 & 0.176 & 0.000 & 0.000 \\
\hline Change pol. cynicism & -0.037 & 0.116 & -0.031 & 0.330 & -0.049 & 0.351 & 0.329 \\
\hline Change authoritarianism & -0.047 & 0.017 & -0.051 & 0.054 & -0.071 & 0.103 & 0.023 \\
\hline Increased pol. interest & -0.008 & 0.480 & -0.012 & 0.418 & 0.042 & 0.101 & 0.238 \\
\hline Increased memberships & 0.003 & 0.667 & 0.009 & 0.403 & 0.038 & 0.041 & 0.210 \\
\hline Voted '97 abstained '87 & 0.047 & 0.127 & -0.017 & 0.692 & 0.105 & 0.150 & 0.206 \\
\hline
\end{tabular}

Appendix Table 10.6: Non-linear effects of leisure courses

\begin{tabular}{|c|c|c|c|c|c|c|c|}
\hline \multirow[b]{2}{*}{ Outcome } & \multicolumn{2}{|c|}{1 or 2 courses } & \multicolumn{2}{|c|}{$\begin{array}{l}3 \text { to } 10 \\
\text { courses }\end{array}$} & \multicolumn{2}{|c|}{$11+$ courses } & \multirow{2}{*}{$\begin{array}{l}\text { P-val no } \\
\text { learning } \\
\text { effect }\end{array}$} \\
\hline & Effect & P-val & Effect & P-val & Effect & P-val & \\
\hline \multicolumn{8}{|l|}{ Health } \\
\hline Gave up smoking & 0.061 & 0.010 & 0.130 & 0.108 & 0.118 & 0.557 & 0.031 \\
\hline Change in units drunk & -0.724 & 0.021 & -0.360 & 0.665 & 0.853 & 0.695 & 0.130 \\
\hline Increased exercise & 0.057 & 0.000 & 0.066 & 0.088 & 0.150 & 0.158 & 0.000 \\
\hline Change life satisfaction & 0.014 & 0.622 & -0.005 & 0.942 & -0.399 & 0.046 & 0.230 \\
\hline Became depressed & 0.001 & 0.907 & 0.043 & 0.021 & 0.087 & 0.103 & 0.050 \\
\hline Recovered depression & -0.053 & 0.357 & -0.085 & 0.546 & 0.033 & 0.929 & 0.779 \\
\hline \multicolumn{8}{|l|}{ Social capital } \\
\hline Changed race tolerance & 0.012 & 0.537 & 0.102 & 0.049 & -0.009 & 0.948 & 0.255 \\
\hline Change pol. cynicism & -0.014 & 0.528 & -0.057 & 0.349 & -0.025 & 0.873 & 0.759 \\
\hline Change authoritarianism & -0.052 & 0.005 & -0.040 & 0.428 & -0.278 & 0.039 & 0.008 \\
\hline Increased pol. interest & 0.024 & 0.025 & -0.034 & 0.220 & 0.217 & 0.014 & 0.005 \\
\hline Increased memberships & 0.054 & 0.000 & 0.087 & 0.000 & 0.113 & 0.057 & 0.000 \\
\hline Voted '97 abstained '87 & 0.057 & 0.055 & 0.295 & 0.001 & 0.172 & 0.509 & 0.002 \\
\hline
\end{tabular}




\section{Appendix 11: Regression results with interaction term for gender and prior qualifications included}

Appendix Table 11.1 gives estimated effects of total number of courses taken for men and for women, plus the additional effect for women over men. The model used to generate these results can be described by the following equation:

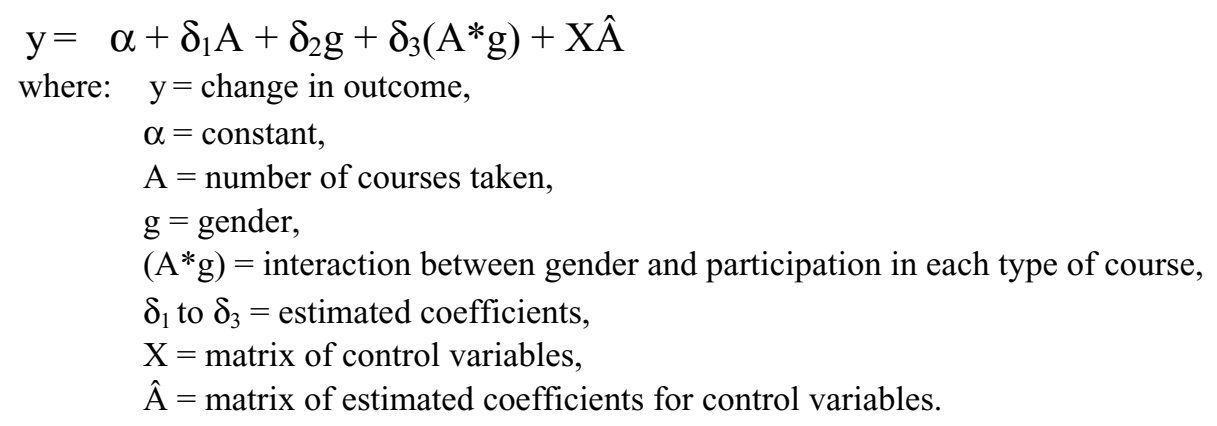

The difference in effect across gender is given by $\delta_{3}$.

Appendix Table 11.1: Estimated effects of participation by gender

\begin{tabular}{|c|c|c|c|c|c|c|}
\hline \multirow[b]{2}{*}{$\begin{array}{c}\text { Outcome } \\
(1)\end{array}$} & \multicolumn{2}{|c|}{ Men } & \multicolumn{2}{|c|}{ Women } & \multicolumn{2}{|c|}{$\begin{array}{c}\text { Interaction } \\
\text { term }\end{array}$} \\
\hline & $\begin{array}{c}\text { Effect } \\
(2) \\
\end{array}$ & $\begin{array}{c}\text { P-val } \\
(3) \\
\end{array}$ & $\begin{array}{c}\text { Effect } \\
(4) \\
\end{array}$ & $\begin{array}{c}\text { P-val } \\
(5) \\
\end{array}$ & $\begin{array}{c}\text { Effect } \\
(6) \\
\end{array}$ & $\begin{array}{c}\text { P-val } \\
(7) \\
\end{array}$ \\
\hline \multicolumn{7}{|l|}{ Health } \\
\hline 1 Gave up smoking & 0.000 & 0.878 & 0.006 & 0.064 & 0.006 & 0.186 \\
\hline 2 Change in units drunk & 0.043 & 0.247 & 0.047 & 0.384 & 0.004 & 0.955 \\
\hline 3 Increased level of exercise & 0.004 & 0.012 & 0.003 & 0.112 & 0.000 & 0.693 \\
\hline 4 Change in life satisfaction & 0.012 & 0.001 & 0.000 & 0.934 & -0.012 & 0.037 \\
\hline 5 Became depressed & 0.001 & 0.137 & -0.001 & 0.576 & -0.002 & 0.183 \\
\hline 6 Recovery from depression & 0.006 & 0.484 & -0.005 & 0.651 & -0.011 & 0.443 \\
\hline \multicolumn{7}{|l|}{ Social capital } \\
\hline 7 Change in race tolerance & 0.015 & 0.000 & 0.009 & 0.007 & -0.006 & 0.109 \\
\hline 8 Change political cynicism & -0.003 & 0.223 & -0.003 & 0.432 & 0.000 & 0.931 \\
\hline 9 Change in authoritarianism & -0.008 & 0.000 & -0.011 & 0.001 & -0.003 & 0.500 \\
\hline 10 Increased political interest & 0.002 & 0.137 & 0.004 & 0.013 & 0.002 & 0.290 \\
\hline 11 Increased memberships & 0.003 & 0.004 & 0.005 & 0.000 & 0.002 & 0.111 \\
\hline 12 Voted '97 abstained '87 & 0.007 & 0.050 & 0.005 & 0.385 & -0.003 & 0.697 \\
\hline
\end{tabular}

The first column lists the outcome variables. The second gives the estimated effects of total number of courses taken on each outcome for men. The third column gives the p-values. The values in the fourth and fifth columns are equivalent to those in the second and third, but for women not men. The sixth column gives the estimated additional effect of learning for women as compared to men. When this value is 
negative, it means that the estimated effects of learning for men are greater in positive magnitude than the estimated effects for women. The values in the final column are p-values for equality of effects across gender. The estimated effect for men is given by $\delta_{1}$, the additional effect for women over men is given by $\delta_{3}$, and the estimated effect of participation for women is given by $\delta_{1}+\delta_{3}$.

Appendix Table 11.2 gives estimated effects of total numbers of courses taken (the linear measure) for each type of course, for men and for women.

The model used to generate these results can be described by the following equation:

$\Delta y=\alpha+\sum_{j} \delta_{j} A_{j}+\sum_{j} \gamma_{j}\left(A^{*} g\right)_{j}+\eta g+X \mathrm{~B}$

where: $y=$ change in outcome, $\mathrm{j}=$ course type (ac, vc, wk, ls),

$A_{j}=$ total number of courses of each type taken, $\delta_{j}=$ coefficients for effects of participation in each course type,

$\mathrm{G}=$ gender,

$\left(\mathrm{A}^{*} \mathrm{~g}\right)_{\mathrm{j}}=$ interactions between gender and participation in each type of course,

$\tilde{\mathrm{a}}_{\mathrm{j}}=$ coefficients for interactions in effects between gender and participation in each type of course,

$\mathrm{X}=$ matrix of control variables,

$\hat{\mathrm{A}}=$ vector of coefficients for the controls variables.

Column 1 lists the outcomes. The first value for each outcome in column 2 (in normal but larger font) gives the estimated effects of the total number of academic accredited courses taken for men. The p-values are given below each estimate in smaller but bold font. Column 3 gives equivalent estimates for women, and column 4 gives equivalent estimates for the interaction term - the additional effect for women over men. The estimated effects in column 2 are the parameter estimates $\delta_{\mathrm{ac}}$, those in column 3 are the values of $\delta_{a c}+\tilde{a}_{a c}$, and those in column 4 are the given by $\tilde{a}_{a c}$. The values in the fifth, sixth, and seventh columns are the same but the effects are for total number of vocational accredited courses taken. The values in the remaining columns relate to work-related and leisure courses.

We conducted additional analyses using the categorical measure of participation in each type of course. The results, which are not reported here, are similar to those using the linear measure of participation.

Appendix Table 11.3 gives the results of regressions that include an interaction term between participation in learning and prior level of qualifications. The model used to generate the results can be described by the following equation:

$y=\alpha+\delta_{1} A+\delta_{2} q+\delta_{3}(A * q)+X \hat{A}$

where: $\mathrm{y}=$ change in outcome,

$\alpha=$ constant,

$\mathrm{A}=$ total number of courses taken,

$\mathrm{q}=$ a dummy variable indicating whether cohort members had below Level 2 qualifications at age 33, $\left(A^{*} q\right)=$ interaction between prior level of qualification and total number of courses taken, 
Appendix Table 11.2: Estimated effects of participation in different types of courses by gender

\begin{tabular}{|c|c|c|c|c|c|c|c|c|c|c|c|c|}
\hline \multirow[b]{2}{*}{$\begin{array}{c}\text { Outcome } \\
\text { (1) }\end{array}$} & \multicolumn{3}{|c|}{ Academic } & \multicolumn{3}{|c|}{ Vocational } & \multicolumn{3}{|c|}{ Work-related } & \multicolumn{3}{|c|}{ Leisure } \\
\hline & $\begin{array}{c}\text { Men } \\
(2)\end{array}$ & $\begin{array}{c}\text { Wmn } \\
\text { (3) }\end{array}$ & $\begin{array}{c}\text { Inter } \\
(4)\end{array}$ & $\begin{array}{c}\text { Men } \\
\text { (5) }\end{array}$ & $\begin{array}{c}\text { Wmn } \\
\text { (6) }\end{array}$ & $\begin{array}{c}\text { Inter } \\
(7)\end{array}$ & $\begin{array}{c}\text { Men } \\
\text { (8) }\end{array}$ & $\begin{array}{c}\text { Wmn } \\
\text { (9) }\end{array}$ & $\begin{array}{l}\text { Inter } \\
(10)\end{array}$ & $\begin{array}{l}\text { Men } \\
\text { (11) }\end{array}$ & $\begin{array}{c}\text { Wmn } \\
\text { (12) }\end{array}$ & $\begin{array}{l}\text { Inter } \\
\text { (13) }\end{array}$ \\
\hline Health & & & & & & & & & & & & \\
\hline Gave up smoking & $\begin{array}{r}.050 \\
.060 \\
\end{array}$ & $\begin{array}{r}-.001 \\
.967 \\
\end{array}$ & $\begin{array}{r}-.051 \\
.142 \\
\end{array}$ & $\begin{array}{r}-.002 \\
.912 \\
\end{array}$ & $\begin{array}{r}.026 \\
.047 \\
\end{array}$ & $\begin{array}{r}0.028 \\
.203 \\
\end{array}$ & $\begin{array}{r}-.001 \\
.715\end{array}$ & $\begin{array}{r}.002 \\
.581 \\
\end{array}$ & $\begin{array}{r}.003 \\
.508 \\
\end{array}$ & $\begin{array}{r}.019 \\
.211 \\
\end{array}$ & $\begin{array}{r}.027 \\
.024 \\
\end{array}$ & $\begin{array}{r}.007 \\
.698 \\
\end{array}$ \\
\hline $\begin{array}{l}\text { Change in } \\
\text { units drunk }\end{array}$ & $\begin{array}{r}-.184 \\
.618\end{array}$ & $\begin{array}{r}.124 \\
.701\end{array}$ & $\begin{array}{r}.308 \\
.528\end{array}$ & $\begin{array}{r}-.606 \\
.020\end{array}$ & $\begin{array}{r}-.119 \\
.579\end{array}$ & $\begin{array}{r}.487 \\
.147\end{array}$ & $\begin{array}{r}.076 \\
.058\end{array}$ & $\begin{array}{r}.089 \\
.165\end{array}$ & $\begin{array}{r}.013 \\
.858\end{array}$ & $\begin{array}{r}-.133 \\
.465\end{array}$ & $\begin{array}{r}-.086 \\
.534\end{array}$ & $\begin{array}{r}.047 \\
.837\end{array}$ \\
\hline $\begin{array}{l}\text { Increased level of } \\
\text { exercise }\end{array}$ & $\begin{array}{r}.024 \\
.170 \\
\end{array}$ & $\begin{array}{r}.017 \\
.216 \\
\end{array}$ & $\begin{array}{r}.017 \\
.752 \\
\end{array}$ & $\begin{array}{r}.013 \\
.274 \\
\end{array}$ & $\begin{array}{r}.006 \\
.530 \\
\end{array}$ & $\begin{array}{r}-.019 \\
.622 \\
\end{array}$ & $\begin{array}{r}.002 \\
.218 \\
\end{array}$ & $\begin{array}{r}.001 \\
.638 \\
\end{array}$ & $\begin{array}{r}-.002 \\
.785 \\
\end{array}$ & $\begin{array}{r}.014 \\
.095 \\
\end{array}$ & $\begin{array}{r}.017 \\
.010 \\
\end{array}$ & $\begin{array}{r}.005 \\
.768 \\
\end{array}$ \\
\hline $\begin{array}{l}\text { Improved life } \\
\text { satisfaction }\end{array}$ & $\begin{array}{r}.060 \\
.081\end{array}$ & $\begin{array}{r}.036 \\
.2\end{array}$ & $\begin{array}{r}-.024 \\
.582\end{array}$ & $\begin{array}{r}-.054 \\
.020\end{array}$ & $\begin{array}{r}.009 \\
.618\end{array}$ & $\begin{array}{r}.063 \\
.030\end{array}$ & $\begin{array}{r}.013 \\
.001\end{array}$ & $\begin{array}{r}.001 \\
.817\end{array}$ & $\begin{array}{r}-.012 \\
.083 \\
\end{array}$ & $\begin{array}{r}.008 \\
.610\end{array}$ & $\begin{array}{r}-.022 \\
.088\end{array}$ & $\begin{array}{r}-.030 \\
.145\end{array}$ \\
\hline Became depressed & $\begin{array}{r}.014 \\
.041 \\
\end{array}$ & $\begin{array}{r}.003 \\
.596 \\
\end{array}$ & $\begin{array}{r}-.011 \\
.233 \\
\end{array}$ & $\begin{array}{r}.000 \\
.954 \\
\end{array}$ & $\begin{array}{r}-.001 \\
.711 \\
\end{array}$ & $\begin{array}{r}-.001 \\
.870 \\
\end{array}$ & $\begin{array}{r}.001 \\
.531 \\
\end{array}$ & $\begin{array}{r}-.002 \\
.116 \\
\end{array}$ & $\begin{array}{r}-.003 \\
.094 \\
\end{array}$ & $\begin{array}{r}.006 \\
.053 \\
\end{array}$ & $\begin{array}{r}.005 \\
\mathbf{. 0 6 0} \\
\end{array}$ & $\begin{array}{r}-.002 \\
.703 \\
\end{array}$ \\
\hline $\begin{array}{l}\text { Recovered from } \\
\text { depression }\end{array}$ & $\begin{array}{r}.101 \\
.254 \\
\end{array}$ & $\begin{array}{r}-.023 \\
.678 \\
\end{array}$ & $\begin{array}{r}-.124 \\
.231 \\
\end{array}$ & $\begin{array}{r}.034 \\
.577 \\
\end{array}$ & $\begin{array}{r}.040 \\
.176 \\
\end{array}$ & $\begin{array}{r}.006 \\
.930 \\
\end{array}$ & $\begin{array}{r}.001 \\
.900 \\
\end{array}$ & $\begin{array}{r}-.006 \\
.770 \\
\end{array}$ & $\begin{array}{r}-.007 \\
.750 \\
\end{array}$ & $\begin{array}{r}.014 \\
.674 \\
\end{array}$ & $\begin{array}{r}-.029 \\
.262 \\
\end{array}$ & $\begin{array}{r}-.043 \\
.290 \\
\end{array}$ \\
\hline $\begin{array}{l}\text { Social capital } \\
\text { Increased race } \\
\text { tolerance }\end{array}$ & $\begin{array}{r}.091 \\
.000\end{array}$ & $\begin{array}{r}.085 \\
.000\end{array}$ & $\begin{array}{r}-.007 \\
.829\end{array}$ & $\begin{array}{r}.021 \\
.204\end{array}$ & $\begin{array}{r}.024 \\
.046\end{array}$ & $\begin{array}{r}.003 \\
.863\end{array}$ & $\begin{array}{r}.012 \\
.000\end{array}$ & $\begin{array}{r}.005 \\
.176\end{array}$ & $\begin{array}{r}-.007 \\
.137\end{array}$ & $\begin{array}{r}.039 \\
.001\end{array}$ & $\begin{array}{r}-.002 \\
.797\end{array}$ & $\begin{array}{r}-.041 \\
.004\end{array}$ \\
\hline $\begin{array}{l}\text { Increased political } \\
\text { cynicism }\end{array}$ & $\begin{array}{r}-.059 \\
.033 \\
\end{array}$ & $\begin{array}{r}-.033 \\
.148 \\
\end{array}$ & $\begin{array}{r}.027 \\
.456 \\
\end{array}$ & $\begin{array}{r}-.009 \\
.649 \\
\end{array}$ & $\begin{array}{r}.014 \\
.334 \\
\end{array}$ & $\begin{array}{r}.022 \\
.344 \\
\end{array}$ & $\begin{array}{r}-.001 \\
.774 \\
\end{array}$ & $\begin{array}{r}-.004 \\
.432 \\
\end{array}$ & $\begin{array}{r}-.003 \\
.617 \\
\end{array}$ & $\begin{array}{r}-.024 \\
.070 \\
\end{array}$ & $\begin{array}{r}-.001 \\
.891 \\
\end{array}$ & $\begin{array}{r}.023 \\
.175 \\
\end{array}$ \\
\hline $\begin{array}{l}\text { Increased } \\
\text { authoritarianism }\end{array}$ & $\begin{array}{r}-.135 \\
.000\end{array}$ & $\begin{array}{r}-.106 \\
.000\end{array}$ & $\begin{array}{r}.029 \\
.325\end{array}$ & $\begin{array}{r}-.020 \\
.198\end{array}$ & $\begin{array}{r}-.017 \\
.146\end{array}$ & $\begin{array}{r}.003 \\
.869\end{array}$ & $\begin{array}{r}-.007 \\
.007\end{array}$ & $\begin{array}{r}.000 \\
.981\end{array}$ & $\begin{array}{r}.007 \\
.143\end{array}$ & $\begin{array}{r}-.001 \\
.894\end{array}$ & $\begin{array}{r}-.034 \\
.000\end{array}$ & $\begin{array}{r}-.033 \\
.018\end{array}$ \\
\hline $\begin{array}{l}\text { Increased political } \\
\text { interest }\end{array}$ & $\begin{array}{r}.029 \\
.022 \\
\end{array}$ & $\begin{array}{r}.028 \\
.003 \\
\end{array}$ & $\begin{array}{r}-.001 \\
.967 \\
\end{array}$ & $\begin{array}{r}.015 \\
.066 \\
\end{array}$ & $\begin{array}{r}.004 \\
.569 \\
\end{array}$ & $\begin{array}{r}-.012 \\
.258 \\
\end{array}$ & $\begin{array}{r}.001 \\
.294 \\
\end{array}$ & $\begin{array}{r}.001 \\
.587 \\
\end{array}$ & $\begin{array}{r}0 \\
.905 \\
\end{array}$ & $\begin{array}{r}-.003 \\
.638 \\
\end{array}$ & $\begin{array}{r}.011 \\
.015 \\
\end{array}$ & $\begin{array}{r}.014 \\
.094 \\
\end{array}$ \\
\hline $\begin{array}{l}\text { Increased number } \\
\text { of memberships }\end{array}$ & $\begin{array}{r}.008 \\
.346\end{array}$ & $\begin{array}{r}.005 \\
.483\end{array}$ & $\begin{array}{r}-.003 \\
.758\end{array}$ & $\begin{array}{r}.007 \\
.251\end{array}$ & $\begin{array}{r}.002 \\
.635\end{array}$ & $\begin{array}{r}-.005 \\
.509\end{array}$ & $\begin{array}{r}.001 \\
.137\end{array}$ & $\begin{array}{r}.003 \\
.010\end{array}$ & $\begin{array}{r}.002 \\
.249\end{array}$ & $\begin{array}{r}.013 \\
.000\end{array}$ & $\begin{array}{r}.013 \\
.000\end{array}$ & $\begin{array}{r}.000 \\
.961\end{array}$ \\
\hline $\begin{array}{l}\text { Voted in } 1997 \\
\text { abstained } 1987\end{array}$ & $\begin{array}{r}.023 \\
.479 \\
\end{array}$ & $\begin{array}{r}.023 \\
.483 \\
\end{array}$ & $\begin{array}{r}-.001 \\
.990 \\
\end{array}$ & $\begin{array}{r}.014 \\
.557 \\
\end{array}$ & $\begin{array}{r}.000 \\
.983 \\
\end{array}$ & $\begin{array}{r}-.014 \\
.622 \\
\end{array}$ & $\begin{array}{r}.005 \\
.257 \\
\end{array}$ & $\begin{array}{r}-.002 \\
.758 \\
\end{array}$ & $\begin{array}{r}-.007 \\
\quad .407 \\
\end{array}$ & $\begin{array}{r}.069 \\
\mathbf{. 0 0 6} \\
\end{array}$ & $\begin{array}{r}.034 \\
.033 \\
\end{array}$ & $\begin{array}{r}-.035 \\
.235 \\
\end{array}$ \\
\hline
\end{tabular}

NOTE: Probabilities that estimates are zero are given below each estimate in bold font 
$\delta_{1}$ to $\delta_{3}=$ estimated coefficients,

$\mathrm{X}=$ matrix of control variables,

$\hat{\mathrm{A}}=$ matrix of estimated coefficients for control variables.

From this model, we can test whether the effects of participation differ between those with below Level 2 qualifications at age 33 and those with Level 2 qualification and above at the same age.

Appendix Table 11.3: Estimated effects of participation by level of highest qualification at age 33

$\begin{array}{ccc}\begin{array}{c}\text { Those with } \\ \text { L2 }+\end{array} & \begin{array}{c}\text { Those with } \\ \text { below L2 }\end{array} & \begin{array}{c}\text { Interaction } \\ \text { term }\end{array} \\ \text { qualifications } & \text { qualifications } & \end{array}$

\begin{tabular}{|c|c|c|c|c|c|c|c|}
\hline \multicolumn{2}{|c|}{ Outcome } & \multicolumn{2}{|c|}{ at 33} & \multicolumn{2}{|c|}{33} & \multirow[b]{2}{*}{$\begin{array}{r}\text { Effect } \\
(6) \\
\end{array}$} & \multirow[b]{2}{*}{$\begin{array}{l}\text { P- } \\
\text { val } \\
(7) \\
\end{array}$} \\
\hline 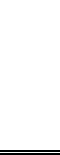 & $\begin{array}{c}\text { Outcome } \\
(1) \\
\end{array}$ & $\begin{array}{r}\text { Effect } \\
(2) \\
\end{array}$ & $\begin{array}{l}\text { P- } \\
\text { val } \\
(3) \\
\end{array}$ & $\begin{array}{r}\text { Effect } \\
(4) \\
\end{array}$ & $\begin{array}{l}\text { P- } \\
\text { val } \\
(5) \\
\end{array}$ & & \\
\hline \multicolumn{8}{|c|}{ Health } \\
\hline 1 & Gave up smoking & 0.003 & 0.318 & 0.006 & 0.151 & 0.003 & 0.522 \\
\hline 2 & Change in units drunk & 0.066 & 0.065 & -0.01 & 0.862 & -0.076 & 0.261 \\
\hline 3 & Increased exercise & 0.003 & 0.072 & 0.005 & 0.041 & 0.004 & 0.187 \\
\hline 4 & Change in life satisfaction & 0.008 & 0.018 & 0.009 & 0.093 & 0.001 & 0.875 \\
\hline 5 & Became depressed & 0.000 & 0.599 & 0.000 & 0.869 & -0.001 & 0.671 \\
\hline 6 & Recovered from depression & 0.011 & 0.350 & 0.001 & 0.915 & -0.010 & 0.473 \\
\hline \multicolumn{8}{|c|}{ Social capital } \\
\hline 7 & Change in race tolerance & & & & & & \\
\hline 8 & Change political cynicism & 0.012 & 0.000 & 0.017 & 0.000 & 0.005 & 0.225 \\
\hline 9 & Change authoritarianism & -0.003 & 0.272 & -0.009 & 0.027 & -0.006 & 0.197 \\
\hline 10 & Increased political interest & -0.011 & 0.000 & -0.012 & 0.001 & -0.001 & 0.850 \\
\hline 11 & Increased memberships & 0.002 & 0.103 & 0.006 & 0.001 & 0.004 & 0.049 \\
\hline 12 & Voted 1997 abstained 1987 & 0.004 & 0.000 & 0.005 & 0.000 & 0.001 & 0.467 \\
\hline
\end{tabular}

The values in the table are equivalent to those in Appendix Table 11.1 except that they apply to two education groups as opposed to two genders. The values in the second and third columns apply to those with Level 2 and above qualifications at age 33 , the values in the fourth and fifth columns apply to those with below Level 2 qualifications, and the values in the sixth and seventh columns apply to the additional learning effect for those with below Level 2 qualifications at age 33 as compared to those with Level 2 plus qualifications at the same age. The values in columns 2, 4, and 6 are given by the parameter estimates $\delta_{1}, \delta_{1}+\delta_{3}$, and $\delta_{3}$, respectively.

Appendix Table 11.4 gives estimated effects of total numbers of courses taken (the linear measure) for each type of course, for each education group. The model used to 


\begin{tabular}{|c|c|c|c|c|c|c|c|c|c|c|c|c|}
\hline \multirow[b]{2}{*}{$\begin{array}{l}\text { Outcome } \\
\text { (1) }\end{array}$} & \multicolumn{2}{|c|}{ Academic } & \multicolumn{4}{|c|}{ Vocational } & \multicolumn{3}{|c|}{ Work-related } & \multicolumn{2}{|l|}{ Leisure } & \multirow[b]{2}{*}{$\begin{array}{l}\text { Inter } \\
(13) \\
\end{array}$} \\
\hline & $\begin{array}{l}\mathrm{L} 2+ \\
(2) \\
\end{array}$ & $\begin{array}{l}\text { BL2 } \\
(3) \\
\end{array}$ & $\begin{array}{l}\text { Inter } \\
(4) \\
\end{array}$ & $\begin{array}{l}\mathbf{L} 2+ \\
(5) \\
\end{array}$ & $\begin{array}{l}\text { BL2 } \\
(6) \\
\end{array}$ & $\begin{array}{l}\text { Inter } \\
(7) \\
\end{array}$ & $\begin{array}{l}\mathrm{L} 2+ \\
(8)\end{array}$ & $\begin{array}{l}\text { BL2 } \\
(9) \\
\end{array}$ & $\begin{array}{l}\text { Inter } \\
(\mathbf{1 0}) \\
\end{array}$ & $\begin{array}{l}\text { L2+ } \\
(11) \\
\end{array}$ & $\begin{array}{l}\text { BL2 } \\
(12) \\
\end{array}$ & \\
\hline \multicolumn{13}{|l|}{ Health } \\
\hline \multirow[t]{2}{*}{ Gave up smoking } & 0.015 & 0.035 & 0.02 & 0.009 & 0.019 & 0.011 & 0 & 0.001 & 0.001 & 0.027 & 0.028 & 0.001 \\
\hline & 0.516 & 0.134 & 0.545 & 0.544 & 0.236 & 0.625 & 0.96 & 0.806 & 0.857 & 0.017 & 0.083 & 0.974 \\
\hline \multirow{2}{*}{$\begin{array}{l}\text { Change in } \\
\text { units drunk }\end{array}$} & 0.233 & -0.597 & -0.83 & -0.067 & -0.709 & -0.642 & 0.082 & 0.08 & -0.002 & -0.08 & -0.141 & -0.06 \\
\hline & 0.426 & 0.163 & 0.109 & 0.741 & 0.013 & 0.067 & 0.035 & 0.232 & 0.982 & 0.55 & 0.455 & 0.794 \\
\hline \multirow{2}{*}{$\begin{array}{l}\text { Increased level of } \\
\text { exercise }\end{array}$} & 0.01 & 0.014 & 0.004 & 0.003 & 0.004 & 0.001 & 0.004 & 0 & -0.004 & 0.008 & 0.033 & 0.026 \\
\hline & 0.398 & 0.408 & 0.851 & 0.732 & 0.727 & 0.929 & 0.017 & 0.969 & 0.216 & 0.169 & 0 & 0.009 \\
\hline \multirow{2}{*}{$\begin{array}{l}\text { Improved life } \\
\text { satisfaction }\end{array}$} & 0.021 & 0.102 & 0.081 & -0.02 & -0.005 & 0.015 & 0.011 & 0.006 & -0.005 & -0.016 & 0.009 & 0.025 \\
\hline & 0.411 & 0.007 & 0.081 & 0.247 & 0.832 & 0.619 & 0.002 & 0.302 & 0.502 & 0.193 & 0.605 & 0.24 \\
\hline \multirow[t]{2}{*}{ Became depressed } & -0.005 & 0.018 & 0.023 & 0.002 & -0.01 & -0.012 & 0 & -0.002 & -0.002 & 0.005 & 0.006 & 0.001 \\
\hline & 0.477 & 0.006 & 0.015 & 0.611 & 0.077 & 0.081 & 0.956 & 0.261 & 0.334 & 0.068 & 0.101 & 0.852 \\
\hline \multirow{2}{*}{$\begin{array}{l}\text { Recovery from } \\
\text { depression }\end{array}$} & 0.044 & 0.018 & -0.025 & 0.077 & 0.036 & -0.041 & -0.004 & 0.001 & 0.004 & 0.009 & -0.024 & -0.033 \\
\hline & 0.508 & 0.756 & 0.774 & 0.058 & 0.345 & 0.46 & 0.844 & 0.955 & 0.839 & 0.701 & 0.426 & 0.388 \\
\hline \multirow{2}{*}{$\begin{array}{l}\text { Social capital } \\
\text { Increased race } \\
\text { tolerance }\end{array}$} & 0.095 & 0.093 & -0.002 & 0.015 & 0.02 & 0.005 & 0.01 & 0.013 & 0.003 & 0.016 & 0.027 & 0.011 \\
\hline & 0 & 0 & 0.948 & 0.21 & 0.23 & 0.801 & 0 & 0.002 & 0.498 & 0.065 & 0.027 & 0.456 \\
\hline \multirow{2}{*}{$\begin{array}{l}\text { Increased political } \\
\text { cynicism }\end{array}$} & -0.057 & -0.054 & 0.003 & 0.01 & 0.017 & 0.007 & -0.001 & -0.005 & -0.004 & -0.012 & -0.036 & -0.025 \\
\hline & 0.008 & 0.084 & 0.945 & 0.479 & 0.384 & 0.765 & 0.682 & 0.278 & 0.465 & 0.246 & 0.011 & 0.154 \\
\hline \multirow{2}{*}{$\begin{array}{l}\text { Increased } \\
\text { authoritarianism }\end{array}$} & -0.141 & -0.12 & 0.02 & -0.01 & -0.008 & 0.002 & -0.006 & -0.005 & 0.001 & -0.033 & -0.034 & 0 \\
\hline & 0 & 0 & 0.519 & 0.393 & 0.616 & 0.931 & 0.022 & 0.255 & 0.841 & 0 & 0.004 & 0.993 \\
\hline \multirow{2}{*}{$\begin{array}{l}\text { Increased political } \\
\text { interest }\end{array}$} & 0.03 & 0.037 & 0.007 & 0.007 & 0.005 & -0.002 & 0.001 & 0.004 & 0.003 & 0.007 & 0.014 & 0.007 \\
\hline & 0.002 & 0.003 & 0.652 & 0.225 & 0.566 & 0.829 & 0.694 & 0.072 & 0.18 & 0.106 & 0.025 & 0.369 \\
\hline \multirow{2}{*}{$\begin{array}{l}\text { Increased number } \\
\text { of memberships }\end{array}$} & 0.011 & 0.013 & 0.002 & -0.001 & 0.007 & 0.008 & 0.003 & 0.001 & -0.002 & 0.014 & 0.024 & 0.01 \\
\hline & 0.112 & 0.191 & 0.838 & 0.849 & 0.306 & 0.339 & 0.001 & 0.642 & 0.299 & 0 & 0 & 0.042 \\
\hline \multirow{2}{*}{$\begin{array}{l}\text { Voted } 1997 \\
\text { abstained } 1987\end{array}$} & 0.082 & -0.012 & -0.094 & 0.009 & -0.002 & -0.01 & 0.001 & 0.007 & 0.006 & 0.034 & 0.124 & 0.09 \\
\hline & 0.013 & 0.746 & 0.059 & 0.597 & 0.949 & 0.726 & 0.789 & 0.184 & 0.375 & 0.024 & 0.001 & 0.019 \\
\hline
\end{tabular}


generate these results is similar to that for Appendix Table 11.2, but the interactions are between participation in each course type and prior qualification level, not gender.

Column 1 lists the outcomes. The first value for each outcome in column 2 (in normal but larger font) gives the estimated effects of the total number of academic accredited courses taken for those with Level 2 qualifications and above at age 33. The p-values are given below each estimate in smaller but bold font. Column 3 gives equivalent estimates for those with below Level 2 qualifications at age 33, and column 4 gives equivalent estimates for the interaction term - the additional effect for those with below Level 2 qualifications at age 33 over those with higher qualifications at the same age. The estimated effects in column 2 are the parameter estimates $\delta_{\mathrm{ac}}$, those in column 3 are the values of $\delta_{a c}+\tilde{a}_{a c}$, and those in column 4 are the given by $\tilde{a}_{\mathrm{ac}}$. The values in the fifth, sixth, and seventh columns are the same but the effects are for total number of vocational accredited courses taken. The values in the remaining columns relate to work-related and leisure courses.

We conducted additional analyses using the categorical measure of participation in each type of course. The results, which are not reported here, are similar to those using the linear measure of participation. 


\section{Wider Benefits of Learning Research Report No. 8}

\section{The Contribution of Adult Learning to Health and Social Capital}

The research described in this report assesses the effects of adult learning on twelve health and social capital outcomes. Data from a national British cohort are used to track changes in people's lives between 33 and 42, and the links between these changes and adult learning are estimated. The findings suggest that adult learning has effects on a wide range of outcomes and plays an important role in contributing to the small shifts in attitudes and behaviours that take place during mid adulthood. More detailed findings relating to specific outcomes, types of courses taken, and groups of learners provide further interesting evidence about why and when adult learning matters.

Dr Leon Feinstein is the Research Director of the Centre for Research on the Wider Benefits of Learning at the Institute of Education.

Cathie Hammond and John Preston are Research Officers at the Centre for Research on the Wider Benefits of Learning. Cathie is Strand Manager for health and John is Strand Manager for social capital and cohesion.

Laura Woods is a former Research Officer at the Centre for Longitudinal Studies at the Institute of Education.

Professor John Bynner is Director of the Bedford Group for Lifecourse and Statistical Studies at the Institute of Education and Director of the Centre for Research on the Wider Benefits of Learning.

ISBN 189845339 X 